\title{
Beiträge \\ zur Chirurgie der Ureteren und der Nieren ${ }^{1}$ ).
}

\author{
Von \\ Dr. Wilhelm Tauffer, \\ Universitätsprofessor in Budapest.
}

Meine erste Erfahrung auf dem Gebiete der Nieren-Chirurgie beginnt mit dem Jahre 1877, da mir an der Seite Hegar's der Antheil zufiel, die Nachbehandlung jenes Falles zu leiten, der auch in der Literatur allgemein bekannt wurde, der dem so ziemlich analogen Fall Nussbaum's vorausging und bereits zu einer Zeit eine Rolle spielte, da Simon's Fall einer Exstirpation der Niere sozusagen noch als Unicum galt. Bei Hegar gab die gelegentlich der Operation einer Bauchgeschwulst erfolgte zufällige Verletzung eines Ureters, zufolge deren sich eine Ureter-Bauchfistel entwickelte, den Gegenstand der Nachbehandlung ab. Ebenso wie in Nussbaum's Fall, gelang es auch diesmal zwischen der Blase und der Ureter-Bauchfistel eine ständige Communication zu Stande zu bringen, und der Kranken die Niere zu erhalten; während es zu erwarten war, dass unter dem Einflusse des von Simon unter ähnlichen Verhältnissen glücklich mit einer Nierenexstirpation beendeten Falles, sowohl Hegar als Nussbaum eine Nierenexstirpation vornehmen würden.

Diese 3 Fälle bilden gewissermassen die Grundlage der heutigen Fortschritte der Nierenchirurgie, und unter diesen bleibt ewig denkwürdig der Fall Simon's, welcher für alle Zeiten der Grundstein der Fortschritte der Nierenchirurgie bilden wird. Der

1) Nach einem Vortrag, gehalten in der K. ungar. Gesellschaft der Aerzte in Budapest. 
Heidelberger Chirurg Czerny, als der würdige Nachfolger Simon's, ward auch auf diesem Gebiete des Meisters Nachfolger, und mit ihm zusammen wirkten gewissermassen sämmtliche Chirurgen Deutschlands während der letzten anderthalb Decennien an der Ausarbeitung dieser chirurgischen Fachfrage mit, die im Verlaufe dieser Zeit eine riesige Literatur schuf. Theilnehmer an dieser Thätigkeit waren in grossem Maassstabe Engländer und Franzosen - und eben dieser, einen grossen Kreis umspannenden Collectivarbeit haben wir den heatigen Fortschritt zu verdanken. Es unterliegt jedoch keinem Zweifel, dass, was Diagnostik, Indicationen und das operative Verfahren betrifft, die Ansichten noch sehr verschieden sind. Indess vom Gesichtspunkte der auf anderen Gebieten gewonnen Erfahrungen ausgehend, ist es zweifellos, dass wir uns auf richtigem Wege befinden und uns der einhelligen Lösung der Fragen nähern. Das Beispiel, welches uns vor Augen schwebt, hole ich mir von einem anderen Gebiete der Chirurgie, nämlich aus dem Kreise der verschiedensten Erkrankungen der Ovarien; denn kaum gab es eine medicinische Specialfrage, die sich in einem grösseren Kreise bewegte, als die Frage der Pathologie und Therapie der Ovarien. Und siehe da, Olshausen's klassische Arbeit: „Die Krankheiten der Ovarien", in dem grossen Werke über Chirurgie von Billroth und Luecke hat auf einmal Ruhe geschaffen und, vielleicht mit Ausnahme der Aetiologie, bezüglich der pathologischen Anatomie, der Diagnostik, Symptomatologie, der Indicationen, Therapie, ferner der erreichbaren Resultate, gestaltete sich diese grosse Frage zu einer gut geordneten Wissenschaft, die heute in allen Details der Weiterentwicklung fähig, auf einer früher kaum geahnten Stufe der Vollkommenheit der Vorrathskammer unseres Wissens einverleibt werden kann. Sowie früher auf diesem Gebiete tausend widersprechende, unterstützende, oder ergänzende Erkenntnisse die Literatur ausfüllten, in welchem Labyrinthe schliesslich OIshausen's grosses Werk den Leitfaden bildete: so sehen wir jetzt dieselbe Procedur auf dem Gebiete der Nierenchirurgie. Alles ist in Bewegung, eine unermessliche Erfahrung häuft sich an, die Literatur schwirrt förmlich von der Menge der fachgemässen Mittheilungen, und wenn ich mich nicht täusche, so dürfte die Zeit nicht ferne sein, da auch diese Fragen ihren Meister finden werden, der ordnend, sichtend und formend, auch dieses grosse Thema uns unterbreiten wird, um es dann als ein vollkommenes, gesondertes Ganzes unserem 
Wissensschatz einverleiben zu können. Einstweilen jedoch leben wir noch im Zeitalter der Detail-Arbeit, so dass ein jeder Gedankenaustausch neue Gedanken auslöst. Ich finde es somit zeitgemäss mitzutheilen, was ich selbst auf diesem Gebiete erfahren habe, und dazu beizutragen, dass dieses wichtige Thema in unserem heimathlichen medicinischen Geistesleben unter die Tagesfragen aufgenommen werde.

\section{Zur Chirurgie der Ureteren.}

Die Frage der Nieren-Chirurgie tritt am augenscheinlichsten in jenen Fällen zu Tage, in denen die Nieren-Exstirpation, so wie zuerst bei Simon, zufolge Durchschneidung eines Ureters, somit in dem Falle einer Ureter-Fistel, zur Nothwendigkeit wird.

Es ist auffallend, dass sich mit der Frage der Verletzung der Ureteren in der Literatur so wenige Fachmänner beschäftigen, und dass in der Mehrzahl der Fälle die Durchschneidung des Ureters schon als feststehende Indication zur Exstirpation der Niere gilt. Nach meiner Auffassung berühren sich hier zwei Fragen; u. z. zuerst die Frage der Verletzung des Ureters, die Entstehung der Fistel für sich allein, z. B. bei der Operation von schweren Bauchgeschwülsten, mit den anatomischen und chirurgischen Details solcher Fälle; ferner zweitens: die auf theoretischer und empirischer Grundlage erfolgende Abwägung und Feststellung jener chirurgischen Verfahren, wie man in ähnlichen Fällen, nämlich wenn wir den Ureter durchschnitten haben, vorzugehen habe. Denn die Exstirpation der Niere ist überhaupt nicht das einzige und nicht das ausschliesslich zu befolgende Verfahren, wie ich dies in den folgenden Fällen demonstriren werde. Und wenn schliesslich dennoch die Nephrectomie nicht umgangen werden kann, so tanchen noch viele wichtige Fragen auf, z. B. um nur Einiges zu erwähnen, $a b$ die Nephrectomie zugleich mit der Bauch-Operation ausgeführt werde; ferner, ob der Weg ein transperitonealer, oder aber ein extraperitoneal-lumbaler sein soll?

Dom ersten der in diese Gruppe gehörenden Fälle begegnete ich im Jahre 1886; aus der Krankengeschichte will ich in Kürze das Folgende mittheilen:

Frau A. R. (1886. Journal-No. 120) 28 J. alt, verehelicht, steril, acquirirte im Alter von 20 Jahren Lues, vor 6 Jahren eine Peritonitis, die sich seither mehrmals wiederholte; vor 5 Monaten wurde sie unter 
Krämpfen, Fieber und Schüttelfrost plötzlich krank und von dieser Zeit an war in ihrem Bauche ein Tumor nachweisbar. Bei der Untersuchung fand raan eine bis an den Nabel reichende, fluctuirende Geschwulst, die tief ins Becken hinabreicht und den Uterus nach rechts und vorne drängt, im Becken fixirt ist und den Douglas'schen Raum nach abwärts wölbt. Das remittirende Fieber, die entzündliche Natur des Tumors, und die grossen Schmerzen deuteten auf eitrigen Inhalt. Die Geiahren einer mittelst Laparotomie zu bewerkstelligenden Entfernung der Geschwulst vor Augen haltend, erschien die Entleerung durch das Scheidengewölbe als zweckentsprechend, weshalb ich vorher mittelst Troicarts den stinkenden, jauchigen Inhalt constatirte, dann einen wie bei der Haematocele retrouterina üblichen Einschnitt quer durch das hintere Scheidengewölbe vollführte und durch die 2-3 Querfinger breite Oeffnung ein doppeltes Drainrohr einführte. Die Kranke war von diesem Tage an fieberfrei; am 14. Tage erweckt das copiöse, urinöse Secret den Verdacht einer Ureter-Verletzung, die am 15. Tage thatsächlich constatirt wird; am 23. Tage tritt die überaus schwache Kranke im Interesse der Reconvalescenz vorläufig aus der Anstalt aus, um daselbst 4 Monate später behufs Behandlung der Ureterfistel neuerdings aufgenommen zu werden.

Den peripherischen Stumpf des Ureters gelang es weder von der Blase, noch von der Scheide aus aufzufinden, und so mussten wir, um die im Scheidengewölbe befindliche Ureterfistel, mit der Blase in Verbindung zu bringen, eine künstliche Scheidenfistel anlegen, deren Herstellung wir mittelst einer Blei-Bougie zu erreichen strebten. Nach 2 Wochen ist die künstliche Oeffnung hergestellt. Nach Einfübrung eines elastischen Katheters durch die Harnoöhre, Blase und die Oeffnung der künstlichen Blase in die Ureterfistel worde durch eine entsprechende quere Auffrischung des Scheidengewölbes im Interesse der Canalisation der Ureter-Blase die plastische Operation vollzogen. Vom 2. Tage angefangen Fieber, am 3. treten Symptome einer Harnverhaltung auf, indem die linke Nierengegend empfindlich wird, welche Empfindlichkeit schwindet, wenn der Harn durch die Scheide wieder hervorbricht; am 8. Tage constatiren wir, gelegentlich der Entfernung der Nähte, die Vereinigung der Wundränder; der Urin entieert sich durch eine haardünne Fistel, es gelang uns jedoch nicht, durch die über der Scheide befindliche Oeffnung mit einer Sonde in die Blase zu gelangen; - uad so mussten wir denn zur Entscheidung dessen, ob durch den auf plastischem Wege hergestelliten Kanal etwas von dem Secrete der linken Niere in die Blase gelangt, folgendes Experiment anwenden:

1. Vor die Schamspalte der aufrecht stehenden Patientin binden wir aufsaugende Watte; die durchnässte Watte und die in der Blase spontan angesammelte Harnmenge wird stündlich gewogen. Das Resultat der 12 stündigen Untersuchungen war nahezu immer das nämliche, a. z. durchschnittlich $510 \mathrm{~g}$ in der Blase und $440 \mathrm{~g}$ in der Watte. Die Differenz kann füglich auf Rechnung der Verdunstung gesetzt werden.

2. In liegender Stellung betrug die Menge des in der Blase angesammelten und mit Katheter stündlich entnommenen Harns durchschnittlich $630 \mathrm{~g}$, in der aufsaugenden Watte $173 \mathrm{~g}$. Die hieraus mit Recht abzuleitende Folgerung ist die, dass der Ureter in der Richtung der Blase canalisirt sei, und dass die linke Niere in liegender Stellung 
einen guten Theil des Urins in die Blase leitet, somit die Indication nur die Schliessung der Haarfistel sein kann.

Die moralisch erschöpfte Kranke richtete dann die Frage an uns, $o b$ es denn ganz verbürgt sei, dass eine neuere Operation nunmehr einen vollkommenen Erfolg haben werde? Selbstverständlich konnte meine diesbezügliche Antwort nur eine answeichende sein, da den sicheren Verschluss einer Ureter-Haarfistel, mittelst einer einzigen Operation, Niemand verbürgen kann. Die ungeduldige Kranke verlangte demgemäss die Exstirpation der Niere, worauf ich, die Nothwendigkeit derselben nicht einsehend, nicht eingehen wollte. Die Kranke wandte sich alsdanu an einen hervorragenden auswärtigen Chirurgen, der im Consilium mit einem fachtüchtigen Meister der Ureteren-Sondirung die Communication 2 wischen linkem Ureter und der Blase nicht constatiren konnte, indess dem Wunsche der Patientin willfahrte und die Exstirpation der linken Niere vollführte. Die Kranke genas.

Die Durchschneidung des Ureters war mir in diesem Falle lange ein Räthsel; war ja doch mein Vorgang eben ein solcher, wie es bei der Haematocele retrouterina zu sein pflegt; ich hielt mich streng an jenes Terrain, welches wir gewöhnlich als das zwischen den beiden Lig. sacro-uterinis befindliche kennen, und so erschien mir die Verletzung, respective Durchschneidung des Ureters nahezu unglaublich; und doch war es so! Die Erklärung fand ich erst später, als in einem vorgerückteren Stadium der Wundbehandlung, nach Verschwinden der Geschwulst, die Schnittlinie, die ursprünglich rückwärts war, gewissermassen ganz in die Richtung des linken Beckens gelangte, dorthin, wo wir gewöhnlich den Ureter finden. Dies lässt sich nur derart erklären, dass die genetisch extraperitoneale Geschwulst in ihrem Vordringen vom unteren Pole bis zur Region des Ureters, gleichzeitig, da sie den Uterus nach rechts und vorne schob, auch den Ureter dislocirte - in der Weise, dass derselbe von seinem regelmässigen Verlaufe abgedrängt, am linken Rande des Promontoriums in das Becken eintreten konnte und in der Nähe der Mittellinie sich sagittaliter über das Becken lagernd, in dieser seiner dislocirten Lage unter das Messer gerieth.

Durch diesen Fall aufmerksam gemacht, beobachtete ich von nun in mehreren hundert Fällen den Verlauf der Ureteren an der Seite von Beckengeschwülsten, und notirte mehrere auffälligo Dislocirungen derselben.

Die Behandlung der Ureter-Scheidenfisteln auf plastischem Wege gehört unstreitig auch heute noch zu den schwierigen Aufgaben, aber nichtsdestoweniger bin ich überzeugt, dass es keinen Gynäkologen giebt, dor in diesem Leiden die Indikation zur Neph- 
rectomie erblicken würde, bevor er nicht alle anderen Behandlungsarten versucht hätte. In meinem Falle befand ich mich bereits auf der Höhe dieses Weges und ich zweifelte keinen Augenblick, dass die Schliessung der Haarfistel möglich sei. Die Kranke hatte jedoch bereits ihre Geduld verloren, und wollte, selbst um den Preis einer Nierenexstirpation, von ihrem Leiden rasch and sicher befreit werden, und dieses Ziel erreichte sie auch. Ich bin jedoch auch heute noch der Ansicht, dass die Nierenexstirpation in einem solshen fille nicht angezeigt sei; denn angenommen, aber nicht zugegeben, dass keine Oeffung zwischen Blase und Scheidengewölbe bestand, so müsste man auch dann noch eine solche machen, um mit mehr Glück und vielleicht auch mehr Geschicklichkeit, als sie mir beschieden, auf plastischem Wege den Ureter durch das Scheidengewölbe in die Blase zu kanalisiren.

Im Anschlusse an diesen Fall taucht noch eine, durch die ganze Nierenchirurgie sich dahinziehende Frage auf; nämlich die, welchen Einfluss wohl die Exstirpation der Niere auf den ganzen Organismus habe, da doch die Entscheidung mehrerer anderer Fragen, z. B. die Parallele der Nephrotomie und der Nephrectomie, die Exstirpation oder operative Fixation der beweglichen Niere etc. hievon abhängt?

Abgesehen von der chirurgischen Bedeutung der Operation, ist es unzweifelhaft, dass der mit einer einzigen Niere lebende Mensch während der ganzen Dauer seines Lebens mehr Gefahren ausgesetzt ist, als ein anderer; wie oft fanden wir in der Leiche, dass die eine Niere bedeutend krankhaft verändert, ja selbst geschrumpft war, und dass dennoch das Individuum ohne Symptome einer Nierenerkrankung gelebt habe? Wenn es nun blos die eine Niere gehabt hätte, so hätte gewiss diese Erkrankung derselben schon in einer früheren Zeit zum Tode geführt. Wenn wir auch von jenen Nierenerkrankungen alısehen, zu denen ein solches einnieriges Individuum eo ipso disponirt ist, ist es etwa gleichgiltig, ob in einer anderen, Jedermann betreffenden Krankheit für die Entleerung jener Verbrennungsprodukte des Organismus, deren einzelne Theile in die Niere gelangen, eine oder aber zwei Nieren sorgen?! Unzweifelhaft sieht ein solches, einer seiner Nieren beraubtes, Individuum mit mehr Gefahren dem Leben entgegen, als jenes, das zwei Nieren hat; so dass schon dieser eine Umstand genügend ist, um uns bei unserem Vorgehen den grössten Conservatismus einzuflössen. Wir werden indess im Nachfolgenden sehen, 
dass dieses Princip sogar auf dem Gebiete der chirurgischen Behandlung der kranken Niere bereits zur Geltung gelangt ist und dass unsere Intention stets die ist, dass, so weit möglich, wir die noch brauchbaren Theile der Niere zu erhalten bestrebt sein sollen.

Wer sich mit der Operation von Bauchgeschwülsten viel beschäftigt, begegnet unbedingt Fällen, wo es nothwendig ist, in der Tiefe des Beckens eine blutende Stelle schleunigst zu comprimiren, eventuell zu ligiren, ein widerstrebendes Gewebe zu reseciren, einen Hülsen- oder Rindentheil mit der Scheere zu reduciren, eine grossen Widerstand leistende Geschwulst mit Gewalt aus der Tiefe des Beckens zu entwickeln. Bei solcher Gelegenheit taucht in meinem Gedächtnisse jedesmal die Möglichkeit der Verletzung eines Ureters auf, weshalb ich sehr vorsichtig bin; doch trotz dieser Vorsicht geschieht es dennoch, dass die Verletzung des Ureters manchmal unvermeidlich ist; ebenso bei mir, wie bei Anderen. Schon seit Langem verfolge ich mit Aufmerksamkeit diese Frage und fand, dass die disponirenden Momente in einem Theile der Fülle in den anatomischen Verhältnissen gelegen sind.

Die von Olshausen unter dem Namen "Cystoma proliferum papillare" in eine besondere Gruppe eingereihten Eierstock-Greschwülste sind dadurch charakterisirt, dass sio nahezu immer bilateral sind, oder, wenn sie es auch zur Zeit der Operation noch nicht sind, wir erwarten können, dass sich aus dem anderen, anscheinend noch gesunden Ovarium, binnen relativ kurzer Zeit auch oine ähnliche Geschwulst entwickeln wird. Diese Geschwülste wachsen langsam; in die Tiefe des Beckens eingewachsen, klammern sie sich hartnäckig sowobl an den Untergrund, als an die umgebenden Organe an, schleichen sich zwischen Blase und Uterus ein, und das Peritoneum des Uterus in die Höhe hebend, bilden sie einen dicken, musculären Mantel, wobei noch za bemerken ist, dass sie oft genug zu secundären Erkrankungen des Peritoneums Anlass geben. - Zu dieser Charakteristik möchte ich meinerseits noch hinzufügen, dass sie sieh beiderseitig, vielleicht auch nieht isochronisch, und trotz ihrer versehiedenen Entwickelung in auffällig analoger Weise den nachbarlichen Organen gegenüber verhalten: nämlich ihr Verhältniss zur Tuba, zur Uteruswand, zur Blase und zum Ureter ist auf der einen Seite genau dasselbe, wie auf der anderen, und besonders möchte ich noch bemerken, dass sie die Ureteren viel eher von ihrem Orte zu ver- 
drängen pflegen, als Geschwülste anderer Art, welchem Unstande es zuzuschreiben ist, dass wir bei der Operation der Geschwülste dieser Art (die - nebenbei bemerkt - technisch die schwierigsten sind) relativ so oft mit jenem gefährlichen ()rgan (Ureter) in Collision gerathen.

Erwähnenswerth ist auch, dass in Begleitung der Ureteren eine genügend starke Arterie verläuft, welche sich unmittelbar an die Ureterenwand fest anschmiegt und von derselben schwer isolirt werden kann. Diese Arterie ist die aus der Art. renalis stammende Ureterica, die in den anatomischen Lehrbüchern, als scheinbar unbedeutend, des Näheren kaum gewürdigt wird, deren Kenntniss jedoch, von unserem Gesichtspunkte aus, eine grosse Tragweite besitzt. Wenn wir nämlich bei der Entwicklung dieser Gesehwülste in dem oftmals zäh zusammenhaltenden Bindegewebo arbeiten, können wir leicht diese Arterie durchreissen und so kann denn bei solcher Gelegenheit, bevor es noch gelungen wäre die Geschwulst zu entwickeln, und wir uns inmitten der unberechenbaren Schwierigkeit dieser Procedur befinden, eine starke arterielle Blutung das ganze Gesichtsfeld in der Tiefe überschwemmen, welche zu stillen unbedingt und sofort nothwendig ist; und dieser kritische Moment, in welchem mit einer Péan'schen oder irgend einer anderen Pincette, gleichsam im Finsteren, das Gefäss rasch erfasst werden muss, ist es, da auch der Ureter selbst in unser Instrument hinein geräth. Aber selbst dies käme nicht in Betracht, wenn der Ureter regelmässig verliefe; denn, da uns dio Nachbarschaft bekannt ist, so wüssten wir, was wir nun zu thun hätten. Indess verhält sich die Sache anders; denn der Ureter findet sich oft genug in überraschender und unerwarteter Weise dislocirt, und wir können nicht bei einer jeden da und dort auftretenden arteriellen Blutang jedesmal auch die Anwesenheit dos Ureters vermuthen. Nun ist aber bei einer solchen Gelegenheit das Rathen und Vermuthen gewiss nicht am Platze; wir müssen rasch und sicher vorschreiten, denn wenn wir bei einer jeden Blutung früher jede Eventualität erwägen müssten oder sollten, so könnte die Kranke am Operationstische verbluten, - und so geschieht es denn, dass wir an der rasch erfassten, ligirten und resecirten Stelle mit einem Male das klaffende Iumen des Ureters erblicken. Jedem mit der Operation $\nabla$ on Banchgeschwülsten viel beschäftigten Operateur dürfte der Fall vorgekommen sein, dass nach der Entwicklung eines bedentenden Tumors, der Ureter - 
wenn auch mit unversehrtem Lumen - in der Richtung seines Verlaufes, manchmal in der Länge von $10-15 \mathrm{~cm}$, von seiner Umgebung losgelöst, ganz frei als ein fingerdicker cylindrischer Strang ins Becken herabhängt. Besorgt fragen wir uns alsdann, auf welche Weise wohl später die Ernährung des Gebildes erfolgen, und ob nicht Necrose dasselbe bedrohen werde? In einem solchen Falle entscheidet dann über das fernere Schicksal die Art. ureterica, welche sich fest an die Ureterenwand anschmiegt und für sich allein wenigstens so lange für die Ernährung des Ureters sorgt, bis die bekannte Plasticität der Umgebung, durch die sich neu bildenden Gefässverbindungen das ihrige dazu beiträgt. Zu dieser Gruppe der Ereignisse gehört auch, dass inmitten der Ligirung oder Umschlingung der zahlreichen blutenden Arterien und anderer Gefässe, die Reihe schliesslich auch an die Arterie des Ureters kömmt und der umschlingende oder unterbindende Faden den Ureter selbst gefasst hat, ohne dass wir hieryon zufolge seiner Lage auch nur eine Ahnung hätten! Ich glaube, dass dieser Umstand sich viel öfter ereignet, als die Operateure bievon Kenntniss haben; aber selbst dann noch eilt die Natur in manchen Fällen zu Hilfe; denn es ist bekannt, dass nach Unterbindung des Ureters der stagnirende Harn, wenn er aseptisch ist, wohl acute Hydronephrose mit den der Spannung entsprechenden starken Schmerzen, aber nicht Fieber verursacht - und dass nach einer gewissen Zeit der Harn resorbirt wird, nachdem das Gewebe der Niere unter dem constanten Drucke atrophirte. Die Hilfe der Natur besteht in einem solchen Falle darin; dass die andere Niere die ganze Thätigkeit zu leisten im Stande ist (Guyon: ,Retentions rénales. Annales des maladies des organs génito-urinales." IX. Bd. pag. 605. 1891).

Indem ich mir die Möglicheit einer Unterbindung les Ureters stets vor Augen hielt, stellte ich auf Grund wiederholter Erfahrung bei meinen Laparotomien mir als Regel auf - und empfehle dieselbe auch Jedermann - dass, so oft in der Tiefe des Beckens Umschlingungen und Unterbindungen vorkommen, ich nach Beendigung der Operation den Verlauf der Ureteren in Augenschein nehme. Diesem Umstande verdanke ich es, dass ich wiederholt noch rechtzeitig, wenn auch mit Schwierigkeit, die Unterbindungsstelle löste.

Die Erkenntniss der Situation jst übrigens in einer solchen Zeit nicht schwer, da, wenn der Ureter irgendwo ligirt worden 
ist, in seinem Lumen während der Operationsdauer eine Staung auftritt; und wenn ich dann die Abtastung in einer entsprechenden Höhe beginne, so erkenne ich an der einen oder anderen Seite der Wirbelsäule in der Form eines starken cylindrischen Stranges den gefüllten Ureter. Die Nothwendigkeit solcher Untersuchung des Ureters und Nierenkelches werde ich auch noch in anderer Form za demonstriren Gelegenheit haben, wenn ich, im Anschlusse an einen Fall vọn Nephrolithiasis, darauf zurückkehren werde.

Eine besondere Beachtung verdient aus dem Gesichtspunkte unseres Gegenstandes, die Dislocation der Ureteren betreffend, jene extraperitoneale Entwickelung der Geschwulst, wo selbe in die Tiefe des Beckens wachsend, zwischen Uterus und Blase geräth und gleichzeitig diese beiden Organe vollkommen von einander trennt. Der Uterus liegt dann in einem seitlichen und hinteren Quadranten des Beckens, die Blase aber kommt auf der nämlichen Seite, von der Mittellinie gänzlich verdrängt, neben einen seitlichen Querast des Schambeins, oft erstaunlich hoch emporgehoben zu liegen. Indem nun die Blase so nach der einen Seite hin wanderte, zerrte sie auch den entsprechenden Ureter mit nach sich, welch cylindrisches Gebilde wegen seiner zähen Structur einen grösseren Widerstand leistet, und an der kugelförmigen Peripherie der Geschwulst gegen die Mittellinie hin oder eventuell an der äusseren Peripherie nach aussen und oben sich erhebt und in auffälliger Weise, eventuell im Nivean des Beckeneinganges, an der Peripherie der Geschwulst unmittelbar unter der Bauchwand nach der entgegengesetzten Seite der Blase zieht. Diese Dislocation beobachtete ich sogar in einem solchen Grade, dass der linke Ureter an der seitlichen Oberfläche der Geschwulst, nahezu in der Höhe des Nabels zum Vorschein kam und eben diese Dislocation der Blase nach der soeben erwähnten Seite und oben, lenkte so sehr unsere Aufmerksamkeit auf diesen ausserordentlichen Umstand.

Der Druck, den die Geschwulst auf den Ureter ausübt, verursacht in vielen Fällen die Erkrankung des Ureters oder der Blase, in erster Reihe jedoch: Schwierigkeiten der Harnentleerung, Rückstauung des Harns, deren Folgen wieder als Hydronephrosis, Pyelonephrosis etc. dann leicht einzusehen sind.

Die eben geschilderte Dislocation der Ureteren beruht meinerseits nicht auf einer willkürlichen Combination, sondern ist auf der Wahrnehmung gut beobachteter Fälle aufgebaut - und ich bedaure nur, dass ich wegen Kürze der Zeit - jene Fälle über- 
geben muss, die das Gesagte zu illustriren geeignet wären; insofern ich mich auf jenes Terrain beschränken muss, wo zufolge factischer Verletzung der Ureteren ein speciell chirurgischer Eingriff nothwendig ward.

Zu diesen zählt folgender Fall, der seinerzeit den Gegenstand einer kurzen Demonstration in der Gesellschaft der Aerzte bildete; wenn ich bei dieser Gelegenheit neuerdings wieder auf denselben zurückzukommen mir erlaube, geschieht dies blos aus dem Grunde, weil dieser Fall in dem Rahmen dieser Fachfrage einen hervorragenden Platz einnimmt.

J. F. (1885/6, J.-No. 37), 26jähr. Frau, IIp., leidet seit einem Jahre an einer Geschwulst. Im September 1885 wurde eine rechtsseitige kindskopfgrosse, tief intraligamentär sitzende Geschwulst diagnosticirt. Bei der Laparotomie: Spaltung der peritonealen Hülse, wobei jedoch die schichtenweise Auslösung nicht gelingt; nach Ruptur der Geschwulst ergoss sich der Inbalt der papillären Höhle in die Bauchhöhle. Die Entfernung der nun collabirten Geschwulst war mit grosser Schwierigkeit verbunden, da kein schälbares Stratum zu entdecken war; während der mähsamen Arbeit entstand plötzlich eine starke arterielle Blutung. Endlich nach zahlreichen Ab- und Unterbindungen gelang die Entwickelung des Sackes. Mit dem Eintritt ruhigerer Momente entdeckten wir zugleich, dass auch der rechte Ureter durchschnitten ist, und in der Länge von etwa $12 \mathrm{~cm}$ frei ins Becken berabhängt. Wir bestrebten uns nun vor Allem und zwar mit Erfolg, die Enden des durchschnittenen Ureters zusammenzunăhen. Zu diesem Zwecke legten wir ein $4 \mathrm{~cm}$ langes Stück eines englischen Katheters No. 8, der in der Mitte auf einen Faden befestigt wurde, rechts und links in die 2 durchschnittene Lumina des Ureters provisorisch ein, und adaptirten so die geschnittenen Enden mit etwa 6-8 Nähten und entfernten das Stück Katheter vor dem Schürzen der drei letzten Knoten. Zur Sicherang der Nähte zogen wir nun mit einigen Nähten das den Ureter umgebende Bindegewebe heran, und sicherten auf diese Weise die Naht vor Zerrung. - Nun sahen wir den genähten, entblössten und versenkten Ureter, der etwas nach rechts vom Promontorium ins Becken herabhängt. Sowohl das zerpflückte Bett der Geschwulst (der grosse todte Raum [Mikulicz], der unreine Charakter der Operation, als anch das weniger verlässliche Nähen des Utreters zwang uns zur Drainage. Glasdrain nach oben und unten nach breiter Eröffnung des Scheidengewölbes.

Operationsdauer $3 \frac{1}{2}^{\circ}$ Stunden.

Der Verlauf war, abgerechnet einen Stichlkanaläbscess, der einige Tage Fieber verursachte und eine kurzen Katheterisationscystitis, bezüglich der Heilung des Abdomen ein ungestörter. Am 25. Tage verliess - Pat. das Bett und am 35. die Anstalt. - Die ambulatorische Behandlung der Drainagefisteln nahm noch eine Woche in Anspruch.

3 Jahre später bildete sich aus dem gelegentlich der Operation als gesund befundenen linken Ovarium heraus eine neue Geschwulst, die den Uterus jetzt nach rechts schob, von der Grösse eines Kindskopfes war, und sich extraperitoneal entwickelte. Pat. wurde von meinem 
Assistenten, Privatdocenten Dr. Dirner im Jahre 1889 zum zweiten Male mit Erfolg operirt. Die anatomischen Verhältnisse und die feinere histologische Structur der Geschwulst war auch bei dieser Gelegenheit mit den beim ersten Male gefundenen identisch. (In bistologischer Beziehung beschrieb diesen Fall mein gewesener Assistent Dr. v. Velits, derzeit Professor in Pressburg in den Spalten des "Orvosi Hetilap".)

Soviel mir bekannt, ist dies der erste Fall in der Literatur, in welchem demonstrirt wurde, dass die Heilung eines durchschnittenen Ureters auch auf directem plastischem Wege möglich sei. Derselben Beurtheilung unterliegt auch mein zweiter, analoger Fall, dessen Krankengeschichte kurz die folgende ist:

K. W. (1892, J.-No. 106), 40 J. alt, 0p. Leidet bereits seit Jahren an chronischer Cystitis, mit Schmerzen in der linksseitigen Nierengegend. Ein grosser Bauchtumor, der zeitweilig sich bald verkleinert, bald vergrössert; beim Verkleineren bessert sich der Zustand. Im Monate November 1892 wird die entkräftete, abgemagerte Kranke behufs Operation ihrer Ovarialgeschwulst auf unsere Klinik aufgenommen. Bei der Operation ist die Entwicklung der in der linksseitigen Bauchgegend sitzenden, extraperitonealen Geschwulst mit grossen Schwierigkeiten verbunden zumal wegen der profusen Blutung. Die Hülse ist oedematös, schlaff, von grossen Gefässen durchsetzt, massig, so dass nach Entfernung der Geschwulst die Reduktion jener nothwendig erscheint. Nachdem wir endlich mit diesem Abschnitte fertig sind, bestreben wir uns die Mantelwände zusammenzunähen, und hiemit das extraperitoneale Cavum von der Bauchhöhle auszaschliessen, - nun aber taucht vor uns in der Nähe des Uterus, in der zerpflückten Wundhöhle ein bläulich durchsichtiger, dünnwandiger, zolldicker, rasch entstandener, schwellender Tumor auf, der ein Hämatom zu sein scheint. Dieser Befund veranlasst uns, den Inhalt zu extleeren und die Quelle der Blutung zu suchen. Eingeschnitten, entleert sich jedoch nicht Blut, sondern Harn - und ein Lumen blickt uns entgegen, von dem wir constatiren, dass dies das Lumen des linksseitigen, in der Nähe der Blase unterbundenen Ureters sei, dessen Lumen in nahezu 2 Dritttheilen durchgeschnitten war. Die Verlaufsrichtung mit der Sonde verfolgend, constatiren wir den lose befestigten Ureter in dem gewesenen, zerfetzten Geschwulstmantel neben dem Promontorium in die Höhe steigend. Mit grosser Mühe gelang es uns, die Unterbindungsstelle zu lösen und die Schnittenden des zum grossen Theile durchschnittenen Ureters über dem in der bekannten Weise eingefügten GummiCylinder mit seidenen Knopfuähten zu vereinigen. Wie bereits erwähnt, war das Lumen des Ureters erweitert und die Niere fühlte sich auch recht gross und massig an. Die Geschwulst verdrängte und hob also den Ureter so in die Höhe, dass derselbe an der rechtsseitigen Peripherie der (links entwickelten) Geschwulst unmittelbar neben dem Uterus zur Blase herunter lief. Die Ureterennaht schien so exact, dass wir von einer Drainage absehen konnten. Der Verlauf war, eine Cystitis abgerechnet, reactionslos und die Kranke verliess die Anstalt am 25. Tage geheilt. 
Einem interessanten Falle der Nierenchirurgie begegnete ich im Jahre 1890, welcher seinerzeit auch den Gegenstand einer kurzen Demonstration in der Gesellschaft der Aerzte bildete. Zufolge der von hier ausgegangenen Referate gelangte der Fall auch in die Literatur, wo ich demselben wiederholt, aber immer falsch mitgetheilt, begegnete. Dieser Fall ist interessant genug, um richtig gekannt zu sein; denn es können von demselben einige Consequenzen von allgemeinem Werthe abgeleitet werden. Ich finde es demnach nicht für überflüssig, denselben hier - wo wir uns mit der Chirurgie der Ureteren beschäftigen - zu besprechen.

Bereits anlässlich der Demonstration hatte ich darauf hingewiesen, welche grosse Rolle in der Nierenchirurgie dem Cystoscop beschieden ist - zumal in solchen Fällen, in welchen wir über die Qualität einer jeden Niere und ihres Ureters einen besonderen Aufschluss gewinnen müssen. Es ist nämlich bekannt, dass man nach mässiger Füllung der Blase mit dem Cystoscop die Mündungen der Ureteren vortrefflich einstellen kann und dass der, durch den aus dem Ureter periodisch in rhythmischer Weise einfliessenden Harn erzeugte kleine Wirbel pünktlich zu beobachten ist. Dies ist so sehr charakteristisch, dass dessen Mangel auf der einen oder anderen Seite ein sicheres Zeichen für den Verschluss des betreffenden Ureters bildet. In einem anderen Falle hingegen kann die Differenz des in die mit reinem Wasser angefüllten Blase einströmenden Harnes insofern pünktlich erkannt werden, als letzterer da normal rein, dort aber eventuell flockig, sedimentös, blutig ete. sein kann. In jüngster Zeit hat sich das Cystoscop zu einem solchen werthvollen diagnostischen Hilfsmittel gestaltet, dass man dasselbe bei der heutigen Diagnostik nicht mehr entbehren kann. Ein solcher, mit dem Cystoscop pünktlich determinirter Fall war auch der, von welchem ich berichten will. Es ist in demselben die Rede von einem dritten Ureter, der ausserhalb des Sphincters der Blase in die Urethra einmündend, continuirliches Harnträufeln verursachte, nebstdem dass die Kranke periodisch den in ihrer Blase angesammelten Harn entleerte.

Die Krankengeschichte ist die Folgende:

S. B. (1889-90. Journal-No. 170) $14 \mathrm{~J}$. alt, Op., ledig, leidet seit ihrer Geburt an Harnträufeln. Die Erforschung der Ursache machte recht viel Sehwierigkeiten, bis wir endlich im oberen Drit theil der weiten Urethra an der linksseitigen hinteren Wand eine Oeffnung entdeckten, durch welche der Ureteren-Catheter in die Höhe und etwas nach hinten 
und links geleitet werden kounte; der Urin floss tropfenweise durch den Catheter ab. Wenn man bei einer solchen Gelegenheit zugleich die cystoskopische Untersuchung vornimmt, so kann man die Einmündung der beiden normalen Ureteren in die Blase bestimmt beobachten; nebstdem kann auch bei Bewegung der Sonde entlang der linken hinteren Blasenwand, entsprechend dem Gange der Sonde die nach innen sich vorwölbende Faltung der Schleimhaut, resp. der Blasenwand gesehen werden, ohne dass der Sondenknopf irgendwo in der Blase zum Vorschein gekommen wäre. $\mathrm{Da}$ durch den Catheter der Urin constant träufelt, dieser aber - wie es der cystoskopische Befund bezeugt - nicht der Blase entstammt, wurde es unzweifelhaft, dass wir es hier mit einem dritten, in die Urethra mündenden Creter zu thun hatten, der vorerst in der Wand der Urethra selbst, bald aber parallel der hinteren Wand der Harnblase, in deren unmittelbarer Nachbarschaft nach oben und links hinzieht.

$\mathrm{Ob}$ nun der überzählige Ureter einen Ast des linken normalen Ureters bildet, oder mit diesem parallel zur linken Niere zieht, und ob er selbstständig aus einem besonderen Nierenkelche entspringt, bleibt unentschieden. Wir bezweckten nun die Mündung des überzähligen, aberranten Ureters in die Blase oberhalb des Sphincter vesicae zu versetzen, u. z. mittelst Epicystotomie derart, dass wir nach entsprechender Eröffnung der Blasenhöhle, mit Hilfe einer in den aberranten Ureter eingeführten Knopfsonde, deren Wand innerhalb der Einmündung des linken Ureters und oberhalb gegen die Höhle der Blase hervorwölbten und mit dem Messer den Schnitt in der Längsrichtung derart führten, dass nun der Knopf der Sonde in der Blase zum Vorschein kommen sollte. Indem wir ferner aus dem peripheren Stumpfe ein Stückchen quer herausschnitten, verschorften wir gleichzeitig mit dem PaquelinBrenner den zurückbleibenden Theil, um dessen Obliteration herbeizufübren. Die Einmündung des proximalen Stumpfes constatirten wir sodann mit der Sonde, indem wir die Entleerung einiger Tropfen Urins in die Blase beobachten konnten. Das Ureter-Ende lag in der BlasenWand derart gut fixirt, dass wir zur Sicherung der Einmündang nichts Besonderes zu thun hatten. Nach Schliessung der Blase und der Bauchwunde genas das Mädchen ohne jegliche Reaction und ward vom Harnträufeln für immer befreit. -

In solchen Fällen von Harnträufeln in Folge eines vermutheten 3. Ureters, kann ich nicht genug die Untersuchung mittelst Cystoskops anempfehlen; denn es scheint, dass das von mir befolgte Vorgehen nicht blos in einem Falle gelingen wird. Der dritte Ureter mündet oft genug auch in das Scheidengewölbe, und da pflegt der Gynäkologe zumeist so vorzugehen, wie ich es in meinem ersten Falle nach Durchschneidung des Ureters intendirte; nämlich man legt eine künstliche Blasen-Scheidefistel an und schliesst auf plastischem Wege das Scheidengewölbe, indem man derart den Ureter gegen die Blase hin kanalisirt. Wenn wir einen solchen Fall mittelst Cystoskops untersuchen, und in den abnormon Ureter eine Sonde einführend, deren Knopf gegen das Lumen der Blase heben, 
so ist die Schicht, die sich nach innen wölbt, weder dick noch massig. Wenn es uns jetzt mittelst Epicystotomie gelingt, den Ureter in der von mir befolgten Weise mit dem Lumen der Blase zu verbinden, und wir mittelst Paquelin den peripherischen, in das Scheidengewölbe mündenden Antheil des Ureters zur Obliteration bringen, so können wir, meiner Ansicht nach, binnen kürzerer Zeit eine si herere Heilung erreichen, als durch die langwierige, von Seiten der Kranken und des Arztes gleichmässig eine grosse Ausdauer erfordernde, künstliche Blasen-Scheiden-Fistel und die darauf folgende Plastik. Im Uebrigen wäre es der Mühe werth, diese Erwägung auch auf jene Fälle auszudehnen, in denen die Uroter-Scheidengewölbe-Fistel, zu Folge anderer Ursache, zu Stande gekommen ist.

\section{Fälle von Nephrectomie.}

In den vorangehenden, mit den Ureteren complicirten Fällen, gelang die völlige Erhaltung der Niere; indess giebt es trotz des grössten Conservatismus noch eine andere Gruppe von Fällen, in welchen die Durchschneidung oder Verletzung des Ureters theils wegen der unmittelbaren Schwierigkeiten der Situation, theils wegen der Folgezustände zur Exstirpation der Niere zwingt. Derartige Fälle hatte ich vier. In zwei Fällen hatte ich es mit soliden Geschwülsten zu thun, u, z. mit einem Fibromyom des Ligam. latum und mit einem extraperitoneal entwickelten Adenofibrom des Ovariums; in den anderen 2 Fällen handelte es sich um cystöse Geschwülste.

Die Krankengeschichten mögen in Kürze folgen.

J. G. (1890. Journal-No. 55), 44 Jahre alt, 3 para. Wegen eines intraligamentären subserösen Fibromyoms wurde dieselbe am 27. Mai 1890 einer Laparotomie unterzogen. Nach Entwicklung des zwischen den Stratis des Lig. lat. sich entwickelten Fibromyoms, welches mit dem Uterushals durch einen kindsarmdicken Stiel in Verbindung stand, ging die Blutstillung mit ziemlicher Schwierigkeit von Statten. Sowohl die Arteria uterina, als die A. spermatica musste umstochen werden, schliesslich jedoch gelang es, das die Höhle der Geschwulst darstellende extraperitoneale Terrain mittelst Etage-Naht derart zusammenzuziehen, dass dasselbe wesentlich reducirt, aus der Bauchhöhle gewissermassen ganz ausgeschlossen ward. Mit einem Stück des peritonealen Antheils der Hülse wurde auch die von ihrem Peritoneum entblösste Uteruswunde bedeckt. Am 5. Tage nach der Operation bekommt Patientin Fieber, wird sehr unruhig, erbricht, hat intensiven Bauchschmerz, und anter diesen Erscheinungen erreicht die Temperatur am 12. Tage die 
Höhe von $40^{\circ}$. Durch das Scheidengewölbe hindurch ist ein Exsudat zu tasten, obne dass jedoch eine Suppuration constatirbar und demnach zur Eröffnung Gelegenheit geboten wäre. Am 17. Tage erfolgt Durchbruch in den Darm, am 18. Tage lässt sich anch in der Narbenlinie der Bauchwand Fluctuation nachweisen, und durch Einschnitt viel übelriechender Eiter entleeren. Diese Eiterretention gab noch sehr viel zu schaffen, da angesichts der blos durch frische Adhäsionen geschützten Peritonealhöhle, die Drainage nur mit grosser Vorsicht möglich war. Nach Wochen wird eines Tages beim Verbandwechsel ein profuses urinöses Secret bemerkt, womit gleichzeitig auch die aus der Blase entleerte Urinmenge sich verminderte. Mittelss cystoskopischer Untersuchung der Blase wird constatirt, dass die Abscesshöhle mit der Blase nicht communicirt; ebenso wird es zur Gewissheit, dass der Harn der linksseitigen Niere sich ganz durch die Fistel entleert. Wir haben es somit mit einem Abscess der Bauchböhle zu than, der durch die Bauchwand hindurch mit der Aussenwelt, dem Darmtract und dem Ureterlumen communicirt. Die Ursache davon mag ein Anstechen des Ureters gewesen sein. Im Interesse der Heilung des Abscesses führten wir nach Eröffung des hinteren Scheidengewölbes ein Drainrohr durch. Nachdem wir auf diese Weise die Reduction der Abscesshöhle erreicht hatten, erwogen wir das der Ureterfistel gegenüber zu befolgende Vorgeben. Das constante Harnträufeln nämlich verursacht Excoriation der Bauchwände und macht hierdurch die Kranke arbeitsunfähig. Die auf ihre Händearbeit angewiesene Pat. wünscht eine dringende, gründliche Hilfe. Das Cystoskop hatte es als sicher bezeichnet, dass aus dem linksseitigen Ureter nichts in die Blase gelangt; somit haben wir es mit einer Fistel des linken Ureters zu thun. Zwischen der Blase und dem Bauchhöhlen-Abscess war eine so bedeutende Induration zu finden, dass die unmittelbare Kanalisirung yon der Blase her keinen Erfolg versprach; zu dieser Zeit war aber der Darmdurcbbruch auch schon geschlossen, und so beschäftigte uns denn eine einfache UreterBauchfistel. Nachdem wir gar keinen anderen $W_{e g}$ hatten, um den linkseitigen Ureter in die Blase zu Ieiten, und die Kranke in diesem Zustande mit constantem Harnträufeln und inmitten der zu Folge der Staung des Urins in der Abscesshöble sich ergebenden Gefahren nicht belassen werden konnte, beschlossen wir die Exstirpation der linksseitigen Niere, die Sorge um die Schliessung der Bauchwand-Scheidenfistel für später belassend. Früher jedoch mussten wir uns von dem integren Zustande der rechten Niere Gewissheit verschaffen. Im Sinne der Untersuchung des Herrn Assistenten Dr. Alex. v. Korányi ist die rechte Niere gesund, ja es scheint, als wenn diese intacte Niere zum grossen Theil bereits die Aufgabe der Anderen übenommen hätte insofern als in dem von derselben entleerten Harn die Menge des Harnstoffes dem normalen Harnstoffquantum, wenn der Urin von beiden Nieren stammt, entspricht. Die linke Niere, deren Secret durch die Fistel wir aufzufangen in der Lage waren, scheidet blos eine minimale Menge Harnstoff aus; überdies verminderte sich ihr Secret wesentlich, so dass sie das Bild einer eirrhotischen Niere darstellt.

Unter solchen Umständen hatten wir jm Januar 1891 unter den günstigsten Auspicien die Exstirpation der linken Niere vorgenommen; Lumbalschnitt nach Simon; die Niere mittelst bedeutender Adbäsionen fixirt. Um Raum zu gewinnen wird die 12. Rippe resecirt, worauf die Enucleation der Niere, die Unterbindung des Ureters und der Nieren- 
gefässe ohne Schwierigkeit von Statten geht. Die Unterbindungsfäden wurden herausgeleitet, die Höhle mit Jodoformgaze drainirt. - Später, seit ich den Czerny'schen Lumbalschnitt benutzte, hatte ich Gelegenheit mich davon zu überzeugen, dass hierdurch die Resection der Rippe vermieden werden kann.

Nach der Operation fieberfrei; indess verräth eine geringe Eiweissmenge im Urin, dass die Niere gereizt wird, nebstdem verminderte sich auch das Harnstoffquantum, was den Umstand documentirt, dass die Reizung in den filtrirenden Nierenpartien stattfindet.

Die genauen, von dem Herrn Dr. Alex. v. Korányi ausgeführten Harnuntersuchungen ergaben folgende Resultate:

Tag nach der-Operation:

\begin{tabular}{|c|c|c|c|c|c|}
\hline & Quantität & speeif. Gewicht & Reaction & Eiweiss & Harnstoff $\mathrm{pCt}$. \\
\hline I. & $650 \mathrm{ccm}$ & 1031 & sauer & wenig & - \\
\hline II. & 550 & 1030 & $n$ & $n$ & $4,50=25,19$ \\
\hline III. & 450 & 1020 & $n$ & $\eta$ & $4,83=22$ \\
\hline IV. & 435 & 1030 & $n$ & $n$ & $4,76=20,7$ \\
\hline
\end{tabular}
Reaction.

Die Harne geben mit $\mathrm{NO}_{\mathfrak{5}}$ die Rosenbach'sche burgunderrothe

Das im Harne enthaltene, quantitativ nicht zu bestimmende Eiweiss deutet darauf hin, dass die Niere gereizt sei; die Verminderung des Harnstoffquantums aber darauf, dass der Reiz das Nierenepithel betrifft; die Verminderung der Harnmenge ohne entsprechende Steigerung des specifischen Gewichtes schliesslich darauf, dass der Reiz die filtrirenden Nierenpartien betrifft. Alldies kann auf die durch den Ausschluss des linken Nierengefässsystems zu Stande gekommene, collaterale Hyperämie zurückgeführt werden. Die Rosenbach'sche Reaction dentet auf die im Darmtracte vor sich gehenden, näher nicht zu bestimmenden, abnormen Processe hin. Sowohl die Niere, als die Functionsstörung des Darmtracts indiciren eine Milchdiät. Medicamente, die die Niere reizen, (wie z. B. die Carbolsäure) sind contraindicirt.

Die Milchdiät bewirkte nun bald Besserung in der Niere und auch die Bauchwand-Scheidengewölbe-Fistel schrumpfte bei sorgfältiger Reinigung zusehends zusammen und nach 2 Monaten trat vollkommene Heilung ein. Die Kranke wird wohl noch mit einer etwa 4-5 cm langen Bauchwandfistel entlassen, die jedoch gegen die Scheide hin nicht communicirt und die nach dem Berichte ihres Ordinarius sehr rasch heilte. -

In diesem Falle ist die Geschichte der Ureter-Bauchfistel in Vielem derjenigen von Hegar's und Nussbaum's Fällen ähnlich; mit dem Unterschiede jedoch, dass die Einleitung des Ureters in 
die Blase hier unmöglich war, insofern als man zwischen der geschrumpften Abscesshöhle und der Bauchwand einen die Blase und den Ureter verbindenden, ständigen Kanal nicht herstellen konnte, - u. z. deshalb nicht, weil, mögen wir denselben auf welche Art immer darstellen, die schrumpfende Narbe und die Schwielen den Kanal bald zusammendrücken werden; andererseits aber die Bildung einer Epithelbedeckung für den künstlichen Kanal unmöglich schien; - und somit war nur noch eine Procedur möglich, nämlich: die Exstirpation der Niere, welche - wie wir gesehen auch zur Heilung führte.

Der fulgende hierher gehörende Fall ist:

J. K. (1887/88. Journal-No. 108), 36 Jahre alt, IIIpara. Seit 4 Jahren Geschwulst, Athembeschwerden; am 15. Mai 1888 Eintritt in die Klinik. Bis zum Processus xyphoideus reichende, grosse, cystöse Geschwulst. Uterus bedeutend in die Höhe gehoben, von der Geschwulst nicht isolirbar. Bei der Laparotomie wurde, conform der Diagnose, eine extraperitoneale Geschwulst gefunden, deren Ausschälung aus der musculären Kapsel - Mangels einer Schichte - sehr erschwert ist. Nach Ausschälung der Geschwulst mussten an der zerrissenen Kapsel, wegen profuser Blutung, ringsherum Massenligaturen angelegt werden. Nach vollendeter Operation stellt sich bei üblicher Untersuchung der Ureteren heraus, dass unter den tief gelegenen Ligaturen, sich auch der rechtsseitige, durchschnittene Ureter befindet. Wie in jedem Falle wurde auch in diesem vor allem die Zusammennähung der Ureterenden erwogen; aber der Ureter war - wie es scheint - durch den anhaltenden Drack der Geschwulst und die hierdurch bedingte Urinstaung ausserordentlich erweitert und von solch dünner Wandung, dass er zum Zusammennähen durchaus ungeeignet erschien, und somit nichts anderes, als die Exstirpation der rechtsseitigen Niere übrig blieb. Die Nephrectomie vollzogen wir mittelst typischen Lumbalschnitts nach Czerny im unmittelbaren Anschluss an die Laparotomie, die Unterbindungsfäden nach aussen geleitet. Jodoformgaze-Drainage. -

Die Bauchgeschwulst war ein proliferirendes, glanduläres Cystom. Das Becken der exstirpirten rechten Niere erweitert, um die gewundenen Kanäle - ersten und zweiten Grades - herum eine von früherer Blutung herrührende Pigmentation; in dem medullaren Theile der Niere, in den die geraden Harnkanäle verbindenden, bindegewebigen Lymphräumen in grösserer Menge amorphes, älteres Blutpigment. Dieser Befund der Niere, verglichen damit, dass der gelegentlich der Operation durchschnistene Ureter wesentlich erweitert, seine Wandung ausserordentlich diinn und zum directen Nähen eo ipso ungeeignet war, beweist klar, dass zu Folge des Druckes dieser Geschwulst schon früher im Ureter eine Staunng bestand, welche sowohl die Erweiterung des Ureters, als die des Nierenbeckens und zugleich in der Niere die Folgen der starken Stauung - nämlich in der Rinde und in der Marksubstanz Blutergüsse - verursachte.

Der Verlauf war ein ganz befriedigender und ungestörter. Die linke Niere übernahm ohne jede Schwierigkeit die Compensation, so dass am nächsten Tage nach der Operation die Harnmenge $1285 \mathrm{ccm}$ 
betrug mit einem specifischen Gewichte von 1018. Die Kranke verlässt das Bett am 25. Tage und erfreut sich seither des besten Wohlseins.

Aus der Betrachtung dieses Falles lassen sich gewisse Consequenzen von allgemeiner Bedeutung ableiten. Und zwar alterirte die Exstirpation der Niere absolut nicht die Heilung, so dass dieselbe so sehr ohne jedes Symptom verlief, dass sie geeignet wäre den Beobachter bezüglich der Nierenexstirpation auf einen falschen Weg zu leiten. Die Compensation war rom ersten Tage an eine vollkommene; die zurückgebliebene linke Niere lieferte einen auch quantitativ normalen Harn, so dass derselbe bereits am 2. Tage $1285 \mathrm{ccm}$ betrug mit einem specif. Gewi ht von 1018.

Die eben geschilderte Beschaffenheit des Ureters und der Niere liefert die Erklärung für diese auffallende Erscheinung. Das Verständniss für den betreffenden Zusammenhang finde ich in einer experimental-thereotischen Arbeit, welche von Faver in Virchow's Archir erschienen ist ${ }^{1}$ ). Faver bewies an Thierexperimenten, dass die Ursache der nach Nephrectomien anftretenden, relativ grossen Sterblichkeit in den meisten Fällen in einer Nephritis parenchymatosa acutissima gelegen ist, die aus einer specifischen Ptomainaemie entsteht; in der Weise nämlich, dass die plötzlich belastete, zurückbleibende Niere nicht im Stande ist, die nöthige vicariirende Funktion zu übernehmen, wodurch die Bakterien des Blutes und deren Produkte sich anhäufen und diese specielle Krankheit der Niere verursachen. Zur Vermeidung dessen empfiehlt Faver die zweizeitige Nephrectomie, indem er an Thierexperimenten nachwies, dass zufolge der einseitigen Ureterunterbindung blos $12 \mathrm{pCt}$. der Versuchsthiere zu Grunde gehen, und dass bei den derart behandelten Thieren, wenn die Niere erst nach 14 Tagen exstirpirt wurde, sämmtliche Thiere am Leben blieben, d. h. die Mortalität 0 pCt. war.

Wenn wir in dieser Weise operiren, so erscheint uns die Nierenexstirpation deshalb ungefährlich, weil die zweite Niere nicht auf einmal, nicht mit einem Schlag, sondern allmählich die Funktion der anderen übernimmt. Wenn wir nun diese Theorie bei unserer Kranken anwenden, so beweisen die in dem Ureter,

1) Virchow's Arch. 127, I, S. 33, 1892. Die Ursache der Eklampsie eine Ptomainämie etc. - Ebenda 129, I, S. 40, 1892, Ueber eine neue Methode der Nephrectomie. 
im Nierenbecken und im Nierenparenchym gefundenen Veränderungen zur Genüge, dass zufolge der Compression des Ureters längere Zeit hindurch eine Staung bestand, und dass unterdessen die zweite Niere Zeit und Gelegenheit hatte, sich an die vicariirende Thätigkeit zu gewöhnen.

Meiner Ansicht nach sind diese und ähnliche Fälle geeignet, die Faver'sche Theorie zu erhärten. Auch den negativen Beweis dieser Theorie fand ich in einem anderen Falle; wo bei der in Heilung begriffenen Kranken die Nephritis parenchymatosa acutissima mit dem Beginne der Urämie den Tod herbeiführte.

Der Fall ist in Kürze der folgende:

Frau A. K. (1892, J.-No. 12), 24 J. alt, 0p., kam am 6. Februar 1892 auf die Klinik. Seit 3 Jahren Geschwulst, die sich zwischen den Ligam. latis entwickelnd, den Uterus in die Höhe hebt, nach links schiebt and von demselben nicht isolirt werden kann. Gelegentlich der Laparotomie finden wir eine rechtsseitige, extraperitoneale Geschwulst, die den Uterus hoch nach links und oben erhebt. Collosales venöses Gefässnetz der Blätter des Lig. latum. Die Blase ist stark nach links gerückt, ausgezogen und theilweise an der Oberfiäche der Geschwulst situirt. Nach Spaltung der Kapsel entwickeln wir die Geschwulst aus ihrem Bette, was jedoch mit einer sehr grossen Blutung einhergeht, die erst nach zahlreichen, in der Nähe des Uterus angebrachten Massenunterbindungen sistirt. Die Blase zeigt bei ihrer Abschälung von der Geschwulst auf Handtellerfläche die entblösste Muscularis, ja an einer Stelle ist auch die Schleimhaut etwa $2 \mathrm{~cm}$ eingerissen, die im weiteren Verlaufe eine eigene Naht nothwendig macht. Nachdem die Blutung gestillt und die Geschwulst herausgegraben war, wurden in der Tiefe des Bettes sehr zahlreiche Umstechungen nothwendig. Auf der anderen Seite Exstirpation einer einfachen, kleinfaustgrossen, taboovarialen Geschwulst. Bei der üblichen Untersuchung des betr. Ureters findet sich ein cylindrisches Gebilde, welches sich seitwärts im Verlaufe der Wirbelsäule in das Becken herablässt und zwischen den Unterbindungsmassen in einem klaffenden venenartigen Stumpf endet - an einer Stelle, wo wir vorher wegen einer ziemlich starken arteriellen Blutung eine Unterbindung vornehmen mussten. Als nun diese Masse gelöst wurde, constatirten wir, dass der rechtsseitige Ureter durchschnitten sei. Den peripherischen Stumpf des Ureters konnten wir trotz des eifrigsten Suchens nicht auffinden. Derselbe mag wohl in den zerfetzten Unterbindungsmassen irgendwo versteckt sein, die jedoch mit Rücksicht auf die kaum bewältigte enorme Blutung - nicht gelöst werden können. Nachdem derart die unmittelbare Vereinigung der Ureterstümpfe ausgeschlossen war, standen wir vor der Frage, wie wir nun eigentlich den durchschnittenen Ureter versorgen sollen - und es blieb keine andere Wahl zurück, als die Exstirpation der rechten Niere, oder aber die Bildung einer Ureterbauchwandfistel mittelst Herausnähens des Ureters. - Bei der Beurtheilung dieser Situation stand ich unter dem Eindrucke meiner früheren ausgezeichneten Erfahrung, wo nämlich die vicariirende Thätigkeit sich so 
prompt einstellte; - und mit Rücksicht darauf, dass der Zustand der Kranken ein überaus befriedigender war, beschloss ich leider die sofortige Exstirpation der Niere! Die Exstirpation vollzogen wir mittelst typischen Lumbalschnittes, die Wunde vernähten wir zum grossen Theile, und nachdem wir die Unterbindungsfäden nach aussen geführt, legten wir ein Drainrohr und Jodoformgaze ein. Hierauf die Bauchwundennaht. Die Dauer der Operation war über $2 \frac{1}{2}$ Stunden; die exstirpirte Niere durchaus gesund.

Decursus: Nach der Operation gelangt die Kranke in überans schwachem Zustande ins Bett, erholt sich jedoch auf Excitantien rasch. Der Urin ist am ersten Tage blutig, $150-200 \mathrm{~cm}$; vom 2. Tage angefangen jedoch reinigt sich derselbe, ist $500 \mathrm{ccm}$, von saurer Reaction, keine fremden Formelemente enthaltend. Am 3. Tage ist die Menge des Urins bereits $750 \mathrm{ccm}$, am 4. Tage sogar $1250 \mathrm{ccm}$. Die Kranke ist fieberfrej, in der Peritonealhöhle und in der Lumbalregion keinerlei Symptome. Im Widerspruch damit stand das Allgemeinbefinden der Patientin; denn das Erbrechen, der Kopfschmerz hört nicht auf, es tritt Somnolenz ein, am 4. Tage ist die Temperatur $38,2^{\circ}$, bald $38,7^{\circ}$, der Puls frequent, 120-140, schwach; die Erscheinungen der Urämie und die Schwäche der Herzthätigkeit dauern fort und am 5. Tage früh stirbt die Kranke.

Das klinische Bild deutete ausser Anämie auf Urämie hin; der Sectionsbefund aber lantete: ,Die linke Niere etwas vergrössert, schlaff, blutarm, blass gelblich-grau, ihre Corticalsubstanz mit punktförmigen gelben Flecken eingestreut; die Kapsel leicht abstreifbar, unter derselben erweiterte Venensterne und punktförmige, purpurrothe Ecchymosen zu finden".

Die Epicrise ist in mehrfacher Hinsicht interessant. Und zwar schien die Niere an den ersten drei Tagen in ihrer vicariirenden Thätigkeit einen Fortschritt zu bekunden. Denn am ersten Tage war der Urin blutig, am zweiten bereits rein, am 3. schon anf $750 \mathrm{ccm}$ und vollends am 4. auf $1250 \mathrm{ccm}$ gestiegen; aber eben gleichzeitig trat auch Fieber anf; die Urinsecretion verringert sich unter den Erscheinungen von Urämie, die Herzschwäche wird mminent, und diese neuere Wendung - die acute Nephritis macht binnen 24 Stunden dem Leben der Kranken ein Ende. Diese Niere war augenscheinlich für die vicariirende Thätigkeit nicht vorbereitet (die exstirpirte Niere fanden wir durchaus gesund) und so trat denn mit der acuten Nierenentzündung gleichzeitig der Tod ein. Die Frage ist demnach wichtig genug, um in Betracht gezogen zu werden; denn wenn neuere Erfahrungen die Aufassung Faver's bewahrheiten sollten, so gehört die Zukunft der zweizeitigen Nierenexstirpation!

Die zweite Lehre, die ich zu meinem eigenen Nutzen von diesem Falle abgeleitet habe, ist, dass wenn durch irgend eine andere, bedeutsame, etwa langandauernde Bauchhöhlenoperation, 
oder einen Bulutverlust ets. der Organismus geschwächt wurde, und ich mich einem durchschnittenen Ureter gegenüber befinde, boi welchem die unmittelbare Vereinigung der Ureterenstümpfe unmöglich ist, die Nephrectomie aber unausweichlich erscheint, so vollziehen wir dieselbe nicht in einer und derselben Sitzung, sondern, nachdem wir den Ureter herausgenäht, warten wir die Heilung $a b$, und nur erst dann, wenn diese erfolgt ist, wenn der Organismus seine Widerstandsfähigkeit wiedererlangt hat, schreiten wir zur zweiten - an und für sich auch hochbedeutsamen - Operation, da wir bereits Zeit und Gelegenheit hatten, jedes einzelne Detail derselben hinreichend abzuwägen, namentlich aber die Functionsfähigkeit der zweiten Niere kennen zu lernen. Wohl gem'erkt, wenn wir die Bauchhöhle bereits eröffnet haben, benützen wir die Gelegenheit dazu, damit wir uns sowohl über die Verhältnisse der später za exstirpirenden, als die der zurückbleibenden Niere durch directe Betastung gründliche Kenntniss verschaffen - vor Augen haltend, dass die Entwickelungsanomalien der Niere, wie z. B. Hufeisenniere, einseitige Niere etc. keineswegs zu den Seltenheiten gehören.

Ich kenne und würdige die Schwierigkeiten und Nachtheile der zweizeitigen, verschobenen Nierenexstirpation zur Genüge. Die Kranke hat sich zum grossen Schritt entschlossen, und bei dieser Gelegenheit sowohl ihre psychische Kraft, als ihre materiellen Mittel vielleicht gänzlich in Anspruch genommen; es mag nun das Erwachen ein bitteres sein, wenn nach Ueberstehen der durch die Operation bedingten Gefahr u. s. W. die Kranke wegen eines accidentellen Leidens neuerdings einer eben solchen oder noch gefährlicheren Operation gewärtig sein muss. In der That ist eine einzeitige Operation sehr verlockend, zumal nach einer solchen Erfahrung, wie ich sie in meinem zweiten, vor diesem erzählten Falle gemacht - da die Nephrectomie eigentlich nicht einmal ins Gewicht $\mathrm{zu}$ fallen schien! Indess würde ich es meinerseits sehr erwägen, $a b$ in einem analogen Falle die einzeitige Operation statthaft sei - and ich könnte mich hieza nur unter besonders günstigen Umständen wieder entschliessen.

Im Anschluss an diesen Fall, mit dessen Epicrise ich mich nun beschäftige, ist auch noch die Frage wichtig, welche Bedentung wohl die nun als nebensächlich erscheinende, vernähte Blasenverletzung in der Zukunft habe? Die Kranke hatte 5 Tage gelebt und in der Bauchhöhle zeigten sich keinerlei Spuren einer 
Erkrankung; am 4. Tage hatte sie noch $1250 \mathrm{ccm}$ Urin entleert, womit erwiesen ist, dass die Blasennaht festhielt und dass die Blasenwunde, wie in zahlreichen anderen Fällen, ihrer Heilung entgegensah. Ich beabsichtige nun nicht, mich an dieser Stelle über das Wesen und die Bedeutung der Blasenverletzungen zu verbreiten, erwähne deshalb nur flüchtig, dass ich mehrere solche Fälle hatte, wo die genähte Blasenwunde selbst bei Gelegenheit von sehr grossen Defecten die glatte Heilung nicht alterirte.

Die grossen Vortheile der zweizeitigen Operation mir gut vor Augen haltend, ging ich auch in dem nachfolgenden Falle vor, mit dessen Resultat zufrieden zu sein, ich vollauf Ursache hatte.

K. G. (1892, J.-No. 573). Seit 5 Jahren Geschwulst und quälende Unterleibs- und Kreuzschmerzen. Am 21. Sept. 1892 Aufnahme auf die Klinik. Neben dem Uterus linksseitig mit demselben breit verwachsen, eine in der Tiefe des Beckens sitzende Geschwulst, über die noch entschieden werden müsste, ob sie ein dickwandiges, glanduläres Cystom, oder aber ein solider Tumor sei? Beim Bauchschnitt stossen wir auf eine solide Geschwulst, die theilweise sich subserös entwickelte, das Ligam. lat. auseinander trennte und bis an die linksseitige und rückwärtige Wand des Uterus heranrückte. Die anatomische Diagnose lautete (nach Prof. Scheuthauer): Adenofibroma lacunare et cysticum ovarii sinistri. Nach Spaltung der Kapsel geht die Ausschälung der Geschwulst nnter profuser Blutung von Statten; zahlreiche Umstechungen und Unterbindungen. Nach Beendigung der Operation nehmen wir bei regelrechter Ureteruntersuchung den unterbundenen und durchschnittenen linksseitigen Ureter in der Höhe des Beckeneinganges wahr, indess der dem Becken angehörige Theil des Ureters fehlte, und es den Anschein hatte, als ob ein Theil desselben bei Gelegenheit der Redultion der Kapsel ansgeschnitten worden wäre. Nach Vernähung der Kapsel und thunlichster Bedeckung des Uterus mit Peritoneum, ward es lslar, dass die Exstirpation der linksseitigen Niere unvermeidlich sei; um so eher, da bei der Kürze des Ureterstumpfes dessen Einnähung in die Blase selbst bei einer künstlichen Oeffnung nicht denkbar war. Die lange Dauer der Operation und der grosse Blutverlust liessen bei der auch sonst sehr schwachen Fran im Vereine mit der aus meinen Erfahrungen resultirenden Entschliessung es nicht als statthaft erscheinen, sofort die Nephrectomie vorzunehmen - und so wurde denn die Ausnähung des Ureters nothwendig. Dies jedoch war nicht so einfach; denn, wie ich bereits erwähnte, die Durchschneidung des Ureters geschah in der Höhe des Beckeneinganges, somit erschien die Einführung des Ureterstumpfes in die Bauchwunde nicht als zweckmässig, da der zur Verfügung stehende Ureterantheil viel zu kurz war. Ferner erschien es als unzweckmässig auch schon deshalb, weil, wenn wir es vorgenommen bätten, der ausgespannte cylindrische Strang von der hinteren Wand der Bauchhöhle nach vorne gezogen, eine Brücke von hinten nach vorne gebildet haben würde, auf welcher dann das ganze Convolut der Dünddärme geritten bätte. Bei solchem Vorgehen bestünde wohl die Gefahr, dass der heransgenähte Ureter aus der Bauchwunde ausreisst; oder aber, dass die reitenden Därme sich unter einander verschlingen. Um nun beide Nachtheile zu vermeiden, lüfteten wir den 
Ureter in der Lumbalgegend unter dem parietalen Peritoneum und, indem wir über der mesenterialen Wurzel der Gedärme ein Loch machten, fübrten wir den Ureter durch die untere Lamelle des Mesocolons hindurch, also auf dem kürzesten Wege, d. h. über den Dünndärmen hinweg und unter dem Quercolon vorbei ohne Spannung zur Bauchwunde heraus. Behufs Sicherung der Fixirung nähten wir das Peritoneum der Bauchwand an den Rand der Bauchwunde in der Weise heraus, dass der Ureter circulär mit Peritoneum umgeben, respective umnäht war. Zunächst stände wohl das fest, dass wir den durchschnittenen Ureter, durch eine in dor Lumbalregion gesetzte Oefinung bindurch an die Körperoberfläche zu leiten gehabt hätten, wodurch wir jeder ferneren Complication seitens der Bauchhöhle hätten vorbeugen können. -

Dass wir indess trotzdem nicht diesen Weg eingeschlagen haben, findet seine Erklärung einfach darin, dass wir die durch den grossen Eingriff erschöpfte Kranke einer neueren complicirten operativen Einwirkung nicht exponiren wollten - und deshalb Mittel and Wege suchten, um nur die Operation ehestens beendigen zu können. Die Dauer der Operation betrug 3 Stunden. Der aus dem durchschnittenen Ureter fliessende Urin wurde mittelst eines entsprechenden englischen Katheters durch den Verband hindurch in einen geeigneten Recipienten geleitet.

Der Verlauf war ein vollkommen ungestörter, die Heilıng innerhalb der Bauchhöhle ohne jede Reaction. Die Resultate der Harnuntersuchung des aus beiden Nieren stammenden Harns können wir auf Grund der sorgfältigen Aufzeichnungen des klinischen Praktikanten, Herrn Dr. Neumann, in Folgendem zusammenfassen:

In den ersten Tagen nach der Operation machten wir bezüglich der Tagesmenge des Urins die Wahrnehmung, dass der durch die Blase sich entleerende Urin (den wir der Kürze halber mit A bezeichnen wollen) bedeutend mehr war, als die Tagesmenge des durch die Fistel sich entleerenden Urins (B), (z. B. A:650 ccm B : $400 \mathrm{ccm}$ - A: $680 \mathrm{ccm}$ - B: $440 \mathrm{ccm}) ;$ trotzdem wir bei dem Auffangen des Urins die grösste Pünktlichkeit befolgten. An dem der Operation folgenden Tage enthielten beide Urinantheile eine grössere Menge Eiweiss. Bezüglich der Concentration beider Urinantheile aber machten wir die interessante Erfahrung, dass der A-Urin, trotzdem er in den ersten Tagen quantitativ bedeutend mehr, als der B-Urin war, dennoch ein grösseres, specifisches Gewicht zeigte (z. B. A : 1020, B:1016), — die Differenz indess kam binnen einigen Tagen wieder zum Ausgleich. -

Am 7. Tage nach der Operation änderte sich das Verhältniss der zweierlei Urine bezüglich ihrer Quantität in der Weise, dass nunmehr die Quantität des B-Urins die der rechten Niere übertraf; gleichzeitig wurde der B-Urin stärker alkalisch, enthielt eine mässige Menge Eiter und bildete ein sehr reiches, zumeist aus Schleimfetzen bestehendes Sediment, sein specifisches Gewicht aber sank auf 1010, enthielt ausser Eiter noch Eiweiss; unter dem Mikroskope aber konnte man etwas anderes, als eine ausserordentlich grosse Menge Eit rrzellen, nicht nachweisen. Der A-Urin war sodann während der ganzen Zeit der Beobachtung - bis zur Vornahme der Nephrectomie - durchaus normal, abgesehen von jenen in grösseren Zeiträumen aufgetretenen, durch einen mässigen Blasencatarrh verursachten Veränderungen, welche indess nach einigen Blasenwaschungen spurlos verschwanden. 
Das Verhältniss zwischen den Tagesmengen des ans den beiden Nieren stammenden Urins war auch in der Folge sebr verschieden, und zwar in dem Sinne, dass, wenn der B-Urin eine grössere Menge Eiter enthielt, auch dessen Tagesmenge zunahm; wenn es aber gelang mittelst einer physiologischen Kochsalzlösung oder durch Waschungen mit einer schwachen Borsäurelösung den Katarrh des Nierenbeckens, respective den der Ureterschleimhaut zu mässigen, so verringerte sich auch alsdann die Orinmenge, und zwar selbst unter die Menge des durch die Blase entleerten (A-) Urins.

Auch der Eiweissgehalt des B-Urins schien im Zusammenhange zu stehen mit der Trritation der Schleimhaut des Nierenbeckens und jener von hier aus auf das Gewebe der Niere selbst sich erstreckenden Irritation, - derart, dass je mehr Eiter der Urin enthielt, desto grösser auch dessen Eiweissgehalt war, so dass derselbe manchmal sogar 1.5 pM. (nach Essbach determinirt) erreichte; während ein andermal, wenn sich der Urin auch seinen physicalischen Eigenschaften nach dem normalen näherte, er kaum 0.5 pMl betrug, - wobei man Nierenformelemente ebenso wenig nachweisen konnte, wie bei einem Eiweissgehalt von $1.5 \mathrm{pM}$.

Wie gross die Menge des vom Catarrhe des Nierenbeckens respective der Schleimhaut des Ureters producirten Schleimes sein könne, davon uns zu überzeugen, hatten wir Gelegenheit, als wir einmal die Auswaschung des Ureters vornehmen wollten, und hierzu mittelst des gewohnten mässigen Druckes die ausspülende Flüssigkeit zu ivjiciren ausser Stande waren. Nach der Ursache des Hindernisses forschend, fanden wir, dass das Lumen des Ureters förmlich verstopft war mit cylindrischen, mehrere Centimeter langen, einen förmlichen Abdruck des Ureters darstellenden, wurmformigen, dem geronnenen Fibrin sehr ähnlichen, die Abträufelung des Urins behindernden Massen, welche zu entfernen uns nur durch eine in Form eines stärkeren Strables erfolgte Injection der Flüssigkeit gelang. Am folgenden Tage war der Abfluss des Urins wohl ungestört, indess enthielt derselbe noch immer eine grössere Menge geronnenen Schleimdetritus, der am Boden des Gefässes in Form von äusserst winzigen schneeflockenartigen Flocculis angesammelt war.

Am 29. Tage stand die Kranke auf und ein an den Drain der Bauchwand entsprechend befestigtes Gefäss fing von nun an das Secret der linken Niere auf.

Es tauchte in der Literatur die Frage auf, ob eine solche Niere, deren Ureter in die Bauchfistel mündet, auch gesund bleibe, oder ob nicht, früher oder später, eine Pyelonephritis die Folge der abnormen Mündung wäre? Bertini sah wohl unter solchen Umständen die Niere 16 Monate lang gesund, musste aber sodann, zufolge Nephritis, die Nephrectomie vornehmen. Le Dentu und Pozzi beobachteten auch eine unter ähnlichen Umständen längero oder kürzere Zeit gesund verbliebene Niere (ersterer durch 13 Tage, letzterer sogar durch mehrere Monate). Indess können wir von unserer Kranken auf Grund pünktlicher Beobachtung sagen, dass sich wohl bei ihr auf Schritt und Tritt eine beginnende Pyelitis 
zeigte, dass es uns jedoch jedesmal gelang, dieselbe durch Auswaschen des Nierenbeckens mit einer 0,6 proc. Kochsalzlösung zu coupiren. Dass indess diese, bislang andauernden Erkrankungen, nicht ohne Wirkung auf die Niere selbst verblieben, das hatten wir zum Theil aus dem im B-Urin, wenn auch in geringer Menge, aber immerhin ständig gefundenen Albumen, später aber, nach vollzogener Nierenexstirpation, direct auf histologischem Wege, zu constatiren Gelegenheit.

Auch eine interessante physiologische Beobachtung bot sich uns bei dieser Gelegenheit bezüglich der peristaltischen Bewegung des Ureters dar. Gewöhnlich sind wir der Ansicht, dass die engere Blasenmündung des Ureters dem Einströmen des im Ureter sich ansammelnden Harns im Wege steht, und, dass es eine rhythmische, peristaltische Zusammenziehung sei, die das Einströmen des Harns in die Blase bewirke.

In unserem Falle, wo höchstens ein etwa $10 \mathrm{~cm}$ langes Stück des Ureters erhalten und ausgenäht war, konnte man beobachten, dass die als peristaltisch erscheinende Thätigkeit wirklich vorhanden sei, indem der Harn auch hier sich rhythmisch entleerte; demnach lässt sich in einem offenen Harnleiter kaum eine solche Stauung des Harns vorstellen, der gegenüber die peristaltische Thätigkeit der Ureterenwand sich äussern könnte; woraus schliesslich gefolgert werden muss, dass die periodische Entleerung des Harns nicht in der Peristaltik des Ureters, sondern vielleicht in der zeitweiligen Zusammenziehung des Nierenbeckens, oder aber vielleicht noch in einem anderen, etwa im Mechanismus der Harnausscheidung zu suchenden Umstande, begründet sei.

Bevor wir dic dem ausgenähten Ureter entsprechende Niere exstirpirten, mussten wir den Zustand der rechten Niere einer gründlichen Untersuchung unterziehen; ob nämlich dieselbe auch gesund sei?, ob sie die schwere Arbeit der gesammten Harnausscheidung werde übernehmen können? Diese Untersuchung, die im Interesse der einschlägigen Erkenntniss der Filtrationsfähigkeit der Nieren, für jede einzelne derselben separat vorgenommen wurde, bestand darin, dass wir die Kranke in täglich aufsteigender Menge eine abgemessene Menge Flüssigkeit trinken liessen, wobei die Diurese sehr pünktlich der gesteigerten Einfuhr entsprach. Was andererseits die Ausscheidungsfähigkeit der Nieren betraf, diesbezüglich wurden Versuche mit Jodkali und Natr. salicylic. gemacht, aus denen hervorging, dass die Nieren diese Heilmittel in einer der normalen 
entsprechenden Weise ausscheiden. (Ueber diesen Gegenstand wird übrigens mein klinischer Praktikant, Herr Dr. Siegfried Neumann, der die Untersuchungen vorgenommen, in diesem Archiv demnächst ausführlich berichten.)

Es war daher unzweifelhaft, dass die Function der A-Niere vollkommen normal war.

Und somit war auch, bloss eine einfache Consequenz meines aus meinen früheren Fällen geschöpften Urtheils, mein Bestreben: die zu belassende Niere deshalb zu einer gesteigerten Thätigkeit vorzubereiten, damit derselben nach erfolgter Exstirpation die vicariirende Thätigkeit nicht auf einmal zukomme.

In dieser Absicht bestrebte ich mich zeitweilig den ausgenähten Ureter abzuschliessen; zuförderst mittelst eines verstopfenden Werkzeuges, einer aufgeblähten Fischblase, eines Gummiballons, sodann durch Unterbindung des Ureters selbst. Einen Erfolg jedoch konnte ich jedesmal nur für einige Stunden erzielen, weil in dem Ureter nur zubald eine solche Spannung entstand, dass sie den Ballon hinausschleuderte, ja, dass selbst die Wand des Ureters in dem Kanal des unterbundenen Fadens einriss und der Urin sich einen Weg bahnte. Die peritoneale Höhle aber zu eröffnen, und den Ureterstumpf behufs einer tieferen Unterbindung herauszupräpariren, schien ein solch gewagtes Unternehmen, dass ich es für unzulässig erachtete.

Allenfalls bleibt jedoch die Beobachtung interessant, dass die Ausdehnung des Ureters, bez. des Nierenbeckens in Folge der Unterbindung bis zu dem Grade, dass die Wandung des Ureters in dem Kanale der Ligatur einriss, bei der Kranken gar keinen Schmerz, sondern höchstens das Gefühl einer stärkeren Spannung hervorrief.

Hierdurch wird erklärlich, warum wir wiederholt in Begleitung anderer Leiden genug hochgradigen Nierenbecken- und Uretererweiterungen begegnen, ohne dass dieselben im Leben irgend eine Erscheinung hervorgerufen hätten. Während unserer Beobachtung orkrankte Patientin an Polyarthr. rheum., die Monate hindurch von dem einen Gelenke zum anderen wanderte, und für einige Zeit die Ausführung der Operation unmöglich machte!

In unserem Operationsplane mussten wir auch dem ausgenähten Ureterstumpfe Rechnung tragen. Zweierlei Möglichkeiten standen diesfalls vor uns: entweder den die Bauchhöhle durch- 
ziehenden Ureter auf dem Wege der Laparotomie herauszupräpariren, oder aber die Niere mittelst Lumbalschnittes herauszunehmen und den Ureter drin zu lassen. Es mussten jedoch die wichtigen Vor- und Nachtheile beiderlei Vorgänge erwogen werden. Und zwar: sollte auf dem Wege der Laparotomie, d. h. auf transperitoneale Weise die Exstirpation der Niere und des Ureters erfolgen, so würden wir in diesem Falle nicht nur den gewöhnlichen Schwierigkeiten begegnen, da bekanntlich eine schwere Laparotomie und die Exstirpation einer grossen extraperitonealen Geschwulst bereits vorausgegangen war, und es Erfahrungssache ist, dass nach einer solchen Operation sich unberechenbare Adhäsionen bilden, wie wir deren bei einer jeden secundären Laparotomie zu finden gewohnt sind. Im gegenwärtigen Falle wird die Complication dieser Adhäsion noch durch den von rückwärts nach vorne ziehenden Ureter gesteigert. Der Darmkanal aber ist ein solcher, wie er eben bei solchen Adhäsionen noch durchgängig sein kann. Vorausgesetzt nun den günstigsten Fall, nämlich jenen, dass wir den Ureter mittelst Laparotomie von den adhärenten Därmen herauspräpariren und es uns glücklicher Weise gelingt, auch zur Niere gut vorzudringen und diese za entfernen - so bleibt noch die grosse Frage offen, auf welche Weise nun die Canalisation der unter einander in Fixation sich befindlichen Gedärme inmitten dieser neuen Gruppirung und der zu erwartenden neueren Adhäsionen erfolgen kann? - ob nicht etwa eine Drehung, eine winkelige Knickung, eine Narbenschrumpfung, oder schliesslich eine neuere Adhäsion die Impermeabilität des Darmes verursachen werde? Die vielfachen Zufälle dieser hochwichtigen Operation demnach würden auf diese Weise, nämlich bei der transperitonealen Operation, noch um eine Complication vermehrt werden, daher wir von derselben gänzlich absehen mussten.

Der zweite Vorgang: die Nephrectomie mittelst Lumbalschnittes, bietet nicht mehr Schwierigkeiten dar, als jede andere Nierenexstirpation; höchstens erscheint das Herausheben der Niere vor die Wundöffunng, dadurch, dass sie durch den kurzen Ureter fixirt ist, einigermaassen erschwert zu sein. Wir mussten es jedoch als einen grossen Nachtheil betrachten, dass der Ureter bei dieser Procedur dringelassen wird, und dass dieses Drinbelassen nicht gleichwerthig damit sei, woran wir unter anderen Umständen gewöhnt sind, nämlich, dass der unterbundene Ureter, als ein von seiner physiologischen Function ausgeschlossenes, unschädliches 
Organ, schrumpfe und für den Organismus irrelevant werde, da hier der Ureter ein offener Kanal ist, der seit jeher mit der Aussenwelt communicirt und keineswegs steril ist, demnach auch organische Stoffe zweifelhafter, eventuell gefährlicher Art in das Terrain des Stumpfes hineindrainiren könne.

Diese Schwierigkeiten glaubten wir in der Weise besiegen zu können, dass wir die Isolirung des Ureters von den Nierengefässen, die Bloslegung seines Lumens, sodann die Einwärtsstülpung seiner Schleimhautränder und schliesslich die Einnähung der Ureterenmündung in Aussicht nahmen. Sóllte dies gelingen, so würde dann der Ureter für das Terrain des Stumpfes irrelevant bleiben und die Tragweite der ganzen Operation zur Bedeutung einer einfachen Nierenexstirpation herabsinken.

Auf Grund dieses Gedankenganges schritten wir am 9. März $1893 \mathrm{zu}$ folgender Operation.

Typische Nierenexstirpation mittelst Czerny'schen Lumbalschnittes. Wie im Vorhinein ersichtlich war, ging die Heranshebung der Niere mit Schwierigkeiten einher. Der Ureter zog in der Gegend der fixirten Bauchwandöffnung die vordere Bauchwand trichterförmig nach sich hinauf, verursachte jedoch sonst kein ernstes Hinderniss. Nach Loslösung des Ureters gelang die beabsichtigte Einnähung des Lumens desselben gut. Nachdem wir auch die Nierengefässe entsprechend isolirten und die Ligatur mit Seidenfäden bewerkstelligten, gewannen wir einen kleinen Stumpf. Die Stumpfverbältnisse waren dermassen günstige, dass wir die Wundhöhle ohne Drainage schliessen zu können glaubten. Die Maskelschichten versorgten wir mit einer besonderen Catgutnaht, die Hautwunde aber mit einer fortlaufenden Seidennaht.

Die Heilung ging nicht glatt von Statten, denn am 8. Tage stieg die Abendtemperatur anf $38,3^{\circ}$ und in der Gegend der bereits verheilten Lumbalwunde zeigte sich in der Tiefe Empfindiichkeit, an der Oberfläche Röthe. Gleichzeitig kam durch die Bauchwandöffnung des Ureters ein Tropfen übelriechenden Eiters zum Vorschein. Indem wir die Bedeutung des vernähten Ureters in der Wundhöhle nicht a.usser Acht liessen, eröffneten wir bereits am folgenden Tage, obschon die Temperatur nicht über $38,0^{\circ}$ war, die frische Narbe und den in der Tiefe verborgenen Abscess (der in dem lockeren bindegewebigen Raume zur raschen Ausbreitung eventuell auch zur Senkung führen konnte) und indem wir denselben mit einer breiten Oeffnung vernähten, drainirten wir ihn gleichzeitig gründlich. Diese Eröffnung verlängerte einigermassen die Heilungsdauer, obschon die Kranke von diesem Tage an wieder andauernd fieberfrei blieb.

Auch von Seite der Niere ging der Verlauf nicht ganz glatt vor sich, obschon die zurückgebliebene rechte Niere vom ersten Augenblicke an die ganze Arbeit der Urinentleerung besorgte.

Die Menge des während 6 Stunden nach der Operation mittelst Catheters gewonnenen Urins betrug 320 Gubikcentimeter, dessen specifisches Gewicht 1016, die Reaction normal sauer. Eiweiss war in dem- 
selben nur in sebr geringen Spuren nachweisbar, unter dem Mikroskop wenige hyaline Cylinder. In dem von Nachmittags 5 Uhr desselben Tages bis um $8 \mathrm{Uhr}$ früh des nächsten genommenen Urin waren diese Cylinder nicht mehr auffindbar, obschon der Harn noch immer minimale Mengen von Eiweiss enthielt. Wäbrend der folgenden 5 Tage war der Urin bezüglich seiner physikalischen Eigenschaften vollkommen normal, sein spec. Gewicht 1017-1023, die Tagesmenge entsprach der aufgenommenen - und pünktlich abgemessenen - Flüssigkeitsmenge, Eiweiss blos in kaum nachweisbaren Spuren. Indess an dem der Operation folgenden 6. Tage erweckte schon die Farbe des Urins den Verdacht, dass er etwas Blut entbalte - und thatsächlich waren wir im Stande, sowohl chemisch als mikroskopisch in demselben Blut nachzuweisen. Am selben Tage stieg auch der Eiweissgehalt um etwas, am nächstfolgenden 7 . Tage vermehrte sich wesentlich sowohl der Blutals der Eiweissgehalt, ja unter dem Mikroskope zeigten sich sogar einige hyaline und sehr wenige feinkörnige Cylinder. Trotz dieser wesentlichen Veränderungen tauchten in dem Allgemeinbefinden oder in der Temperaturbewegung der Patientin keine krankhaften Erscheinungen auf, und diese periodische Veränderung in der Niere gelangte überhaupt nur durch die überaus pünktliche Beobachtung zu unserer Kenntniss. Am 8. Tage verschwanden die Cylinder aus dem Harn, der Blut- und Eiweissgehalt verminderte sich ebenfalls und war von nun an tag-täglich weniger nachzuweisen - so dass am 12. Tage das Blut vollkommen verschwand, der Eiweissgehalt aber blos in verschwindenden Spuren nachweisbar war. Das specifische Gewicht des Urins sank allmählich von 1023, dem Stande am Tage der Operation bis auf 1016 -1017, anf welchem es auch fernerhin verblieb.

Vom 12. Tage an waren seitens der Niere keinerlei Symptome mehr zu beobachten.

\section{Nierengeschwülste.}

\section{A. Hydronephrosis und Pyonephrosis.}

Die Diagnostik der Nierengeschwülste giebt auch bei unseren heutigen Kenntnissen noch immer zu vielen Irrthümern Anlass; namentlich ist es die Hydronephrosis, bei welcher gegenüber von Ovariencysten eine Differentialdiagnose oftmals fast unmöglich wird. Le Joung erwähnt in seiner aus der Klinik Czerny's erschienenen Dissertation, dass von den bekannten Hydronephroseoperationen etwa 40-50pCt. auf Grund eines diagnostischen Irrthums zur Operation gelangten. Unangenehm, ja selbst verhängnissvoll kann ein solcher Irrthum werden, wenn der Operateur, da er seinen Irrthum wahrgenommen, bereits in der Operation weiter vorgeschritten ist, als dass er von deren Fortsetzung abstehen oder seinen Operationsplan ändern könnte, um einen auderen Weg und Modus zu finden, an dem Zustande der Kranken zu helfen. Nach meiner Ansicht dürfte die Gefahr nicht in jenen Fällen sein, wo 
es nicht gelungen ist, die Differentialdiagnose in irgend einer Richtung entschieden zu haben, da wir in diesen Fällen auf der Hut sein werden, als vielmehr dort, wo der Gedanke an eine Nierengeschwulst nicht einmal aufgetaucht war - und wo es zu Beginne der Operation unmöglich war, auf Grund der obschwebenden Verhältnisse die Lage in ihrer Wirklichkeit zu erkennen.

Unter unseren Fällen waren es zwei, in welchen die Differentialdiagnose zufolge ganz verschiedener Ursachen in der Schwebe blieb. Von beiden können wir jedoch gewisse allgemeine Lehren ableiten - weshalb wir auch dieselben hier mittheilen wollen.

T. B. (1886/87, J.-No. 17), 39 J. alt, ledig, 0-P. Ihr Leiden acquirirte sie im Kindesalter, als sie im Alter von 7 Jabren von einer Kiste herab auf den Bauch fiel. Im Alter von 12 Jahren - eine Bauchgeschwulst, derenthalben eine Punction vorgenommen wurde, die in den folgenden 12 Jahren 6 mal wiederholt werden musste, darunter im Alter von 23 Jahren auf einer chirurgischen Klinik. Nach dieser Punction hatte Pat. 6 Jahre lang Rube. Vom 29. Jahre an wurden die Punctionen immer öfter nöthig, bis sie einmal nach einer solchen eine Bauchfellentzündung bekam, mit der sie lange Zeit hindurch darniederlag. Wegen einer Bauchgeschwulst und starker Schmerzen sucht sie im October 1886 unsere Klinik anf. Die Bauchhöhle wird durch eine mannskopfgrosse Geschwulst nicht ganz ausgefüllt, es 'scheint, dass früher die Bauchwände unter grösserer Spannung standen und demgemäss permanent erschlafften. Die Banchwände sind schlaff, dünn, an zwei Seiten in der Gegend der Hüftbeinkämme liegen dieselben abgeflacht da. Die Grenze der Geschwulst bezeichnet eine an zwei Seiten auch mit freiem Auge wahrnehmbare Furche, über welcher die Bauchwände an die Geschwulst stark anhaften, nicht in Falten gelegt und ebenso wenig verschoben werden können. Die Geschwulst ist nicht beweglich, nach oben reicht sie bis unter die Leber hinein, nach unten erstreckt sie sich bis zum Beckeneingang, mit ihrer Hauptmasse aber sitzt sie ein wenig in der rechtsseitigen Hälfte der Bauchböhle. An ihrer Oberfäche ist wegen starker Spannung keine Fluctuation constatirbar.

Der Percussionsschall ist über der Geschwulst überall leer, nach links ausser dem Geschwulstrande hell-tympanitisch; an der rechten Seite ist ein handbreiter, einen tympanitischen Schall gebender Raum zu constatiren; die Lumbalgegend giebt auf dieser Seite einen leeren Schall. Die Leberdämpfung ist nicht zu begrenzen, zwischen ihr nnd der Geschwulst ist keine tympanitische Zone auffindbar. Inspirationsbewegungen haben auf die Geschwulst keinen Einfluss. Die in der Narcose vorgenommene vaginale und rectale Untersuchung ergab, dass der Uterus in Retroposition und Retroversion sich befindet und gut umgreifbar ist; die Geschwulst ist in ihrer, in der Höhe des Beckeneinganges liegenden unteren Peripherie verschiebbar. Linkes Ovarium vorhanden, rechtes nicht auffindbar. Auf der rechten Seite zieht sich vom rechten Uteruspol bis zur Beckenwand ein breiter, flacher Strang hin und windet sich nach aufwärts zur Geschwulst, an weleher ein fingerdicker cylindrischer Strang zu erkennen ist.

Der aufgetauchte Zweifel, ob wir es mit einem aus der Leber her- 
vorgegangenen Echinococcus oder aber etwa mit einer renalen Geschwulst zu thun haben, schien auf Grund dieses Beckenbefundes zerstreut zu sein und glaubten wir nach Allem eine von der rechten Seite ausgehende ovariale Geschwulst constatiren zu können - um so eher, da die Harnuntersuchung gar keine auffällige Veränderung aufwies.

Operation am 11. October 1886. Beim Bauchschnitt fanden wir eine zweimannskopfgrosse, extraperitoneale Geschwulst, die ihrem ganzen Umfange nach mit der Bauchwand verwachsen war; ähnliche Verklebungen fixirten auch die einzelnen Gedärme unter einander und mit der Geschwulst. Wir konnten uns nur schwer orientiren und nur aus dem zufällig vor unsere Augen gerathenen Proc. vermiformis constatiren, dass das aufsteigende Colon aufgehoben auf der inneren und seitlichen Oberfläche der Geschwulst reitet und dass dessen ausgespanntes Mesocolon die extraperitoneal gelagerte Geschwulst bekleidet. Es wurde nun klar, dass wir eine Hydronephrose vor uns haben. Um Raum zu gewinnen, entleeren wir mittelst Troicarts 10 Liter einer strohgelben Flüssigkeit aus der Cyste. Nachdem wir die peritoneale Kapsel nach aussen vom Colon ascendens der Länge nach spalteten, gelang die schichtenweise Auslösung derselben hinreichend gut und stiessen wir auf ein grösseres Hinderniss blos an der hinteren Oberfläche der Geschwulst, wo zufolge der entwickelten Gewalt eine starke Arterie, nämlich die Art. renalis entzweiriss. In diesem Momente schwebte die Kranke in der grössten Gefahr, da inmitten der das Terrain überschwemmenden Blutung es nicht leicht gelang, die spritzende Arterie zu fassen. Die weitere Entwickelung konnte ohne jegliche Schwierigkeit geschehen. Der Ureter nahm an der Bildung des Sackes Theil und wurde mit diesem zusammen derart ausgelöst, dass seine Unterbindung in der Höhe des Beckeneinganges erfolgen und der zurückgebliebene Antheil desselben nur der untere sein konnte. Da die Nierengefässe mittelst Seide unterbunden wurden, konnte ein ganz günstiger Stumpf gebildet werden. Die extraperitoneale, stark gequetschte und gerissene Wundhöhle waren wir bestrebt durch fortlaufende Naht der peritonealen Wundränder von der Bauchhöhle auszuschliessen; wir versahen sie überdies aus Vorsicht noch mit einer Drainage, indem wir dem Drain durch die Lumbalregion hindurch einen Weg bildeten.

Der Verlauf war folgender: vom 4. bis zum 8. Tage war die Temperatur einigemal subfebril, am höchsten $38,4^{\circ}$, welcher Zustand mit dem Chloroformgastricismus schwand. Die Drainröhren mit Ausnahme eines kleinen Antheils wurden am 8., letzterer aber am 12. Tage definitiv weggelassen. Der Urin war bereits in den zweiten 24 Stunden 800 Cubikcentimeter mit einem spec. Gewicht von 1018 - und wurde von da ab, wie dies voraussichtlich war, in normaler Quantität und Qualität ausgeschieden. Die Kranke verliess am 23. Tage nach der Operation das Bett.

Wenn wir auf diesen Fall näher eingehen, fallen uns mehrere interessante Momente auf:

1. Die Hydronephrose war chronisch, aus unbekannter Ursache sistirte sie zeitweilig und der Ureter blieb dann so lange impermeabel, bis die grosse Spannung mittelst Punction behoben wurde. Nach einer solchen Punction konnte bisweilen der Ureter jahre- 
lang permeabel bleiben. Demnach scheint es, dass bei Hydronephrose mit hoher Spannung mittelst Punction eine zeitweilige Erleichterung ohne Gefahr bewerkstelligt werden kann.

2. Trotz öfterer Wiederbolung der Punction blieb der hydronephrotische Sack normalen Inhaltes und erhielten wir bei der Operation eine lichte, strohgelbe Flüssigkeit; offenbar wurde die Punction stets zweckentsprechend und mit aseptischen Instrumenten vollzogen.

3. Gelegentlich einer Punction gelangte auch Cysteninhalt in die Bauchhöhle und verursachte eine heftige Peritonitis, die in der (obigen) Anamnese erwähnt wurde und deren unzweifelhafte Beweise wir gelegentlich der Operation in den Verwachsungen fanden.

4. Die nach überstandener Peritonitis aufgetretenen Verwachsungen zwischen den Gedärmen und zwischen den Beckenorganen machten die Differentialdiagnose zwischen Ovarialgeschwulst und Hydronephrose unmöglich, indem das für einen Stiel gehalten wurde, was blos eine breite Massenverwachsung gewesen war.

5. Trotz einer älteren abgelaufenen heftigen Peritonitis war der hydronephrotische Sack aus seiner bindegewebigen Kapsel aussohälbar, obschon, wie wir später sehen werden, die abgelaufene Entzündung anter anderen Umständer die Auslösbarkeit der Geschwulst nahezu unmöglich machte. Der Unterschied besteht darin, dass in der einen Gruppe die Geschwulst selbst und deren bindegewebige Kapsel, während in der anderen nur die Peritonealhöhle Sitz der EEntzündung war. Im ersteren Falle ist die Verwachsung zäh, kaum oder garnicht zu bewältigen, und gestattet keine schichtenweise Auslösung, während im letzteren Falle umgekehrt die peritoneale Verklebung unbesiegbar, indess die Qualität des subperitonealen Gewebes unverändert ist.

Es ist demnach von grösster Wichtigkeit, dass wir den Sitz des auftretenden Entzündungsprocesses richtig diagnosticiren und genau unterscheiden sollen, ob wir es blos mit einer abgelaufenen Peritonitis zu thun haben, oder aber ob in der Geschwulst selbst and in ihrer bindegewebigen Kapsel die accidentelle entzündliche Erkrankung ihren Sitz hatte.

6. Die gesunde Niere, die sich bereits früher allmälig an die compensatorische Thätigkeit gewöhnt hat, hat auf prompte Weise, ohne jede Schwierigkeit des Uebergangs, ihrem Berufe entsprochen, wie wir dies unter solchen Umständen bereits im Obigen betont hatten. 
Die besprochene Kranke präsentirte sich uns nach 2 Jahren im Monate April 1888 mit Herzklopfen und anderen nerpösen Erscheinungen. Herr Prof. von Korányi war so gütig, sie behufs Beobachtung auf seine Klinik aufzunehmen, woher die an uns am 30. April über sie gelangte Nachricht folgendermaassen lautete: „Vollkommen compensirte Insufficienz der Bicuspidalis geringen Grades. Die vorhandene linke Niere hat die Aufgabe der exstirpirten anderen durchaus übernommen, ja selbst bei gesteigerter Einfuhr tritt keine Incompensation auf".

Der zweite zu dieser Gruppe gehörende Fall ist der Folgende:

M. W. (1892. Journal-No. 9), Op., 35 Jahre alt, hat seit 7 Jahren eine Geschwulst; vor 4 Wochen fing sie unter grossen Schmerzen zu fiebern an. Ihre Geschwulst wächst stürmisch. Am 20. Januar 1892 nehmen wir sie mit einer in der Bauchhöhle asymmetrisch gelagerten, aus dem Becken sich erbebenden 2 kopfgrossen, fluctuirenden, entzündlichen, sehr schmerzhaften Geschwulst auf, welche rechterseits tief in die Lumbalregion hineingreift und nicht beweglich ist. Bei der genitalen Untersuchung ist ein retroflectirter Uterus wahrnehmbar, der beweglich ist und vor demselben ist ein Segment der obigen Geschwulst zu tasten. Ein Zusammenhang zwischen der Geschwulst und den Genitalien ist mit Bestimmtheit nicht zu constatiren; aber auch nicht auszuschliessen, denn wegen des hohen Fiebers und der hochgradigen Sensibilität der Geschwulst, so auch der Entzündung des Peritoneums halber war eine eindringliche Untersuchung unstatthaft. Während unserer 12 tägigen Beobachtung wird die auch sonst sehr schwache Frau bei völliger Appetitlosigkeit und unter der Wirkung von 39,5 $5^{\circ}$ Abendtemperaturen zusehends schwächer - und können ihre Schmerzen selbst mit Narcoticis nicht gestillt werden. Der Urin war, mehrmals untersucht, jedesmal normal. Da wir keine andere Ursache im Organismus auffinden konnten, mussten wir die Ursache des intermittirenden Fiebers der eitrigen Beschaffenheit der Geschwulst zuschreiben und die Operation als eine vitale Indication betrachten, vor der Hand unentschieden lassend, ob die Geschwulst ovarialen oder aber renalen Ursprungs sei?

Am 2. Februar 1892 vollzogen wir die Laparotomie. Die Geschwulst ist durchaus subperitoneal. An ihrer inneren Oberfiäche, in der Nähe der Mittellinie, verläuft das aufsteigende Colon. Die untere, gegen das Becken hin blickende Fläche der Geschwulst ist gut zu umgehen und auch von den Beckenorganen zu isoliren. Nach hinten und rechts sitzt sie auf breiter Basis auf. Danach ist es somit unzweifelhaft, dass wir es mit einem Nierensack zu thun haben. Um einen Einriss zu vermeiden, nehmen wir mit grosser Vorsicht eine Troicartpunction vor, und nachdem wir 6-7 Liter eines flüssigeitrigen Inhaltes entleerten, wuschen wir die Höhle aus. Es war nunmehr die Frage zu entscheiden, ob wir die Geschwulst vollständig entfernen oder den Sack herausnähen und drainiren sollten, indem wir eventuell durch die Lumbalgegend hindurch eine Gegenöffnung machten? Wir hatten nämlich von früher her ungünstige Erfahrungen darüber, dass in jenen Fällen, in welchen in der Geschwulst und in dem umgebenden Binde- 
gewebe eine Entzündung abgelaufen war, die Narben und Verwachsungen sehr zäh zu sein pflegten - und dass überdies die Auslösung der Geschwulst zumal der Blutung halber mit solchen Schwierigkeiten einhergehe, die für die Kranken, zumal bei geschwächtem Organismus, leicht verhängnissvoll sein können. Andererseits aber wissen wir auch noch, dass die dem Ausnähen folgende Procedar des Auseiterns Monate andauert, und bei schwacher Constitution mit vielen Gefahren verbunden ist.

Für unser dermaliges Vorgehen war die Thatsache entscheidend, dass die Kranke schon gelegentlich des ersten entzündlichen Anfalles zur Operation gelangte und dass in der Peritonealhöhle keine Verwachsungen vorauszusetzen waren, sowie dass die Entzündung in der Umgebung der Geschwulst sich nicht auf das Bindegewebe zu erstrecken schien. Bereits oben hatten wir erwähnt, dass unter solchen Umständen der hydronephrotische Sack sich relativ leicht aus dem losen peritonealen Gewebe auslösen lässt. Gelingt nun dies, so wären bezüglich des geschwächten Organismus die möglichst vortheilhaftesten Verbältnisse gewonnen, während die nach dem Ausnähen zu erwartende Auseiterung dieser verkümmerte Organismus kaum überstehen könnte. Wir entschlossen uns demnach für die vollkommene Exstirpation, und siebe da! die Auslösung der Geschwulst aus ihrer Kapsel gelang staunend leicht - und indem wir den Ureter separat unterbanden, konnten wir mit Leichtigkeit den ganzen Sack entfernen. Die Verkleinerung der riesigen, extraperitonealen Höhle, sowie den Abschluss derselben gegen die Peritonealhöhle zu nahmen wir derart vor, dass wir das Peritoneum in der ganzen Länge der Spaltung mit fortlaufender Catgutnaht zusammenzogen. Betrachteten wir nach der Zusammennähung die Bauchhöhle, so konnten wir dort sozusagen keine Spur des Vorausgegangenen entdecken.

Decursus. Die Kranke war am Abend des Operationstages zum ersten Male fieberfrei - und ibre Temperatur hob sich von nun an Jkein einziges Mal über $37,5^{\circ}$ ! Die Heilung verlief ungestört. Die Kranke isst einige Tage nach der Operation mit ausgezeichnetem Appetit und steht am 20. Tage auf. Der Harn war am 1. Tage 550 ccm und stufenweise vorschreitend erreichte er am 6. Tage bereits 1300 ccm. Die linksseitige gesunde Niere, nachdem sie eine geraume Zeit hindurch die gesammte Aufgabe der Urinausscheidung leistete, zeigte keinerlei Spur der plötzlichen Belastung. Der Urin war demmach stets von normaler Beschaffenheit. Die exstirpirte Geschwulst war eine Hydronephrose, zu welcher sich aus unbekannter Ursache Eiterung gesellte. Einen grossen Theil der Geschwulst bildet das riesenhaft erweiterte Niereńbecken, und die einzelnen Kelche vergrössern mit f:ustgrossen Erweiterungen den Raum; das Nierengewebe findet sich in $3-5 \mathrm{~mm}$ dicken Schichten circulär in der Wandung des grossen Sackes vor.

Wie in der ganzen Anlage meines Vortrages, so suche ich auch hier dasjenige, was, von diesem Falle ausgehend, von allgemeiner Bedeutung wäre. Und so drängt sich denn mir vor Allem die Frage auf, aus welcher Ursache die früher bestehende Hydronephrose in einem solchen Falle zur eitrigen werde? Meiner 
Ansicht nach könnte dies am besten durch die aus der Harnblase ascendirende Infection erklärt werden. Aus irgend einer äusseren Ursache tritt Katarrh in der Harnblase auf und die Infection schreitet a uf dem Wege des Ureters in die Höhe. Inzwischen heilt der Blasenkatarrh, während die offene Hydronephrose sich zu einer geschlossenen umgestaltet - u. z. in Folge der katarrhalischen Schwellung des Ureters einerseits, ferner wegen des Druckes des sich spannenden Sackes andererseits. Solch zeitweiliger Verschluss hydronephrotischer Säcke gehört nicht zu den Seltenheiten. Sahen wir doch auch in unserem vorherigen Falle, dass Jahre hindurch der geschlossene und offene Zustand mit einander abwechselten, wobei eine hier und da vorgenommene Punction respective der verminderte Druck auf Monate, ja selbst auf Jahre hinaus die Permeabilität des Ureters bewirkte.

Bemerkenswerth und rom Gesiehtspunkte der Prognose zugleich wichtig ist, dass ein einfacher hydronephrotischer Sack, bei Mangel einer entzündlichen Complication in der Umgebung, auf dem Wegeder transperitonealen Operation mit überraschender Leichtigkeit aus seiner Kapsel ausgelöst - und dass nach geschehener Ausschälung die Bauchhöhle von dem Operationsterrain vollständig abgeschlossen werden kann. Eine weitere bemerkenswerthe Erscheinung ist auch, dass trotz der Anwesenheit einer 2 mannskopfgrossen Geschwulst das Nierengewebe noch in einer $1 / 2-1 \mathrm{~cm}$ dicken, functionsfähigen Schicht vorhanden ist, welches Nierengewebe, wenn es ohne Exstirpation der Niere gelingt, z. B. mittelst Nephrotomie den Organismus von einer indirecten imminenten Gefabr zu befreien, noch berufen und auch befähigt ist, einen sehr nützlichen und wichtigen Dienst zu leisten.

Es ist natürlich, dass ein solcher Vorgang, nämlich die Heilung mittelst Nephrotomie und nicht Nephrectomie auch eine sichere Diagnose bezüglich dessen voraussetzt, ob die vorliegende Geschwulst mit eitrigem Inhalt zweifellos anch Pyonephrosis und nicht etwas Anderes sei?

Leider ist eine sichere Diagnose bei einer unter ähnlichen Verhältnissen sich befindlichen Kranken, wie es der mitgetheilte Fall war, oftmals vollkommen unmöglich. Es kann mithin nothwendig werden, sieh mittelst explorativer Laparotomie vom Sachverhalte $\mathrm{zu}$ überzeugen. 
Die explorative Laparotomie erfolgt in solchen Fällen nicht nur zu diagnostischen Zwecken, wie es der Bezeichnung nach den Anschein hat, sondern sie dient auch dazu, dass wir nach unmittelbarer Erkenntniss der Verhältnisse auch erwägen können, welcher Vorgang, nämlich der transperitoneale oder aber der Lumbalschnitt, als Operations-Modus mehr am Platze sei?

Jedermann weiss es, dass die mit einem ganz fehlerlosen aseptischen Apparate vollzogene Eröffnung der Bauchhöhle in einem solchen Falle keine grössere Gefahr bedingt. Denn die Gefahr.ist in der Qualität des zu exstirpirenden Gebildes und in der Communication der retroperitonealen Wundhöhle mit der Peritonealhöhle begründet. Dies ist es, was die transperitoneale $\mathrm{Me}$ thode zufällig gefahrvoller, als die lumbale Operationsweise gestalten kann - und nicht die einfache Eröffnung der Bauchböhle! Wean wir daher in einem zweifelhaften Falle die Laparotomio vornehmen, so hat dies noch keineswegs das zu bedeuten, dass wir eo ipso auf diesem Wege die Operation vornehmen müssen. Im Gegentheile! sie erst führt uns auf den rechten Weg, auf welchem wir alsdann auch von der Bauchhöhle aus indirect das Operationsterrain kennen lernen und unvergleichbar pünktlicher und sicherer unsere Sache vollenden können. Zu solchen Erkenntnissen können wir bloss auf dem Wege der eigenen Erfahrung gelangen; zu bedauern ist nur, dass es manchmal zu spät ist.

Ein zu dieser Gruppe gehörender, in vieler Beziehung interessanter Fall hat uns auch beschäftigt; an unserem diesbezüglichen Interesse nahm auch Herr Prof. Stiller Theil; weshalb wir diesen Fall etwas eingehender mitzutheilen wünschen.

M. Oe. (1885/6. Journal-No. 126), 34 Jahr alt, Ip., bemerkt seit 3 Jahren eine Geschwulst; besonders. in den letzten 3 Monaten Schmerzen in der Geschwulst, die von dieser Zeit an rasch wächst. Quälender Harndrang und - seit 6 Wochen - täglich Fieber.

Am 15. April 1886 wurde Patientin in die Klinik aufgenommen. An der rechten Seite unter der Leber eine $\mathrm{kanm}$ bewegbare, mannskopfgrosse Geschwulst, von welcher sich gegen die Wirbelsäule hin ein auffallend resistenter Antheil zieht. Gelegentlich der in der Narcose vorgenommenen Untersuchung constatiren wir, dass mit den Genitalien kein Zusammenhang besteht. Die Geschwulst folgt den Respirationsbewegungen nicht und ist von der Leber isolirbar. Während unserer Beobachtung intermittirendes, Abends auf $39,5^{\circ}$ steigendes Fieber. Diagnose: Cystische Geschwulst der Niere mit eitrigem Inbalte.

Bauchschnitt in der Linea alba. Die Geschwulst ist extraperitoneal. 
Das nach vorne und gegen die Mittellinie geschobene Colon ascendens, sowie die Dünndärme sind zusammengewachsen. Wir versuchen durch das rechts vom Colon eröffnete Peritoneum hindurch die Ausiösung. Inzwischen riss das Peritoneum aus, ja während der Auslösungsversuche wurde auch das Colon verletzt. Nachdem nun diese Oeffnnng provisorisch vernäht wurde, punctiren wir mit Rücksicht auf die Schwierigkeiten der Auslösung die Geschwulst und lassen aus derselben stinkenden Eiter heraus. Nach Erweiterung dieser Oeflnung stellt es sich heraus, dass die Geschwulst aus zahlreichen, ron einander gänzlich getrennten, selbständigen, verschieden consistenten, Eiter enthaltenden Höhlen zusammengesetzt ist. Ferner erhellte auch, dass die ganze Geschwulst in einer zweiten Kapsel sitze, aus welcher die ganze Geschwulst wohl mit grosser Schwierigkeit, aber immerhin auslösbar war. Der Ureter und die Nierengefässe wurden isolirt, mit Seidenfäden unterbunden.

Die bedeutende Blutung bemühen wir uns mit zahlreichen Umschlingungen und mittelst Druck zu stillen. Die Auslösung der Nierengeschwulst gelang trotz der schwierigen Verbältnisse zur Genüge. Darnach stellte sich heraus, dass noch eine zweite vorhanden ist, welche im Verlaufe der Wirbelsäulemit breiter Basis nach aufwärts sich verbreitet und keine selbstständige Wandung besass, sondern durch Schwielen eingeschlossen ist. An die vollkommene Exstirpirung dieser Geschwulst konnte nicht gedacht werden, da es offenbar war, dass wir es mit einem grossen retroperitonealen Senkungsabscess zu thun hatten. Wir nahmen uns daher vor, diese Abscesshöhle von der Lumbalregion her zu drainiren und womöglich ausserhalb der Peritonealhöhle zu bleiben. Mittelst Lumbalschnittes gelang es, sehr viel, überaus stinkenden Eiter zu entleeren. - Indess brach während der Manipulation die Scheidewand gegen die Kapselhöhle der Geschwulst hin durch und unser Bestreben, die extraperitoneale Behandlung einzuleiten, misslang. Es gab daher keine andere Lösung, als die Kapsel der exstirpirten Geschwulst auszunähen, und die Höhle durch die Bauchwunde und die lumbale Oeffnung hindurch zu drainiren. Die Darmverletzung wurde auf bekannte Weise mit Darmnähten exact versorgt.

Die zufolge der langen Operation, der Narcose und des Blutverlustes sehr geschwächte Kranke gelangte ohne Puls ins Bett und trotz der versuchten Transfusion und anderer Belebungsversuche war der Collaps nicht zu bekämpfen und die Kranke verschied bald.

In diesem Falle war die Diagnose: eine polycystische Geschwulst eitrigen Inhalts; aber wir erkannten den gleichzeitig bestehenden retrorenalen Abscess nicht! Wenn wir die Complication früher erkannt und den Fall mittelst Lumbalschnittes behandelt hätten, so zweifle ich nicht daran, dass derselbe mit einer Heilung geendet hätte.

Indem wir die Erscheinungen genau untersuchen, können wir auch nachträglich nur behaupten, dass in einem analogen Falle die Erkennungszeichen eines retrorenalen Abscesses überaus zweifelhaft sind. Ein Oedem der umgebenden Weichtheile wurde nicht gefunden, die Grenzen der Geschwulst waren gut austastbar, die 
Geschwulst deckte das Gebiet des retroperitonealen Abscesses, das intermittirende Fieber fand in der Nierengeschwulst eitrigen Inhalts seine Erklärung und so hatte die retrorenale Eiteransammlung überhaupt keine selbstständigen Zeichen. Absichtlich sage ich: ein retrorenaler Abscess! Denn die Geschwulst selbst war aus ibrer peritonealen und sogar aus ihrer eigenen fibrösen Kapsel, wenn auch schwer, aber vollkommen ausgelöst und ihr Stumpf unterbunden, als hinter ihr der noch geschlossene retrorenale Abscess erkannt und behufs Entleerung desselben das weitere Verfahren eingeleitet wurde.

$\mathrm{Zu}$ bedauern ist, dass die Obduction nicht gestattet wurde. Es blieb somit ein Zweifel zurück, ob nicht dieser Abscess aus einer Caries der Wirbel selbstständig entstanden ist und ob diese Complication mit der polycystischen Nierengeschwulst eben nur eine zufällige war?

Zu meiner Beruhigung dient es, dass an der Beobachtung dieser Kranken auch die Professoren Korányi und Stiller theilnahmen, dass die Kranke 2 Wochen hindurch auf der Klinik von Prof. Korányi behandelt wurde und dass wir über diese Beobachtungen eine eingehende Verständigung erzielten. Auch Profossor Stiller war so gütig, sich mehrmals auf meine Klinik zu bemühen und sich eingehend mit dem Falle zu befassen, um jene Beobachtungen nicht nur im "Orvosi Hetilap", sondern auch in den Spalten der „Berliner klinischen Wochenschrift" im Jahre 1892 (No. 10-12) zu verwerthen; seine Mittheilung gab Anlass zu dem interessanten Ideenaustausch, den Stiller bezüglich der polyeystischen Nierengeschwülste mit Ewald unterhielt.

Auf Grund dieser Erfahrungen hätte ich den Anhängern der transperitonealen Operationsmethode gegenüber einige $\mathrm{B} \theta-$ merkungen. - Thornton, Terillon, Ruge, Martin, Olshausen, Sänger erblicken einen grossen Vortheil darin, dass, wean wir die Bauchböhle eröffnen, wir uns ausgezeichnet über die Verhältnisse in derselben orientiren können und den Zufuillen des Unvermutheten weniger ausgesetzt sind. Abgesehen nun von den anderen Vortheilen dieser Methode, die ich oben auch selbst betonte, bin ich gezwungen, eben in den mit perirenalen und anderen retroperitonealen Abscessen combinirten Fällen die Vortheile dieser Methode in Zweifel zu ziehen. Wir können nämlich rom obigen Falle als Lehre ableiten, dass ja auch bei der transperitonealen Methode solche Complicationen auftauchen können, die 
wir selbst bei der leichten Uebersichtlichkeit des Terrains zur gewünschten Zeit nicht erkennen. Ich bin überzeugt, dass jene Kranke, wenn sie in die Hände eines solchen Operateurs gelangt wäre, der ein ausschliesslicher Anhänger der Operationsmethode mittelst Lumbalschnittes ist, gerettet worden wäre, denn bei einem solchen Vorgehen würde die im Vorhinein nicht erkannte Complication vor Allem unter sein Messer gerathen sein und es hätte das Wesen der Sache nicht im Mindesten gestört, dass er es nicht mit einem, sondern mit mehreren Abscssen zu thun habe, da es keinerlei Schwierigkeiten verursacht hätte, dieselben nach einander zu eröfnen. - Ich leite daher für mich die Lehre ab, dass in solchen Fällen, wo die Möglichkeit eines retrorenalen Abscesses obschwebt, der Lumbalschnitt und nicht der transperitoneale Weg zu wählen ist!

Indem ich den Vortheil des eventuellen Lumbalschnittes in einem ähnlichen Falle in dieser Weise hervorhebe, wünschte ich nicht missverstanden zu werden, denn es ist unbezweifelbar, dass die transperitoneale Operationsmethode viele und unersetzliche Vortheile besitzt - in allen solchen Fällen, wo die Aufhellung der Verhältnisse der anderen Niere oder aus anderen differentialdiagnostischen Gesichtspunkten die Entscheidung über wesentliche Fragen von Wichtigkeit ist.

Den nächstfolgenden Fall habe ich im Jahre 1886 operirt; bei diesem begann ich auf jene grossen Schwierigkeiten zu achten, welche die Entzündung der Umgebung der Geschwulst gelegentlich der Operation verursacht. Die hier geschöpften Lehren leiteten mich zu jenen Erkenntnissen, welche ich bei der Operation der vorher behandelten zwei Fälle von cystischen Nierengeschwülsten mit Vortheil angewendet habe, wovon ich (mit Bezug auf die Auslösbarkeit der Geschwülste aus ihren Kapseln) bereits im Vorangehenden gesprochen habe.

Wie sehr die vorausgehende Laparotomie im Interesse der Differentialdiagnose wichtig und nützlich sei, kann ich mit folgendem Falle demonstriren:

R. Sch. (1891, J.-No. 3), 27 J. alt, hat õ mal regelmässig geboren; $1 \mathrm{mal}$ im Zusammenhange mit ibrem Leiden hatte sie - vor 2 Monaten - eine Frühgeburt im 8. Monate. In der rechtsseitigen Lumbalgegend fühlt sie bereits seit 2 Jahren zeitweilig bald kleinere, bald grössere Schmerzen. Ibre gegenwärtige, lange Krankheit begann im 4. Monate ibrer Schwangersehaft, somit im Ganzen vor 6 Monaten, als sich die Schmerzen in der Lumbalgegend zu heftigen Krämpfen steigerten, Fieber 
verursachten, bis schliesslich im 8. Monate der Schwangerschaft die Frübgeburt eintrat. Während des Puerperiums besserte sich ihr $\mathrm{Zu}$ stand kaum etwas. Sie gerieth immer yon Nenem ins Bett und ihre Geschwulst an der rechten Seite unter dem Rippenbogen vergrösserte sich. Sie hat ständigen schmerzhaften Harndrang und der Harn ist zeitweilig auffällig roth, ein andermal dicht, trübe, eitrig, zeitweilig jedoch ganz rein. Am 13. Januar 1891 wird Pat. auf unsere Klinik aufgenommen. Die Circulationsorgane der gut entwickelten, aber sebr geschwächten, blutarmen Krankea sind gesund. Im rechtsseitigen Hypochondrium über die Mittellinie nach links reichend liegt quer eine ovale Geschwulst, die sich elastisch anfühlt und die einen unter bedeutendem Druck stehenden flüssigen Inhalt verräth; - die Geschwulst ist mässig beweglich; zwischen Geschwulst und Leber kann man tief eindringen. Letztere ist isolirbar, blos in der Tiefe ist zu fühlen, dass die Geschwulst durch einen Strang an die Leberbasis angeheftet ist. Ueber der Geschwulst sind die Därme gelagert; der Zusammenhang mit den Genitalien ist ausschliessbar; durch die Respirationsbewegungen wird die Lage der Geschwulst nicht beeinflusst. Der Urin zeigt keine wesentliche Veränderung, ausgenommen, dass in demselben zeitweilig eine mässige Menge Eiters vorkommt. - Während einer 14 tägigen Beobachtung wurde constatirt, dass die Geschwulst stabil sei, die Schmerzen nicht aufhören und auf Narcotica sich kaum vermindern. Die Temperatur schwankt Abends immer zwischen 38,5 und 39,5 ". Wegen der quer ovalen Gestalt der Geschwulst and der durch die Därme geschützten Lage derselben, ferner wegen ihrer beschränkten Beweglichkeit können wir uns der Möglichkeit nicht verschliessen, dass wir es nicht mit einer Nieren-, sondern mit einer anderen, etwa aus extraperitonealen Drüsen oder aus dem Pancreas ausgehenden Geschwulst zu thun haben.

Bei der Operation wurde zum Zwecke einer sicheren Orientirung vor Allem in der Linea alba, in der Höhe des Nabels, ein $5 \mathrm{~cm}$ langer explorativer Einschnitt gemacht, wornach dann auf eine, jeden Zweifel anschliessende Weise constatirt war, dass die Geschwulst aus der rechtsseitigen Wanderniere stammt; ferner, dass die linksseitige Niere, nach der Palpation zu urtheilen, gesund sei. Es stand demnach nichts im Wege, dass wir in derselben Sitzung die lumbale Nephrotomie vornehmen. (Da ich selbst dazumal an einem Panaritium litt, so war mein ehemaliger Assistent, Herr Privatdocent Dr. Dirner, so freundlich, die Operation auf meiner Klinik vorzunehmen.)

Die Nephrotomie geschah mit dem Simon'schen Schnitt auf typische Weise. Die Höhle des eröffneten Nierenabscesses war durch das Nierenbecken und die bekannten Erweiterungen der Nierenkelche gebildet, aus welchen Erweiterungen, nachdem deren Scheidewände durchbrochen waren, der Operateur eine einzige Höle zu bilden sich berähte.

Das Nierengewebe umgab in hypertrophirter Dicke die Höble, welche mit einer physiologischen Kochsalzlösung reichlich ausgewaschen wurde. Nachdem wir die Abscesswände in die Wundöffnung herausgenäht hatten, wurde die Höhle mit Jodoformgazestreifen locker ausgestopft.

Die Heilung ging im Beginne nur langsam vor sich und zeigte sich zeitweilig Abends eine Temperatur von $38-38,4^{\circ}$, - anzeigend, dass noch immer eine Eiterretention vorhanden sei. Schliesslich wurde am Ende der 5. Woche ein wieder constatirbarer Abscess eröffnet, 
worauf die Besserung dann rasch vor sich ging, so dass die Kranke nach weiteren 10 Tagen das Bett verlassen konnte.

Mit dem Eintritte der Sommerferien wurde die Kranke mit einer, geringe Mengen Eiter und Urin secernirenden Fistel mit der Weisung entlassen, dass sie zur Nachbehandlung die Klinik besuchen möge.

17 Monate nach der Operation, im Jahre 1892, nachdem die Kranke eine Zeit lang ihre Besuche eingestellt hatte, mussten wir wieder einen neueren Abscess eröffnen. - Die Fistel wurde mit einer Chlorzinklösung ausgespritzt und eine längere Zeit hindurch ohne neuere Störung behandelt.

Am 13. April 1893 sahen wir die Kranke zum letzten Male; seither ist sie anfs Land gezogen und gelegentlich in einer Sitzung der kön. Gesellschaft der Aerzte constatirten wir, dass der Nierenabscess gänzlich und vollkommen verheilte und dass gegenwärtig blos eine kleine, nur eine überaus dünne Sonde einlassende, einige Tropfen Eiter entleerende Banchwandfistel besteht, die bei zweckmässiger Behandlung in allernächster Zuit ohne Zweifel zuheilen wird. - Die Kranke wurde fett, gesund, wohlauf and befindet sich gegenwärtig im 5. Monate ihrer neueren Schwangerschaft, die sie ohne jede Störung erträgt.

Die an diesen Fall knüpfbaren Reflexionen beziehen sich zum Theil auf die Anamnese, theilweise aber auf die Diagnose und auf die Art der definitiven Heilung. Aus der Anamnese ist erwähnenswerth, dass die schwere Krankheit während der letzten Schwangerschaft der Patientin entstand, wobei gleichzeitig sich eine Nierengeschwulst entwickelte. Diese Geschwulst verblieb auch nach der im 8. Monate erfolgten Prühgeburt als ständige Pyonephrose.

Die während der Schwangerschaft ontstehenden Nierengeschwülste besitzen eine grosse Wichtigkeit und sind derzeit noch wenig studirt. Einen, diesem ähnlichen und sehr lehrreichen Fall hatten wir Gelegenheit im Verlaufe des vergangenen Jahres in Gemeinschaft mit den Herren Dr. Dirner, Dr. Tauszk, Dr. Hermann und Prof. Dr. v. Korányi zu beobachten; vielleicht wird einer der erwähnten Herren diesen Fall auch literarisch bearbeiten, doch will ich darüber, wenn auch nur kurz, referiren. Während einer im rechten Horn eines Uterus bicornis sich entwickelnden Schwangerschaft entstand Hydropyonephrosis, indem durch einseitigen Druck der rechtsseitige Ureter comprimirt wurde; später entwickelte sich das Bild einer Nephritis parenchymatosa - und die Kranke schwebte in grösster Lebensgefahr! Die Pyonephrose war intermittirenden Characters und nach Entleerung einer beträchtlichen Menge Eiters beobachteten wir zeitweilige Besserungen. Erwähnenswerth ist, dass Martin in einem ähnlichen Falle während der Gravidität eine Nephrotomie 
vornahm. In unserem Falle löste ein künstlicher Abortus diese Frage, wodurch der Druck auf den Ureter nachliess und die Nierengeschwulst spurlos verschwand, ja selbst die parenchymatöse Erkrankung der Niere in erfreulicher Weise sich rückbildete. Es ist unzweifelhaft, dass in ähnlichen Fällen dies das einzig richtige und das mildeste Verfahren sei; denn, wenn wir so lange warten, bis die Natur hilft, dann können wir leicht dorthin gelangen, wie wir dies in dem den Gegenstand unseres Ausgangspunktes darstellenden Krankheitsverlauf (Frau R. J.) gesehen haben.

Auf meinen Fall zurückkommend, war betreffs der Diagnos $\theta$ interessant, dass mit Rücksicht auf die Gestalt der Geschwulst, ihrer theilweisen Dislocation for die Wirbelsäule, ferner auf den relativ leeren Zustand der Lumbalregion und darauf, dass ursprünglich eine Wanderniere vorhanden gewesen war, weiters auf dio geringe, characteristische Menge des vorhandenen Harns und schliesslich auf das cachectische Aussehen der Kranken: eine sichere Unterscheidung zwischen einer Nierengeschwulst und einer anderen, etwa retroperinealen Geschwulst so lange in suspenso gelassen werden musste, bis die diagnostische Incision nicht vollkommenes Licht über die Frage verbreitete.

Diese Erfahrung dient auch als Beweis dafür, dass wir in einem Falle, wo die Gegenwart oder Abwesenheit der zweiten Niere, sowie der gesunde oder krankhafte Zustand derselben von entscheidendem Belange ist, von der hierüber Licht verbreitenden explorativen Laparotomie, die viele und verschiedenartige Zweifel zu zerstreuen im Stande ist, uns nicht zurückhalten sollen. UnzweifelThaft bleiben auch noch dann viele verschiedenartige, wichtige Fragen ungelöst zurück, wenn nicht die Betastung und Palpation der Niere Aufklärung verschafft, sondern wo sich die Frage um den gesunden und krankhaften Zustand des Parenchyms der zweiten Niere dreht. In solchen Fällen lässt auch die diagnostische Incision im Stich und man muss noch immer nach neuen Mitteln forschen, um die secretorische Thätigkeit der beiden Nieren separat erkennen zu können.

Meine dritte Reflexion im Anschlusse an diesen Fall bezieht sich auf die Art der definitiven Heilung. Diese hat bei der Wahl der Nephrotomie oder der Nephrectomie eine Wichtigkeit von principieller Bedeutung: Der Umstand nämlich, dass wir nach der Nephrotomie 27 Monate lang warteten 
und dann vollkommene Heilung erzielten, spricht dafür, dass wir für den Fall, wenn nach einer Nephrotomie eine Fistel zurückbleibt, lieber geduldig warten sollen, bevor wir uns der mehr minder lästigen Fistel halber zur Exstirpation der Niere entschliessen. Wie es dieser Fall bezeugt, hatte ich diese Intention bereits seit zwei Jahren und jetzt, nach 27 Monaten, sehe ich die Richtigkeit meines Verfahrens gerechtfertigt. In ähnlichem Sinne äusserte sich in jüngster Zeit auch Guyon, der ebenfalls nach Monaten eine vollkommene Heilung nach Nephrotomie mit Pyonephrose erfolgen gesehen hat.

Es ist nothwendig, einen solchen Umstand zu betonen, denn es giebt Viele, die bei einer grösseren Pyo- oder Hydronephrosis die primäre Nephrectomie vornehmen wollen.

Ein ganz ähnlicher, aber auch aus anderen Gesichtspunkten interessanter Fall war der folgende, der aus der Praxis des Herrn Privatdocenten Angyán und des Herrn Dr. Bokor zu meiner Beobachtung gelangte.

I. K. (1892. Journal-No. 92), 36 J. alt, 5p.; seit 13 Jahren weiss sie, dass sie eine rechtsseitige Wanderniere habe. Vor 9 Jahren hat sie Peritonitis überstanden. Ihre gegenwärtige, schwere Erkrankung begann 2 Monate vor ihrer jetzigen Aufnahme am Platten-See, wohin sie sich zum Sommeraufenthalt begab. Die Erkrankung begann mit heftigen Krämpfen und zeigte überdies das Bild einer umschriebenen Peritonitis. Die Herrn DDr. Bokor und Angyán sahen in den letzten Wochen inmitten sehr heftiger Krämpfe und in Begleitung eines sehr bohen Fiebers $3 \mathrm{mal}$ eine mannskopfgrosse, stark gespannte Geschwulst im rechten Hypochondrium entstehen, welche Geschwulst eben so viele Male anf dem Höhepunkt der Spannung und inzwischen heftiger Krämpfe im Verlaufe einer einzigen Nacht spurlos versehwand, - wobei gleichzeitig eine sehr übelriechende, copiöse, eitrige Diarrboe auftrat, worauf der Zustand der Kranken wie mit einem Zauberschlage einem allgemeinen Wohlbefinden Platz machte. In solcher Zeit konnte man, trotz der sorgfältigsten Untersuchung des Unterleibs keine Geschwulst entdecken. - Unter neuerem Fieber, Spannungsgefühl und Schmerzen trat, eventuell im Verlaufe von 24 Stunden, die Geschwulst wieder auf und der Symptomencomplex wiederholte sich.

Ich selbst sah die Kranke zuerst am 30. September 1892 - inmitten eines fieberhaften Zustandes und grosser Schmerzen mit icterischem Anstrich. Bei dieser Gelegenheit bestand die Geschwulst bereits seit 10 Tagen. -

Die mannskopfgrosse Geschwulst ist kugelförmig, ihre obere Grenze reicht bis an den Rippenbogen hinan, von der Leberdämpfung ist sie durch eine schmale, tympanitische Furche zu trennen; nach innen erstreckt sie sich bis zur Mittellinie, nach abwärts reicht sie bis zum Hüftbeinteller. Der Percussionsschall ist über der Geschwulst gedämpft leer, an den Rändern jedoch tympanitisch durchklingend. In der Geschwulst ist Fluctuation fühlbar, die sich auf die Lumbalgegend erstreckt, 
diese Gegend jedoch nicht hervorwölbt. - Auf Grund der Genitaluntersuchnng ist der Ausgang von den Beckenorganen auszuschliessen. Durch Aufblasen des Darmes wird es sichtbar, dass der von der Mittellinie nach links gelegene Antheil der Bauchhöhle bedeutend erweitert, hingegen der rechtsseitige Theil derselben an der Erweiterung nicht betheiligt und dass selbst dazumal über der Geschwulst keine Darmpartie constatirbar sei; ja, dass man zwischen den anfgeblasenen Gedärmen ein dem aufsteigenden Colon entsprechendes, cylindrisches Gebilde am linken Rande der Geschwulst gut erkennen kann. Die Respirationsbewegung beeinflusst die Lage der Geschwulst nicht. - Aus der Anamnese und diesem Befunde ward es klar, dass wir es mit einer eitrigen, mit Darmperforation combinirten Nierengeschwulst zu thun haben und dass die Darmmündung nur unter gewissen, unbekannten, günstigen Umständen durchgängig wird. Die Harnuntersuchung zeigte keine krankhafte Veränderung, woraus die berechtigte Folgerung abgeleitet werden konnte, dass die linke Niere gesund und dass der rechtsseitige Ureter nicht durchgängig sei. Die Respirations- and Circulationsorgane waren gesund.

Das intermittirende Fieber deutete auf Eiterresorption hin. Das Leben der Kranken schwebte in grosser Gefahr - und unter solchen Umständen wurde die Kranke behufs Operation auf die Klinik eingeliefert. -

Die Operation geschah am 1. October mittelst Czerny'schen Lumbalschnittes, auf welchem Wege die Geschwulst sehr gut zugänglich wurde. Bei der Punction erschien eitriger Urin, der nach gehöriger Erweiterung der Oeffnung vollkommen entleert wird. Nach Auswaschung des Sackes wird der eine noch genügend dicke Nierenrinde enthaltende Sack ausgenäht und die Höhle mit Jodoformgaze ausgefüllt. - Decursus: Kranke ist nach der Operation vollkommen fieberlos, Schmerzen hören auf, Urin rein. Die vor der Operation zweifellos bestandenen Symptome der Darmfistel zeigten sich nicht wieder. Der Nierensack producirt einen copiösen eitrigen Harn, so dass täglich 2 mal eventuell auch mehrmals der durchnässte Verband gewechselt werden muss. Der Zustand der Kranken bessert sich rasch, ihre Ernährung nimmt zusehends zu. Die Lumbalwunde granulirt lebhaft. Die Höhle verkleinert sich auffällig rasch und entleert je länger um so weniger Harn.

Nachdem wir uns mittelst cystoskopischer Untersuchung überzeugt hatten, dass auch der Ureter der rechten Niere Urin in die Blase entleert, demnach durchgängig ist, wurde das Lumbaldrain entfernt. Die Tagesmenge des von der Blase gelassenen Urins hob sich auf $1500-2000 \mathrm{ccm}$ und in dem Sediment waren eine Zeit lang hyaline, körnige und fettige Cylinder zu finden, die wahrscheinlich aus der rechtsseitigen Niere der Kranken herrührten. Diese Erscheinungen schwinden bald und die Kranke erhebt sich am 25. Tage nach der Operation - um in der 6. Woche die Klinik gänzlich zu verlassen und ihre Fistel zu Hause behandeln zu lassen. Am 11. Januar 1893, also $3 \frac{1}{3}$ Monate nach der Operation, präsentirt sich dieselbe mit gutem Aussehen, gar keinem Schmerz. Auf der rechten Seite ist die vergrösserte Niere zu tasten; die Lumbalöffnung ist blos dünn - federkielartig, durch dieselbe entleert sich noch immer eitriger Harn. -

Seither ist es nothwendig, die äussere Oeffnung der Fistel zeitweilig zu erweitern, damit der stagnirende, mit Eiter vermengte Harn 
einen freien Abfluss habe. Es lässt sich constatiren, dass die Anfangs mannskopfgrosse Höhle sich rasch reducirt. -

Die Kranke ist, wie man das oft genug erfahren kann, selbst diesem kleinen Leiden gegenüber nunmehr ungeduldig - und fordert auf Grund ihrer eigenen und der während ihres Aufenthaltes auf der Klinik an anderen gemachten Erfahrung mit wahrer Leidenschaft, dass wir, um ihr Leiden gänzlich zu sistiren, ihre beschädigte Niere ganz entfernen sollen. -

Wir sahen jedoch in unserem vorher mitgetheilten Falle, dass selbst nach 27 Monaten noch eine vollständige Heilung erfolgt, wobei die Kranke ihre zweite Niere in relativ gesundem Zustande erhalten kann. Natürlich erfülle ich ihren Wunsch nicht und ich würde es bedauern, wenn sich ein willfähriger Operateur finden würde, der sich wegen dieser eitrigen Fistel von geringer Bedeutung entschliessen könnte, bei dieser ungeduldigen Kranken die Exstirpation der Niere vorzünehmen. - Nur die von Mehreren mitgetheilten Beobachtungen von dem meinigen ähnlichen Fällen werden geeignet sein, zu bewirken, dass in der Nierenchirurgie der Conservatismus ein allgemeiner werde. Denn vor der Hand ist es nicht wenig verlockend durch eine Nierenexstirpation eine rasche und effectvolle Heilung dort zu erzielen, wo ein anderer nur nach monatelanger Arbeit ein Resultat in Aussicht ztellen kann ${ }^{1}$ ).

\section{B. Nephrolithiasis.}

In der Symptomengruppe der Pyonephrosis und der NephroIithiasis tritt in sehr vielen Fällen als gemeinsamer Charakter die Nierengeschwulst auf, -- bedingt durch den stagnirenden Harn und Eiter. Jene 2 Fälle, die mir aus dieser Gruppe vor Augen kamen, boten das einfache Bild der Pyonephrose, - und erst gelegentlich der Operation kamen wir zur Erkenntniss, dass die Erkrankung mit Lithiasis complicirt sei. Indem wir eine Nierengeschwulst diagnosticiren, können wir im Vorhinein nie wissen, ob nicht ein Stein im Nierenbecken vorhanden sei. Es wäre eine grosse Täuschung zu glauben, dass der Nierenstein jedesmal charakteristische Erscheinungen verursacht; im Gegentheil, wir können einen überraschend grossen Stein finden, ohne dass dessen Symptome sich geltend gemacht

1) Nach Abschluss dieser Arbeit erfahre ich, dass anderwärts bei dieser Patientin die Nephrectomie bereits ausgeführt wurde! 
hätten. Dem ersten derartigen Falle begegnete ich im Jahre 1890 - nach einer Orariotomie.

J. L. (Journal - No. 7), 52 Jahre alt, 4 p. Unter überstandenen Krankheiten erwähnt sie ein Leberleiden und, wie es scheint, eine damit im Zusammenhang stehende Kolik. Seit 3 Jahren hat sie eine Bauchgeschwulst. Die zeitweilig sehr intensiven Schmerzen traten in den letzten Jahren auf und die Kranke bezog sie auf die unter grossem Drucke stehende Geschwulst. Die Respirations- und Circulationsorgane sind gesund, die Urinuntersuchung, die vorschriftsmässig vor jeder Laparotomie vorgenommen wird, zeigte zufällig keine krankhafte Veränderung. Bei der Untersuchung der Banchböhle fand sich eine ans dem kleinen Becken aufsteigende, interligamentär entwickelte, linksseitige Geschwulst. Die Ursache der Schmerzen ist in der grossen Spannung und in dem Drucke der Geschwulst gelegen. -

Gelegentlich der Laparotomie finden wir ein mehrkämmeriges Colloid, welches zwischen den Blättern des linken Ligamentum latum bis an den Uterusrand heraustritt und diesen an die rechte Beckenwand andrückte. Operation zwar schwierig, jedoch ohne besondere Complicationen. Decursus: Bis zum 15. Tage fieberfrei, obschon die Kranke bereits am 5. Tage über stechende Schmerzen im linken Hypochondrium klagte, ohne dass jedoch an dieser Stelle durch die dicken, fettreichen Bauchwände etwas nachzuweisen gewesen wäre.

Die Ernähruug anhaltend schlecht; am 10. Tage tritt unter Schmerzen eitrig-blutiger Urin auf. -

Die Ursache dieser Beschaffenheit des Urins blieb vor der Hand unerklärbar. Am 15. Tage treten bei subfebrilem Zustande Erbrechen, heftige Unterleibsschmerzen auf und erst am 19. Tage wird im linken Hypochondrium eine faustgrosse Geschwulst erkennbar. Diese Geschwulst wächst in den nächsten Tagen rasch, wird fluctuirend. Wegen dürftiger Ernährung ist der Kräfteverfall ein rascher und am 20. Tage zeigt sich eine bis $39^{\prime \prime}$ ansteigende Temperatur.

Inmitten der gefährlichen Erscheinungen erscheint es nothwendig, dass die mit eitrigem Inhalt bezeichnete Geschwulst mit dem Dieula foy'schen Apparate punktirt werde, - auf welchem Wege wir früher 300 , später von einer anderen Stelle aus $520 \mathrm{ccm}$ blutigen Eiters entleeren. Hierauf fühlt sich die Kranke eine Zeit lang erleichtert, aber bald steigt das Fieber wieder an und eine neuere Punction wird nothwendig.

Die Localisation und Beschaffenheit der Geschwulst war nicht ganz charakteristisch, denn wir fanden yollkommene Dämpfung in der Grösse einer Handfäche - unter dem Rippenbogen, ausser diesem war der Percussionston bis auf die Lumbalregion überall tympanitisch. Man konnte daher eine abgekapselte Eiteransammlung nicht ausschliessen, obschon die Erscheinungen des Urins auf die Gegenwart einer Nierengeschwulst, $d$. h. Pyonephrose hinwiesen. - Unser Schwanken in der Deutung des Abscesses wurde noch berechtigter durch den Bericht des path. chemischen Institutes, laut welchem in dem durch Punction gewonnenen Eiter auch jede Spar von Harnstoff fehlte.

Inmitten der Zweifel erschien es zweckmässiger, wenn wir durch die vordere Bauchwand hindurch eindringen und uns der unmittelbar zu tastenden Geschwulst von dieser Seite her nähern. Nachdem wir etwa 3 Finger breit vom linken Rippenbogen mit diesem parallel in 
der Länge von 8-10 cm die Bauchwand eröffnet hatten, stiessen wir auf die Oberfläche der Geschwulst.

Um die Peritonealhöhle vor der Verunreinigung durch den bekannten, eitrigen Inhalt der Geschwulst zu schützen, nahmen wir eine vorsichtige Punction vor, und erst, als die Spannung nachgelassen, schritten wir zur entsprechenden, weiten Eröffnung der Geschwulst, indem wir zuvor die Wundränder des Sackes mittelst Naht an das an die Bauchwände geheftete Peritoneum befestigten. $\mathrm{Zu}$ unserer nicht geringen Verwunderung fanden wir in der Geschwulst einen länglichen, höckerigen, hühnereigrossen Stein, dessen Entfernung ohne Schwierigkeit vor sich ging. In den Aushöhlungen der ausgetasteten, erweiterten Kelche waren noch mehrere erbsen- bis haselnussgrosse Steine zu finden, die wir sorgfältig herausholten. Nach gründlicher Auswaschung der Höhle legten wir ein Glasdrain ein und füllten die Wundhöhle mit Jodoformstreifen lose aus.

Das Fieber liess hierauf wohl nach, hörte aber nicht ganz auf, und die Abendtemperaturen schwankten noch immer zwischen $38-38,5^{\prime \prime}$. Die Ernährung ward minimal, die Herzthätigkeit geschwächt und 10 Tage nach der Nierenoperation, am 39. Tage nach der Laparotomie trat der Tod ein.

Die Obduction wurde aur bezüglich der Bauchhöhle gestattet. Es erwies sich, dass in den erweiterten Kelchen der linksseitigen Niere noch mehrere Concremente lagen; in der rechtsseitigen hingegen 2, die noch grösser waren, als die aus der Linksseitigen entfernten nebst zahlreichen kleinen Gebilden - - und dass in dem Nierengewebe sich um die Steine und Steinchen herum kleinere und grössere Abscesse bildeten. In der Peritonealhöhle war bezüglich der Ovariotomie der Heilungsprocess bereits beendet und der Tod war einzig die Folge der Nierenerkrankung. -

Es war das Unglück der Kranken, dass sie zugleich an einer

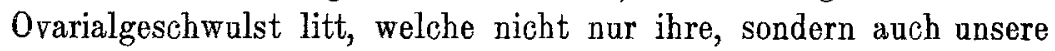
Aufmerksamkeit ganz fesselte. Zweifellos würden wir ohne diese Erkrankung die Ursache der heftigen, kolikartigen Schmerzen an einer anderen Stelle gesucht und auch gefunden haben und es ist nicht unmöglich, dass, wenn wir das Richtige gefunden, die nacheinander an beiden Nieren vollführte Nephrolithotomie mit einer Heilung geendet hätte. -

Der Fall dieser Kranken kann bezüglich meiner obigen Empfehlung als Lehre dienen; nämlich, dass wir selbst beim geringsten Zeichen mittelst Abtastung die Nieren untersuchen sollen, wenn schon einmal die Bauchhöhle aus einer anderen Ursache eröffnet worden ist. -

Mein zweiter wegen eines Nierensteines operirter Fall betraf einen Mann. Diese Krankengeschichte bestätigt am besten die Voraussetzung, dass in dem Falle einer Pyonephrose wir nie sicher wissen können, ob nicht eine Steinbildung die 
Grundlage des Leidens sei, oder ob nicht die bestehende Pyonephrosis im Laufe der Zeit zur Steinbildung geführt habe? Selten begegnen wir einem besser beobachteten Falle, als diesem, dessen auf 8 Jahre zurückreichende pünktliche Daten wir genau kennen. Der sehr intelligente Kranke erlernte förmlich seine Krankheit und nahm gelegentlich des Consiliums mit einer für einen Laien überraschenden Klarheit an dem Ideenaustausche Theil:

Dr. H. B. (Privatfall), 50 J. alt, leidet seit 18 Jahren an Wanderniere. Sein Urin ist seit $14-15$ Jahren trüb und im Laufe dieser Jahre consultirte er die Professoren. Korányi, Stiller und Nothnagel und stand in den letzten Jahren unter der sorgfältigen Behandlung des Herrn Dr. Siegmund Adler. Vor 15 Jahren hatte er einen heftigen Krampfanfall, der sich seither nicht mehr wiederholte. Die Geschwulst wuchs wenn auch unter geringen Erscheinungen langsam wohl, aber stetig. Anch an jenen Krampfanfall erinnert er sich nur wie an ein "verschwommenes Bild" und er setzte dessen Bezichung zu seinem gegenwärtigen Leiden nie voraus. Bis vor einem Jahre hatte derselbe, abgesehen von den im Harne stets beobachteten, aber bereits gewohnten Eiterverluste kein bedeutenderes Leiden. Vor einem Jahre trat zuerst intermittirendes Fieber auf, welches wieder schwand. Seit 3 Monaten ist Pat. bettlägerig; Fieberbewegungen schwächen ihn fortwährend und seine Geschwulst ist erheblich gewachsen. Eine pünktliche Beschreibung der Harnuntersuchung besitzen wir von Prof. PIósz, vom Jahre 1880 angefangen. Ständige Pyelitis. Letztere Zeit war Pyonephrosis diagnosticirt. Nachdem das Fieber anhaltend war und den Kranken mit Erschöpfung bedrohte, stimmte auch er der übereinstimmenden Ansicht der Aerzte zu, dass eine Operation unaufschiebbar sei. Die Operation geschah am 4. März 1893 mittelst Czerny'schen Lumbalschnittes, wobei wir, nachdem wir durch die Bauchwände gedrungen, auffallend nach rückwärts dem Colon descendens begegnen nach dessen Vorwärtsschiebung wir erst die Höhle der Geschwalst eröffnen können. Nach dem Einschnitte entleerte sich 2 Liter mit Urin vermengten, übelriechenden Eiters und mit dem vordringenden Finger fühlten wir einen anffallend grossen Stein. Derselbe war so gross und durch die in die Kelche sich erstreckenden Fortsätze so fest fixirt, dass es erst nach wesentlicher Erweiterung der Wunde und nach Abbröckelung der Fortsätze gelang, denselben hervorzuheben. Der Stein, welchen zu untersuchen Prof. Scheuthauer so gefällig war, betrug 2371/2 Gramm, war von unregelmässiger Kegelform, an seiner Basis zufolge mehrerer $\frac{1}{3}-1 \frac{1}{2} \mathrm{~cm}$ hoher Fortsätze unregelmässig. Die Oberfläche des gelblichröthlichen Steines ist stellenweise durch nahezu thalergrosse, sehwarzbraune, von vorhergegangenen Blutungen stammende Flecke bunt, tropfsteinartig. Die Sägefläche des Steines ist einem unregelmässigen Dreiecke ähnlich, dessen einzelne Seiten $91 / 2,8$ und $6 \mathrm{~cm}$ lang sind. Der Rindentheil ist 2-5 mm dick, härter. Der chemischen Untersuchung nach besteht der Stein aus phosphorsaurem Kalk, neben welchem koblensaurer Kalk und Ammoniak blos in Spuren nachweisbar sind. Nachdem wir die Abscesshöhle mit sterilisirtem Wasser ausgewaschen and das Nierengewebe gründlich untersucht hatten, fanden wir noch einige Receptacula und kleinere Steine und indem wir die Scheidewände zer- 
störten, wandelten wir das Ganze in eine Höhle um. Das Nierenge webe ist auf $3-5 \mathrm{~mm}$ verdünnt, an manchen Stellen jedoch verdickt, ja selbst hypertrophirte Substanz war zu erkennen.

Nachdem der Rand des Nierensackes mittelst Seidennähten mit der Hautwunde vereinigt worden, wurde die Bauchwunde mit Nähten verengert, dann die Blutung mit heissen Schwämmen gestillt - und, nachdem die Höhle mit Jodolgaze ansgefüllt wurde, ein Verband angelegt.

Die Dauer der Operation betrug 1 Stunde, das verbrauchte Chloroform 20 Gramm.

Decursus. Die Temperatur steigt am Operationstage noch auf $38^{\circ}$, hernach aber wird der Kranke fieberfrei. Der Urin reinigt sich bereits am 2. Tage - und enthält bei der Untersuchung weder Eiter noch Eiweiss.

Die Heilung wird nochmals durch eine Temperatursteigerung gestört; am 17. Tage nämlich finden wir Temperatur: $39,2^{\circ}$, deren Ursache in dem Verschlusse eines Receptaculums gefunden wurde, nach dessen Eröffnung jedoch kein Fieber sich mehr zeigte. Die durch die lange Jahre hindurch angehaltene Eiterung und das Monate hindurch andauernde Fieber erschöpfte Kraft des auch sonst gesch wächten und zart gebauten Kranken kehrte nur allmählich wieder, so dass er das Bett erst am 26. Tage nach der Operation verlassen konnte. - Gegenwärtig führt ein Fistelgang noch in eine hühnereigrosse Höhle, der Kräftezustand lässt kaum etwas zu wünschen übrig; als hoher Staatsbeamte geht er seinen Geschäften ungestört nach.

Auf Grund unserer vorhergehenden Erfahrungen ist die Hoffnung begründet, dass die Fistel heilen and die operirte Niere ihrem Besitzer noch wesentliche Dienste leisten wird.

Von unseren Nephrotomien waren, den Fall Frau J. L., wo eine mit Orariotomie complicirte beiderseitige Steinniere vorhanden war, abgerechnet, die anderen drei genesen.

Kaum giebt es noch eine solche dankbare Operation wie diese, welche sozusagen ohne Gefahr einen schweren Kranken von seinem peinlichen Leiden befreit!

Besonders ist es das Gebiet der Nephrolithotomie, auf welchem in jüngster Zeit ein erstaunlicher Fortschritt erfolgte; insofern als dermalen die auf diesem Gebiete geübten Operateure nicht davor zurückschrecken, die aus ihrer Kapsel herausgehobene Niere, wenn nöthig, in der Länge der Convexität oder in der Länge der beiden Pole der Niere aufzuschneiden - zu dem Behufe, um die in derselben verborgenen kleineren Coneremente aufzusuchen; oder aber, um den in den Ureter eingezwängten Stein hervorzuholen. Nach Anwendung der Naht können wir, indem wir die Niere an ihren Platz zurückversetzten, Heilung nicht blos erwarten, sondern auch erreichen. 


\section{Nierentuberkulose.}

Unter den Nierenoperationen bildet die primäre Tuberkulose dieses Organes eine besondere Gruppe. Anfangs zog der Vorschlag, dass die einseitige, primäre Nierentuberkulose auf operative Weise geheilt werden möge, beinahe höhnische Bemerkungen nach sich. Heute ist diese Frage schon insofern geklärt, als die Berechtigung einer operativen Behandlung der diagnosticirten, einseitigen, primären Erkrankung nicht mehr in Zweifel gezogen werden kann. Die grösste Schwierigkeit bereitet jedenfalls die Diagnose. Denn der Nachweis des einzigen, unbedingt sicheren Zeichens - der Tuberkelbacillen - im Harne ist schwer und gelingt auch nicht immer. In einem guten Theile der Fälle wurde a posteriori constatirt, dass die operirte Nierengeschwulst tuberkulöser Natur war. Unsere Wissenschaft jedoch schreitet heute rasch vorwärts; mit den auftauchenden Fragen befassen sich sozusagen die Aerzte der gesammten Erdoberfläche und so ist es nur natürlich, dass, was vor 5 Jahren auf Grund des klinischen Bildes noch als ungelöste Frage vor uns stand, gegenwärtig mit Hilfe des Mikroskopes und der Inoculationen schon lösbar ist.

Ein solcher Fall war auch derjenige, der mir aus der Praxis des Dr. Paldt und des Prof. Stiller vor die Augen trat:

N. G. (Privat-Fall), 34 J. alt, gebar $4 \mathrm{mal}$. Als Anamnese verzeichneten wir, dass die Krankheit in ihrem letzten Wochenbette begonnen, welches vor etwa $1 / 2$ Jahre abgelaufen ist, - zu welcher Zeit die Entleerung eines copiösen, übelriechenden, trüben, eitrigen Harns auffiel. 4 Monate nach der Entbindung begann eine fieberhafte Erkrankung mit einer abendlichen Temperatursteigerung bis auf $40^{\prime \prime}$, doch konnte die Kranke noch längere Zeit ausser Bette bleiben. Nach weiteren 4 Monaten wird das Fieber constant, es treten Schmerzen im Hypochondrium und profuse Eiterentleerungen im Harne auf. Ich sah Pat, am 2. Mai 1888 zum ersten Male. In der Tiefe des rechtsseitigen Hypochondriums fand sich eine glatte, kaum bewegliche, kindskopfgrosse Geschwulst; dieselbe erstreckt sich nicht über die Mittellinie hinaus reicht mit ihrem unteren Antheil bis etwas unter die Querlinie des Nabels herab und füllt gänzlich die Lumbalregion aus. Ueber ihr kann man unter den Rippenbogen nicht eindringen. Durch Percussion war die Gesehwulst vom unteren Rande der Leberdämpfung gut zu separiren, vor ihr lagen Därme. Die Respirationsbewegungen des $Z$ werchfells beeinflussen ihre Lage nicht. Mit den Genitalien war jeder Zusammenhang absolut auszuschliessen. Während meiner Beobachtung hellte sich der Urin zeitweilig auf, ward eiterfrei. $\mathrm{Zu}$ solcher Zeit jedoch entstanden in der Geschwalst heftige Schmerzen, Spannung mit hohem, nahezu $40^{\circ}$ Fieber. Der Zustand der Kranken ist solcherzeit qualvoll, nahezu unerträglich. So oft jedoch im Urin der Eiter wieder erschien 
und die Spannung der Geschwulst aufhörte, war die Kranke Tage hindurch von Schmerzen befreit und fieberfrei, ihr Appetit kehrte wieder and ihre Ernährung besserte sich.

Es war demnach unzweifelhaft, dass eine intermittirende Pyonephrose bestehe und dass das Leiden auf operativem Wege heilbar sei - sowie schliesslich, dass die in Aussicht zu nehmende Operation, die Nephrotomie wäre.

Diese Operation vollführte ich am 18. Mai 1888 im rothen Kreuzspitale. Indem ich mittelst Simon'schen Lumbalschnittes zur Nierengeschwulst gelangte, gerieth ich gelegentlich des Nierenschnittes in eine käsige Masse, aus deren Tiefe etwa 1 Liter übelriechenden Eiters sich entleerte. Inmitten des Ausgrabens der käsigen Masse und des Zerpflückens der Zwischenwände entstand eine starke Blutung, deren Stillung überhaupt unmöglich erschien und die in kurzer Zeit selbst das Leben bedrohte. Unsere übereinstimmende Ansicht ging dahin, dass wir es mit einer Pyelitis caseosa chronica zu thun haben, die wir nach unseren heutigen Kenntnissen als einen tuberkulösen Process betrachten müssen, somit mussten wir einerseits wegen der Art der Erkrankung, andererseits auch wegen der auf andere Weise nicht zu stilleaden Blutung zu der einzigen noch möglichen Rettung, zur totalen Exstirpation der Niere, greifen. Die Ausschälung aus der Kapsel war nicht leicht, denn diese haftete nahezu durchaus zähe der Oberfläche der Geschwulst an, so dass inmitten des durch die Blutung dringend gewordenen Vorgehens das Peritoneum einriss. Zeit zum Schwanken hatten wir nicht, wir mussten rasch zu den grossen Gefässen der Niere gelangen - und so drangen wir vorderhand ohne Rücksicht auf die Verletzung des Peritoneums nach vorwärts, bis wir das Gefässbündel umgangen und dasselbe in eine starke Pincette gefasst hatten - und so der Blutung endlich Herr werden konnten. Nachdem wir die Gefässe und den Ureter unterbunden und die Niere entfernt hatten, folgte eine minutiöse Aufgabe, theilweise im Interesse der vollkommenen Ausreinigung der eröffneten Peritonealhöhle, bis wir schliesslich die 3 fingerbreite Spalte des Peritoneums mit einer fortlaufenden Catgutnaht schliessen konnten. Nachdem die Wandhöhle mit Jodoformgaze lose ansgestopft wurde, reducirten wir nach Möglichkeit die Lumbalwunde.

Die Dauer der Operation betrug 11/2 Stunden; die Kranke gerieth zufolge des grossen Blutverlustes mit nahezu unfühlbarem Pulse und in collabirtem Zustande ins Bett. Analeptica hatten auf die Herzthätigkeit nur geringe Wirkung. Die subnormale Temperatur hielt bis gegen $\mathrm{Abend}$ an. Die Urinausscheidung war in den ersten 24 Stunden minimal, kaum $50-60 \mathrm{ccm}$ und sehr blutig. Tags darauf hob sich die Temperatur auf $38^{\circ} \mathrm{C}$, es trat Anurie auf und die Kranke starb binnen zweimal 24 Stunden nach der Operation.

Die systematische Obdnction blieb anf Wunscb der Familie weg. Indess wurde die rechte Niere dennoch herausgenommen und von Prof. Pertik untersucht: „Frisch mit Osmiumsäure untersucht, findet man eine acute Nephritis parenchymatosa mässigen Grades."

In diesem Falle bildete den Grund der intermittirenden Pyonephrosis ein einseitiger easeoser Process, der nach Allem eine tuberkulöse Grundlage besass. Lehrreich ist in dem Falle, dass im Organismus eine anderswo lokalisirte, ähnliche Erkrankung sich 
niemals bekundete; ferner, dass die Nierentuberkulose primär und einseitig war. Die intendirte Nephrotomie gestaltete sich während der Operation in Folge der Blutung zur Nephrectomie - und was dort unter solchen Nebenumständen zwangsmässig geschah, würde bei unseren heutigen vorgeschrittenen Kenntnissen planmässig geschehen. Denn es ist unzweifelhaft, dass es nur so gelingt, den Organismus von einer solchen Erkrankung rein lokaler Natur gründlich zu befreien. Die Zerreissung des Peritoneums inmitten der Schwierigkeiten der Geschwulstauslösung ist keine seltene Eventualität - und auch nicht so gefährlich. In diesem Falle wenigstens war dieselbe von gar keinen Folgen begleitet and die Erscheinungen einer Peritoneuminfection tauchten nicht auf. Die Todesursache war ausser dem Collaps in der durch die beginnende Entzündung der zurückgebliebenen Niere verursachten Urämie begründet. Dieser tödtlich verlaufene Fall ist keineswegs so zu nehmen, als würde derselbe für das Schicksal der in diese Gruppe gehörenden Fälle charakteristisch sein. Der tödtliche Ausgang hatte eine Ursache, welche bei jeder, aus welcher Ursache immer erfolgenden Nephrectomie eintreten kann, nämlich: der Blutverlust und die zufolge der plötzlichen Belastung der Niere aufgetretene Nephritis parenchymatosa acuta. Die Erfahrung und die in der Literatur auffindbaren Daten zeigen jedoch, dass in aus solchen Ursachen operirten Fällen überraschend schöne Erfolge erzielt werden - und dass wir mit denselben nicht anders bestellt wären, als mit einer jeden anderen Lokaltuberkulose wo, wenn der krankhafte Herd entfernt wird, die Ernährung des Organismus einen Aufschwung nimmt. Die über eine grosse Erfahrung verfügenden Autoren gehen noch weiter und sehen die Exstirpation der tuberkulösen Niere selbst dort noch für angezeigt, wo in einem anderen Organe, z. B. in der Lunge der primäre Herd war, der aber zur Zeit entweder obsolet oder aber wenigstens seit längerer Zeit im schlummernden Zustande gewesen, so dass die Symptome der Krankheit in der Niere als in einem neuen Herde erscheinen. Einst hatte die Voraussetzung, dass der bacilläre Process in der Niere, als in einem paarigen Organe, zn ein- und derselben Zeit beiderseitig auftritt, manche Berechtiging, aber eben das Gegentheil hiervon bezeugt die Erfahrung! Denn die primäre, einseitige Tuberkulose ist vielfach bestätigt worden - und diese hat für unser Vorgehen eine richtungangebende Bedeutung. 


\section{Maligne Nierengeschwülste.}

Die Exstirpation der malignen Nierengeschwülste bietet derzeit noch die schlimmsten Aussichten, indem von den bisher Operirten mehr als $75 \mathrm{pCt}$. nach der Operatien starben. Die Ursache des Todes war in den meisten Fällen darin zu suchen, dass die Operation sehr spät erfolgte, so dass bereits Metastasen den Organismus befielen; oder aber, dass die anatomischen Verhältnisse gelegentlich der Operation derart ungünstig waren, dass der Eingriff in Folge des Blutverlustes und anderer schwerer Complicationen tödtlich wurde.

\section{In diese Gruppe gehören meine folgenden 2 Fälle.}

F. K. (1891, J.-No. 15), 52 J. alt, gebar 6 mal, zuletzt vor 11 Jahren; seit einem Jahre Klimax; seit 8-9 Jahren verspürt sie Schmerzen im Unterleibe, rechterseits besonders während der Arbeit und schon zu jener Zeit wurde bei ihr Wanderniere constatirt. Wegen krampfartiger Schmerzen sucht sie am 18. Februar 1891 die Klinik auf. Im rechten Hypochondrium der geschwächten, leidend aussehenden Kranken liegt eine kindskopfgrosse Geschwulst, die aus der tiefen Lumbalregion hervorragt, sich derb anfühlt und mit der Leberbasis mittelst eines armdicken Stranges in Zusammenhang steht. Der Percussionsschall ist blos in der Gegend des oberen Poles der Geschwulst leer, ringsherum umgiebt dieselbe ein tympanitischer Schall, der bis in die Lumbalregion zu verfolgen ist. Die Respirationsbewegungen des Zwerchfells beeinfiussen kaum die GeGeschwulst. Dieselbe ist nicht beweglich und scheint mit ihrer Basis der Wirbelsäule entlang breit aufzusitzen. Die Geschwulst kann eine Gallenblasengeschwulst, eine Wandgeschwulst der Flexura coli sinistra oder aber eine aus der alten Wanderniere ausgehende Nierengeschwulst sein, die mit der Uterusfläche, der Leber verwachsen ist. Während unserer Beobachtung hatte die Kranke heftige, kolikartige Schmerzen, wobei gleichzeitig die Temperatur auf $38,7^{\circ} \mathrm{C}$. steigt. Trotz wiederholter Untersuchung des Harns ist keinerlei wesentliche Veränderung in demselben wahrzunehmen, mit Ausnahme, dass er auffallend wenig ist - täglich $340-500 \mathrm{ccm}$. Die Krampfparoxysmen treten gewöhnlich in den Abendstunden inmitten der Temperatursteigerung auf; die Kranke pflegt solcherzeit sich unter Qualen zu winden, kalter Schweiss bedeckt ihren Körper und der Paroxysmus lässt von seiner Intensität selbst auf eine starke Morphininjection wenig nach. Die Kranke gelangt im fieberhaften Zustande zur Operation, bei welcher der Bauchschnitt in der rechtsseitigen Mammillarlinie geführt wird. Unmittelbar unter der Bauchwand liegt die kindskopfgrosse Geschwulst retroperitoneal; Colon nach links vorgeschoben und mit der Geschwulst verwachsen. Ebenso derbe Verwachsungen mit der unteren Fläche der Leber. Nach Durchschneidung des Peritoneums lösen wir mit grosser Schwierigkeit den Tumor aus seiner mehrschichtigen Kapsel aus. Der dem Hilus der Niere entsprechende Strang, welcher über 1 Zoll dick ist, tritt in der Höhe des 3. Lumbalwirbels zur Wirbelsäule hinan; in demselben sind sowohl der in seiner Wand verdickte Ureter, sowie die Nierengefässe 
enthalten. Der Stumpf ist sehr kurz, rigid, nicht dehnbar und droht zu zerreissen, weshalb auch die Unterbindung desselben mit Schwierigkeiten einhergeht. Erst nach der Durchschneidung ward es sichtbar, dass die Ureterwandung mehrere Millimeter dick, sein Lumen aber kaum für eine dünne Sonde durchgängig war. Die Nierengefässe werden isolirt unterbunden.

Im unteren Antheile der entfernten Geschwulst zeigt sich gesundes Nierengewebe, die obere grössere Masse hingegen zeigt ein aus gelblichweissen Herden bestehendes Gewebe, in dessen Mitte sich eine nussgrosse, mit trüber Flüssigkeit gefüllte Höhle befindet.

Nach Entfernung der Geschwulst bleibt eine zerklüftete, klaffende, extraperitoneale Höhle zurück, deren Drainirung nothwendig erscheint. Nachdem wir die Kapselränder an das Peritoneum der Bauchwunde herausgenäht, legen wir eine dicke Glasröhre ein und füllen die Wundhöhle mit Jodoformgaze lose aus.

Nach der Operation öfteres Erbrechen, Kranke ist schwach, Temperatur $37,2^{\circ} \mathrm{C}$; Puls über 100 ; am nächsten Tage früh $37,8^{\circ} \mathrm{C}$.; Puls frequent, klein; 24stündiger Urin $400 \mathrm{~g}$. - Die Kranke collabirt zusehends, Excitantien ohne Erfolg, ausserordentliche Unruhe, Prostration; Abends 7 Uhr Bewusstlosigkeit und 36 Stunden nach der Operation Tod.

Nach dem Obductionsprotokoll war die Geschwulst ein Sarcom. In der Brusthöhle fanden sich (von anderen Veränderungen abgeseben) gut umschriebene, subpleurale, ferner in der Tiefe der Lunge sitzende, z̈̈he, compacte, granulirte, graulich - rosafarbene, erbsen- bis haselnussgrosse Herde. Die retroperitonealen Drüsen an den beiden Seiten der Wirbelsäule, in Packeten, infiltrirt.

Dem pathologisch-anatomischen Befunde nach war bereits eine allgemeine Sarcomatose gegenwärtig und die Todesursache in der Erschöpfung des Organismus begründet. Wenn ich das Wesen und die Ausbreitung der Kraukheit gekannt hätte, würde ich gewiss nicht operirt haben. An der Lebenden jedoch zeigten sich die physikalischen Zeichen dieser Veränderungen nicht und bei der eventuellen lokalen Natur des Leidens würde, wenn sich die Krankheit blos erst auf die Niere beschränkt hätte, durch die Operation die Möglichkeit der Heilung gegeben sein.

Mein zweiter zu dieser Gruppe gehörender Fall war eine anatomische Rarität. Die Histologie der malignen Geschwülste der Nieren ist noch wenig bearbeitet und somit kann schon aus diesem Gesichtspunkte unser Fall einen gewissen Werth haben; derselbe - ein Adenocarcinoma haemorrhagicum renis - bildete in den pathologisch-anatomischen Instituten der Herren Professoren Pertik und Scheuthauer den Gegenstand eingehender Untersuchung und wurde entsprechenden Ortes auch ron diesem Gesichtspunkte aus eingehend gewürdigt ${ }^{1}$ ).

A. D. (1892, J.-No. 67), 21 J. alt, 1 Geburt und 1 Abortus. Vor einem Jahre nahm sie während der Schwangerschaft in der linken

1) Siehe: Emil Tauffer, Orv. Hetilap 1893, S. 19 ff. 
Bauchhälfte die Geschwulst wahr, die, zumal nach dem Wochenbette stürmisch zu wachsen begann, und die mir am 30. Septbr. $1891 \mathrm{zu}$ Gesichte kam. Eine gut entwickelte, hinlänglich gut aussehende, mässig genährte Kranke, deren Bauchhöhle durch eine in ibrer linken Bauchhälfte sitzende Geschwulst asymetrisch erweitert ist. Die Geschwulst ist über mannskopfgross, geht unter dem Rippenbogen hervor, hebt denselben empor, ist absolut unbeweglich und elastisch anzufühlen. Ihren genitalen Ursprung konnten wir mittelst in der Narkose vollführter Untersuchung unzweifelhaft ausschliessen, der untere Pol der Geschwulst reicht wahe bis zum Beckeneingang hinab. Vorläufig geht der Verdacht auf einen Milzechinococcus - wir untersuchen deshalb die durch eine Probepunction erhaltene Flüssigkeit. In der blutig-serösen Flüssigkeit finden sich rothe und wenig weisse Blutkörperchen, Echinococcushaken jedoch konnten weder wir, noch Prof. Plósz auffinden. Als die durch wiederholte Punctionen gewonnene Flüssigkeit neuerdings auf Echinococcus untersucht wurde, forschte Prof. Plósz, die Möglichkeit einer Nierengeschwulst vor Augen haltend, gleichzeitig auch nach Harnstoff; es gelang jedoch nicht, denselben nachzuweisen. Die Diagnose schwankte zwischen einer Milzgeschwulst, einem retroperitonealen Sarcom und einer malignen Nierengeschwulst. Jede Wahrscheinlichkeit sprach für eine Nierengeschwulst. Bei der genauen Untersuchung der Kranken auf der Klinik des Prof. v. Korányi gelang es, die Geschwulst von der Milzdämpfung abzugrenzen und indem auch die übrigen physikalischen Zeichen in Betracht gezogen wurden, diagnosticirte schliesslich auch Prof. v. Korányi eine linksseitige, von der Niere stammende Geschwulst. Dieselbe wächst auch während unserer dreiwöchentlichen Beobachtung auffallend stürmisch. Bei der cystoskopischen Untersuchung konnte auch hier constatirt werden, dass aus dem rechtsseitigen Ureter unter Bildung eines normalen Wirbels der Harn sich in die Blase entleere, während aus dem linksseitigen Ureter der Urin sich in geringer Menge mit pflaumartigem Sediment gemischt, ohne Wirbelung in die Blase ergiesst.

Trotz intacten Aussehens des Individuums und seines jugendlichen Alters mussten wir dennoch die rasch wachsende Geschwulst als eine bösartige betrachten - und als solche gelangte sie auch am 21. November 1891 zur

Operation. $20 \mathrm{~cm}$ langer Schnitt in der Linea alba; die Geschwulst ist retroperitoneal gegen oben und seitlich mit dem unteren Antheil der 2-3fach vergrösserten Milz verwachsen; dieselbe hebt das Colon descendens vor sich und schiebt es gegen die Mittellinie hin, welches derart zwischen den inneren Rand der Milz und die Oberfläche der Geschwulst geräth.

In der vor der Hand intakten peritonealen Kapsel verläuft ein riesiges Gefässnetz mit beinahe fingerdicken Venen; die Gefässe des auf dasselbe angewachsenen Netzes sind erweitert und auf diese Weise bedeckt die Oberfï̈che der Geschwulst noch ein zwejtes Gefässnetz. Es schien überaus schwer, sich durch dieses Terrain einen Weg zur Geschwulst zu bahnen und nur nach zahlreichen, vorhergehenden Umschlingungen und Unterbindungen der Gefässe konnten wir die peritoneale Kapsel spalten, um zur Geschwulst gelangen zu können. Nachdem dies geschehen, nahmen wir behufs Verkleinerung der Geschwalst eine Punction vor, wobei sich kaum 1 Liter einer dichten, braunen kaffeesatzähnlichen Flüssigkeit entleerte. Die Belassung der 
Geschwulst in st. q. würde absolnt tödtlich gewesen sein, - und so war denn, um den Preis welcher Gefahr immer, blos die Exstirpation der Geschwulst für die Erhaltung der Kranken am Leben, denkbar. Die Ausschälung geschah unter ausserordentlich starker Blutung. Die nahezu zweimannskopforosse Masse geht aus der linken Niere hervor und zwar derart, dass Letztere auf jener in der Wölbung des Diaphragma nahezu ihrer ganzen Gestalt nach ausgetastet werden kann. Wegen Unmöglichkeit die Geschwulst zu bewegen und wegen ihrer hohen Lagerung unter dem Rippenbogen schien es sehr schwer, die Basis ins Gesichtsfeld zu bringen; es bestand die Gefahr, die grossen Gefässe ab- oder anzureissen. Deshalb ging unser Bestreben dahin, uns einen Weg im Bette der Geschwulst bis zu den grossen Gefässen hin zu bahnen, vor Allem mit einer starken Klemmpincette durchzuschleichen und mit dieser provisorisch den Gefässstumpf zu fassen. Hieranf erst schnitten wir mit einer langen, nach ihrer Wäche gekrümmten Scheere, unter Leitung unserer Finger dieselben auf der Oberfläche der Niere, resp. der Geschwulst durch. Nunmehr erst gelang es die Geschwulst aus ihrer blutenden Kapsel herauszuheben. Da indess die Blutung an hundert Quellen zählte, konnte dieselbe nur so gestillt werden, dass wir nach Massen-Unterbindung des Stumpfes in der Klemm-Pincette die Wandung des grossen Sackes mit fortlaufender Catgutnaht concentrisch zusammenzogen und indem wir hierdurch die Höhle von jeder Seite aus verkleinerten, setzten wir gleichzeitig die blutenden Gefässe unter Druck. Mittelst dieses Kampfes gelang es schliesslich die unmittelbare Gefahr der Verblutung zu beseitigen. Die retroperitoneale Höhle hatten wir mittelst der fortlaufenden Naht sozusagen abgeschlossen - und gleichzeitig das Operationsterrain von der Peritonealhöble ausgeschlossen. Ein Druckverband wurde angelegt. Die Kranke collabirte während der Operation zufolge des grossen Blutverlustes ungemein und gelangte mit kaum fühlbarem Pulse ins Bett. Trotz aller unserer Bemühungen starb die Kranke 9 Stunden nach der Operation unter den Erscheinungen des Collapses.

Die exstirpirte Geschwulst war ein Adenocarcinoma haemorrhagicum renis, welches ron dem unteren Drittel der Niere ausging und dessen obere zwei Drittel intact gelassen hat.

Trotz des jugendlichen Alters des Individuums konnte auf Grund der klinischen Erscheinungen kaum ein $Z_{\text {weifel darüber walten, dass }}$ die Nierengeschwulst eine maligne sei; - und a posteriori ist es erwiesen, dass die Ursache des ausserordentlich raschen Wachsthums eine Folge der Qualität des Gewebes und der in dasselbe erfolgten zeitweiligen Blutergüsse war. Das die Geschwulst umgebende riesige Gefässnetz bot während der Operation eine grosse Gefahr der Verblutung dar und wenn es auch gelang, dieses überaus unangenehme Ereigniss fernzuhalten, so war dennoch der Blutverlust ein solch hochgradiger, dass dieser und der in Folge des grossen operativen Eingriffes eingetretene Shock nach 9 Stunden zum Tode führten.

Die Schwierigkeiten und Gefahren, denen wir gelegentlich der Operation von malignen Nierengeschwülsten begegnen, können uns selbst in solchen Fällen nicht zur Resignation bestimmen; denn, wenn sich unsere Diagnostik vervollkommnet, wird sich auch 
unsere technische Fertigkeit in der Besiegung der grössten Schwierigkeiten steigern und wenn wir früher und besser operiren werden, wird es uns hoffentlich gelingen manches leben zu retten, welches sonst beim Nichtsthun unbedingt verloren ginge. -

\section{Nephrorrhaphie.}

Auf jedem Gebiete kann man die Beobachtung machen, dass während derselben die Häufigkeit der einen oder anderen Erkrankung in auffälliger Weise sich za vermehren seheint. Und so nehmen wir dies gegenwärtig auch bezüglich der Wanderniere wahr, besonders seitdem die Gynäkologen es sich àngewöhnten, gelegentlich ihrer Untersuchungen nicht nur die Genitalien, sondern auch die Verhältnisse sämmtlicher Organe der Bauchhöhle auszutasten und zu erforschen. Ganz überraschend ist, dass wir besonders die rechte Niere gar so oft in einem unregelmässigen, beweglichen Zustande finden. Daher kommt es, dass die Autoren bezüglich der Häufigkeit der Wanderniere überaus abweichende statistische Daten liefern. So fand z. B. Lindner bei einer jeden 5.-6. Frau Wanderniere, während Senator nur in einem jeden 170, untersuchten Falle einer solchen zu begegnen glaubte. - Rollet fand sie unter 5500 Sectionen blos in 0,4 pCt., Fischer-Bencon unter 100 Sectionen in 17 pCt. der Fälle.

Die Erkenntniss der Häufigkeit der Wanderniere ist zweifellos eine grosse Errungenschaft, aber ich befürchte, dass die an dieselbe geknüpften therapeutischen Bestrebungen, wie so oft, auch in diese Frage übers Ziel hinausschiessen werden. Wenigstens auf mich macht es diesen Eindruck, wenn ich von einzelnen Operateuren auf Schritt und Tritt bereits von einer ganzen Serie die Wanderniere fixirender Operationen zu lesen bekomme. Ich fürchte sehr, dass auf diesem Gebiete sehr Vieles und vielleicht Ueberflüssiges geschieht! Dieses Urtheil basire ich darauf, dass so wie ich auch jeder Andere nur ein bestimmtes Krankenmaterial zu überblicken im Stande sei (welches wohl etwas mehr oder weniger als das Meinige sein kann, was aber an dem Wesen der Sache nichts ändert). Wenn ich daher an meinen eigenen Erfahrungen, die aus den Mittheilungen Anderer ersichtlichen Angaben abmesse, so erblicke ich darin einen Gegensatz. Denn seit jenen ungefähr 13-14 Jahren, seitdem nach Hahn die Nephrorrhaphie aufgetaucht 
ist, seitdem ferner durch Landau's ausgezeichnetes Werk: „Die Wanderniere der Frauen. 1881." diese Frage auf die Tagesordnung gelangte, beobachte ich ständig dieses Leiden; und ich kann sagen, dass ich in meiner ganzen klinischen, sowie in meiner Privatpraxis, die doch auch nicht ganz gering ist, nicht mehr als drei so schwere Fälle von Wanderniere gefunden habe, in welchen auf eine andere Weise keine Hilfe möglich war und der operative Vorgang unausweichlich ersthien. Von diesen drei Franen entzog sich eine der Operation und sie erträgt auch noch beute ihr Leiden, lebt mit ihren Schmerzen fort, ist aber an ihrem Leben nicht bedroht. Seit 7 Jahren erscheint dieselbe immer wieder bei mir, um mir ihr Leid zu klagen und behufs einer Controluntersuchung, ob nicht etwa in der Niere eine solche Veränderung eingetreten wäre, wegen welcher die Operation unbedingt vollzogen werden müsste. Es ist dies eine intelligente Dame, die selbst zur Operation entschlossen ist, wenn in dem Nierengewebe eine solche Veränderung auftreten sollte, zufolge der die Operation unvermeidlich wäre. Wie gesagt, diesen Fall beobachte ich bereits seit 7 Jahren, ohne dass eine solche Veränderung bis nun eingetreten wäre. Eine zweite solche Kranke entschwand nach Proposition einer Operation später meinen Blicken und seither konnte ich nichts über ihr Schicksal erfahren; - und blos die dritte, demnach blos ein einziger Fall, gelangte zur Operation, über die ich späterhin sprechen werde.

Es ist hier am Orte auch jener Kranken zu erwähnen, die in dieser Serie die vierte gewesen wäre, wenn wir uns bei ihrer Operation nicht noch rechtzeitig davon überzeugt hätten, dass unsere Diagnose eine irrige war. Es ist nämlich von einer Kranken die Rede, die seinerzeit der Königl. Gesellschaft der Aerzte vorzustellen mein Assistent Dr. Tóth die Ehre hatte, bei welcher von den Professoren Angyán, Kétli, Müller und auf Grund meiner eigenen klinischen Beobachtung eine rechtsseitige Wanderniere diagnosticirt wurde. Nachdem jedoch bezüglich der Diagnose ein Zweifel auftauchte, brachte ich statt einer lumbalen, eine transperitoneale Operation in Vorsehlag, wobei ich anstatt der gesuchten Wanderniere ein aus der Valvula Bauhini ausgehendes Carcinom und eine Intussusception des Coecums vorfand und durch die circuläre Resection des Coecums Heilung erzielte.

Trotz der vielen Kranken, die während dieser Jahre mit beweglicher oder Wanderniere an meinen Augen vorbeizogen, waren 
die Klagen doch nicht so schwer, dass es - durch Tragen eines entsprechenden Bauchgürtels oder nit Hülfe eines entsprechenden Mieders - nicht gelungen wäre, das Leiden wesentlich zu lindern.

Dass ich in dieser Frage nicht befangen bin, dürfte auch dieser Vortrag bezeigen, aus welchem wenigstens soviel erhellt, dass ich unter unermesslich schwierigeren Verbältnissen, mitunter selbst unter desperaten Umständen, der Operation niemals aus dem Wege gehe, wo ich deren Nothwendigkeit erkannt habe. Um wie vieles eher würde ich die kaum gefährliche, in ihren Erfolgen eclatante, von jeder Aufregung freie, relativ leichtere und dankbarere Nierenfixation öfter vornehmen, wenn ich von deren Nothwendigkeit häufiger überzengt zu werden Gelegenheit hätte! Es muss sich demnach derart verhalten, dass Andere bereits unter viel milderen Erscheinungen die Indication zur Operation vorfinden, als ich. Ich weiss zu gut, - steht es doch in der Anamnese mancher zur Nierenoperation (Nephrotomie, Nephrectomie) gelangten Fälle angeführt! - dass in der der Operation vorangehenden und diese bestimmenden langen Krankheit zuvor Wanderniere diagnosticirt war; dass demnach die Wanderniere die disponirende Ursache späterer, schwerer Erkrankungen bildet. Indess wenn ich diese relativ geringe Anzahl schwerer Erkrankungen jenen vielen in derselben Zeit beobachteten, an Wanderniere grösseren oder geringeren Grades Erkrankten gegenüberstelle, so scheint eine solche grössere Erkrankung von ähnlicher Folge, meiner Ansicht nach relativ doch seltener aufzutreten und wenigstens mich nicht zu der Auffassung zu veranlassen, dass die Nierenfixation der späteren schweren Nierenerkrankung gegenüber auch als ein präventives Verfahren eine Berechtigung gewinnen könnte. Eines jedoch erkenne ich an, und das ist: dass derjenige, der sich mit irgend einer Operation öfter und eingehender befasst und in derselben eine grössere Dexterität erlangt hat, zumal wenn er durch die eigene Erfahrung sich von der relativ geringeren Gefährlichkeit jener Operation thunlichst überzeugt hat, selbst bei Klagen und Gefahren geringeren Grades, jenen Zeitpunkt herangekommen sehen wird, wo die Operation - seiner Ueberzeugung nach indicirt ist. Die Berechtigung dieser Auffassung bestreite ich nicht, im Gegentheil, in vielen Fällen unterschreibe ich sogar dieselbe. Denn die Gefährlichkeit und Nützlichkeit irgend einer Operation ist nicht aus der allgemeinen, von Vielen dargestellten 
Statistik zu beurtheilen, sondern jene stehen mit dem Maasse der individuellen Erfahrung des Wissens, der Geschicklichkeit, Gewandtheit und der Vollkommenheit seiner Asepsis in directem Verhältnisse.

Indem ich dies Alles anerkenne, glaube ich dennoch, dass es eine Grenze gebe, wo die Frage derart zu stellen sei, ob eine Operation überhaupt nothwendig sei oder nicht? Diesbezüglich besteht, meiner Ansicht nach, eine Uebertreibung, denn es werden viele Operationen dort vorgenommen, wo solche, strenge genommen, nicht nöthig sind; dieser Umstand aber ist nur zu sehr in die Wagschale zu werfen, denn bezüglich der Resultate der Nephrorrhaphie verhalten sich noch Viele sehr skeptisch, selbst Männer z. B. wie Lawson-Tait und Lindner!

Auch finden wir bei richtiger Erkennung der Resultate, dass diese nicht in etwas Anderem begründet ist, als in der einfachen Fixirung der Niere, - nicht aber in der Reposition und dauerndem Verbleiben derselben an der normalen Stelle. So viel aber können wir in vielen Fällen auch mittelst Bandagen erreichen, ohne dass wir die Kranke einer Operation unterziehen müssten.

Nach diesen allgemeinen Gesichtspunkten wollen wir unseren Fall betrachten:

E. D., 30jährige Frau, hat einmal geboren, fühlt seit 1890 in ihrem Unterleibe eine bewegliche Geschwulst, die bedentenden Schmerz verursacht, zumal bei Bewegung. Sehr oft befällt sie ein quälender Brechleiz mit Aufstossen, Appetitlosigkeit und Verdaunngsbeschwerden. Ihr Unterleib ist gebläht, in der Brust empfindet sie ein beklemmendes Gefühl und die Schmerzen sind oftmals so hochgradig; dass die Kranke mit kaltem Schweisse bedeckt, im Bette sich herumwälzt. Deshalb ist sie auch blutarm und reizbar, betrachtet sich als schwerkrank und ist zu keiner Arbeit fähig. Harndrang, kolikartige Darmschmerzen, Obstipation machen ihren Zustand unerträglich. Im rechten Hypochondrium ist ein nierenförmiges Gebilde zu tasten, welches nach einer jeden Richtung ein leicht bewegliches ist, in der aufrechten Stellung der Kranken bis zum Beckeneingang hinabsteigt und bei erschlafften Bauchwänden über den Nabel hinaus auf die linke Seite hinübergeleitet werden kann. In liegender Stellung ist dasselbe unter den rechtsseitigen Rippenbogen hinauf verschiebbar; kurz: hier liegt ohne Zweifel rechtsseitige Wanderniere vor. Auf der Klinik des Prof. Korány zur Beobachtung übergeben wurde ständig die normale Menge des Urins constatirt und als Ursache sämmtlicher Magen- und anderer Reflexerscheinungen die Wanderniere erkannt. Wir beobachteten bei ihr die bekannte Thatsache, dass die Niere za jeder Menstruationszeit erheblich anschwoll. Bandagen und Massage änderten an dem Zustande gar nichts. Nachdem alle palliativen Mitteln versagten, bestimmten wir die arbeitsunfähige Kranke 
zur Nephroxraphie. Die Operation geschah mittelst $\mathrm{C} z$ erny'schen Lumbalschnittes, wobei ein Assistent von der Banchwand her die Niere in das Operationsterrain schiebt. Nach Durchschneidung der tiefen Schichte der Fascia lumbo-dorsalis und Eröffnung der Fettkapsel der Niere bietet sich nichts Besonderes. Aus der fibrösen Kapsel der hinteren Nierenoberfläche wird ein $3 \mathrm{~cm}$ breites und etwa $6 \mathrm{~cm}$ langes Stück in ovaler Form ausgeschnitten, um die derart wundgemachte Nierenoberfläche mit ihrer vom Fettgewebe beraubten Fascie, respective ihrer Muskelfï̈che zusammenzunähen. Drei Nähte mit Silkwormgut werden durch die fibröse Kapsel der Niere hinein, durch das Nierenparenchym hindurch, auf der anderen Seite neuerdings durch die fibröse Kapsel hinaus gelegt, und hierauf die Fascie, respective die wundgemachte Musculatur an einer solch hohen Stelle mit der Nadel umstochen, dass gelegentlich der später erfolgenden Schürzung der Nähte nahezu die Hälfte der Niere unter dem Rippenbogen Platz nimmt, wobei wir beim Knotenschürzen besonders darauf achten, dass zwischen den Wundflächen sich kein Fett einschiebe. Die auf diese Weise erfolgte Fixirung erweist sich als sehr vortheilhaft und sicher. Die Bauchwandwunde wird mit versenkten Catgutnähten und mit fortlaufender, oberflächlicher Seidennaht versorgt. Die glatte Heilung wird einige Tage durch einen Abscess in der Wundhöhle gestört mit $38,0-38,5^{\circ}$ Fieber, welches jedoch mit dem Eröffnen des Abscesses prompt schwindet. Die Harnuntersuchung wurde täglich vorgenommen und in demselben weder quantitativ noch qualitativ irgend eine Veränderung vorgefunden.

Die Schmerzen hörten mit der Fixirung der Niere auf; die Reflexerscheinungen zeigten sich nicht mehr and das Resultat kann ein vollkommenes genannt werden. - Am 33. Tage nach der Operation verliess die Kranke das Bett, und die entsprechende Fixirung der Niere ist dauernd $\mathrm{zu}$ constatiren.

Aus dem Obigen ergeben sich nun folgende Sätze:

A. Bezüglich der Chirurgie der Ureteren:

1. Die Ureter-Bauchfistel spielt in der Literatur zumeist als fertige Indication zur Nephrectomie eine Rolle und doch wäre es wichtig, die Frage der gelegentlich der Operation $\nabla$ on schweren Bauchgeschwülsten vorkommenden Ureter-Verletzungen in anatomischer und klinischer Hinsicht eingehender zu würdigen.

2. In den Fällen von zufälligen Ureter-Verletzungen ist $\nabla \circ r$ der Nephrectomie jede andere mögliche Art zu versuchen, mittelst welcher der Ureter mit der Blase in Verbindung gebracht werden kann. Die Möglichkeit einer plastischen Vereinigung der Ureterstümpfe ist durch meine Fälle erwiesen.

3. Subperitoneale, in die Tiefe des Beckens wachsende und die Nachbarorgane vor sich zur Seite schiebende Geschwülste dislociren zugleich die Ureteren und dies in einem Maasse, dass dieses Organ oftmals an einer überraschenden Stelle zu liegen kommt. 
und hierdurch der Gefahr einer zufälligen Verletzung ausgesetzt ist. Besonders droht diese Gefahr, wenn die Geschwulst zwischen Blase und Ureter vorgedrungen, diese beiden Organe von einander getrennt hatte.

4. Die bisher wenig gewürdigte Arteria ureterica, die aus der Art. renalis entstammt, ist von unserem Gesichtspunkte aus sehr wichtig und wenn sie bei schwieriger Operation verletat wird, so zwingt die darauf entstehende arterielle Blutung in der Tiefe des Beckens, also in der Nähe des dislocirten, aber nicht erkannten Ureters zur Vornahme der Umschlingung - und Naht, bringt uns also jener Gefahr nahe, dass wir den Ureter unterbinden oder dieses Organ durchschneiden.

5. Der Ureter ist bei schweren Operationen nicht selten in der Länge von $10-15 \mathrm{~cm}$ von jeder umgebenden Verbindung losgelöst und hängt frei ins Becken. Für die Ernährung der Ureterwandung sorgt in einem solchen Falle einzig und allein die Art. ureterica, die sich fest an die fibröse Kapsel der Ureterwandung anheftet und mit dieser vereint, selbst nach der Auslösung des Ureters noch in Verbindung zu finden ist.

6. Bei schweren Laparotomien, namentlich wenn in der Tiefe des Beckens Umstechungen und Unterbindungen vorkamen, ist vor Schluss der Bauchwände jedesmal der Verlauf der Ureteren zu dem Behufe zu untersuchen, ob nicht einer derselben zufälliger Weise mitunterbunden wurde, welches Ereigniss durch ein von stagnirendem Uriu erweitertes, cylindrisches, fingerdickes Gebilde markirt sein dürfte. In einem solchen Falle ist die Unterbindungsstelle um jeden Preis zu lösen.

7. Die zufällige Unterbindung des einen Ureters führt zu acuter Hydronephrose und in Folge des Druckes des keimfreien Urins eventuell zur Schrumpfung des Nierengewebes; somit gefährdet diese Begebenheit das Leben nicht unbedingt.

8. Wenn es sich um eine Ureter-Scheiden-Fistel handelt, so ist die Bildung einer künstlichen Blasen-Scheidenfistel und ein weiteres plastisches Vorgehen im Interesse des directen Verschlusses indicirt und selbst der heutige Fortschritt der Nierenchirurgie berechtigt zi keinem anderen Vorgehen, bevor nicht auch jenes versucht worden ist.

9. Wenn sich ein Ureter tertius vorfindet und wenn der überzählige Ureter in die Urethra oder aber in das Scheidengewölbe einmündet, so ist zu untersuchen, ob nicht dieser Ureter 
sich mit der Blasenwand eine Strecke weit berührt; in letzterem Falle kann derselbe in die mittelst $\mathbf{E}_{1}$ icystotomie eröffnete Blasenhöhle unmittelbar hineingeleitet und der peripherische Antheil desselben mit dem Paquelin-Brenner zerstört werden. -

B. Bezüglich der Nephrotomie und Nephrectomie.

1. In der Nierenchirurgie machen uns die neueren Erfahrungen den Conservatismus zur Pflicht. -

2. Die Erfahrung scheint die Theorie Favre's zu rechtfertigen, dass, nämlich durch die Compression oder die vorhergehende Unterlindung des einen Ureters die andere Niere an die compensirende Thätigkeit gewöhnt werden kann, so dass die nach einer solchen Prämisse vollzogene Nierenexstirpation vom Organismus sehr, ja sogar auffällig leicht ertragen wird; d. h. die zweite Niere nimmt ohne jede Störung die Aufgabe der gesammten Urinausscheidung auf sich. -

3. Die Ursache des nach einer vollzogenen Nierenexstirpation ohne vorausgegangene Angewöhnung erfolgten Todes ist nahezu immer eine Nephr. parenchym. acuta.

Es fragt sich nur in wiefern neuere experimentelle Untersuchungen die Theorie Favre's rechtfertigen werden, der diese acute Nephritis aus einer speciellen Ptomaïnaemie hervorgegangen zu erklären sich bemüht.

4. Sollten Favre's Theorie ausser den klinischen Erfahrungen noch neuere experimentelle Arbeiten rechtfertigen, so gehört die Zukunft der $z$ weizeitigen Nierenexstirpation an.

5. Wenn gelegentlich einer schweren Operation in der Bauchhöhle eine zufällige Durchschneidung des Ureters geschieht, so möge nicht sofort und gleichzeitig eine Nierenexstirpation vorgenommen werden, sondern, wenn es nicht möglich wäre den Ureter mit der Blase in directe Verbindung zu bringen, nähen wir ihn in die Bauchwunde heraus, indem wir eine Ureter-Bauchwandfistel bilden; - die Nephrectomie aber soll einer späteren Zeit vorbehalten werden.

6. In dem Falle einer Ureter-Banchwandfistel lässt sich wohl unter idealen Umständen erreichen, dass die entsprechende Niere ständig gesund bleibe; indess zeigt die Erfahrung, dass zu Folge der ascendirenden Infection früher oder später Pyelitis, ja selbst Nephritis erfolgt; somit ist in dem Falle einer Ureter-Bauchwandfistel die Nephrectomie indicirt. - 
7. Es tauchte uns jene physiologische Beobachtung auf, dass durch den etwa $10 \mathrm{~cm}$ langen und in die Bauchwunde ausgenähten Ureterstumpf der Urin in peristaltischem Rhythmus entleert wurde. Hieraus folgt, dass jene Folgerung gerechtfertigt sei, welche die Ursache der peristaltischen Entleerung des Urins unter normalen Verhältnissen nicht im Ureter, sondern in der rhythmischen Contraction des Nierenbeckens begründet findet. -

C. Bezüglich der Nierengeschwülste.

1. In der Diagnostik der Nierengeschwülste, besonders bezüglich der Hydro- und Pyonephrose sind gegenüber von Ovarialgeschwülsten Irrthümer noch immer häufig und fehlen dafür oftmals charakteristische klinische Erscheinungen.

2. Ein hydronephrotischer Sack kann sich zeitweilig ohne bekannte Ursache vollkommen schliessen (temporäre, intermittirende Hydronephrose).

3. Der gelegentlich einer Punction einer Nierengeschwulst in die Peritonealhöhle gelangte Inhalt verursacht Peritonitis und die auf diese Weise entstandenen Verwachsungen machen die Differentialdiagnose oft unmöglich.

4. Ein hydronephrotischer Sack kann aus seiner bindegewebigen Umgebung leicht ausgelöst werden, wenn keine entzündliche Complication bestand oder auch wenn eine abgelaufene Entzündung blos das Peritoneum betraf; hingegen können die Schwierigkeiten der Ausschälung eventuell unüberwindlich werden, wenn der entzündliche Process perirenal abgelaufen ist.

5. Der Inhalt eines hydronephrotischen Sackes kann zufolge der aus der catarrhalischen Blase ascendirenden Infection eitrig werden und wenn bei solcher Gelegenheit der Ureter sich schliesst und die Entleerung intermittirt, kann der Blasencatarrh heilen, womit jeder Anhaltspunkt dafür schwindet, dass die Infection ihre Ursache in der Blase gefunden hat.

6. In der Wandung eines mittelgrossen hydronephrotischen Sackes kann oft genug ein noch functionsfähiges Nierengewebe ge. funden werden, dessen Erhaltung im Interesse der Kranken sehr wichtig ist.

7. Für den Fall einer zweifelhaften Diagnose ist die explorativo Laparotomie angezeigt, auf welchem Wege sehr viele werthvolle Erkenntnisse gewonnen werden können. Dieser Eingriff schliesst überhaupt nicht aus, dass wir nachträglich mittelst Lum- 
balschnittes die eventuell nothwendig gefundene Nephrectomie extraperitoneal vornehmen.

8. Wenn die Nierengeschwulst mit einem retroperitonealen Abscess combinirt ist, kann der transperitoneale Eingriff verbängnissvoll werden, da die Abscesshöhle mit der Bauchhöhle in Berührung kömmt. Die Erkenntniss dieser Complication aber wird selbst nach vollzogener Laparotomie nicht immer früh genug möglich sein und deshalb, wenn wir auch nur den Verdacht auf einen perirenalen oder einen anderen retroperitonealen Abscess haben, ist stets der Lumbalschnitt zu wählen.

9. Bei hydro- und pyonephrotischen Geschwülsten ist ein bis zur äussersten Grenze gehender Conservatismus zu empfehlen, da die Heilung eines solehen Sackes selbst nach Monaten (in unserem Falle nach 27 Monaten) erwartet werden kann und die Kranke eine funktionsfähige Niere behält.

10. Die während der Gravidität entstehenden Nierengeschwülste sind noch wenig studirt. Die durch Compression des Ureters entstehende Hydro- und Pyonephrose kann eventuell eine Nephritis parenchymatosa verursachen. Die Therapie ist dann: die künstliche Einleitung der Geburt!

11. Das Cystoscop besitzt in der Diagnostik der Nierengeschwülste, zumal bezüglich der Bestimmung, auf welcher Seite die gesunde oder kranke Niere sich befindet, eine sehr wichtige Rolle.

D. Bezüglich der Nephrolithiasis, Nierentuberculose, maligner Nierengeschwülste und der Nephrorraphie.

1. Unter dem klinischen Bilde einer einfachen Pyonephrose können sich eventuell Nierenbeckensteine verbergen, welche die Kranken Jahre hindurch ohne jedes characteristische Symptom mit sich führen können.

2. Wegen Nierensteinen ist die Nephrolithotomie angezeigt.

3. Bei Gelegenheit jeder wegen einer Bauchgesehwulst vorgenommenen Laparotomie untersuchen wir mittelst directer Austastung die Nieren; zumal, wenn die Anamnese, sei es auch vor langer Zeit, auf die Vermuthung eines Nierensteines hinwies.

4. Gelegentlich einer Nephrolithotomie ist vor Augen zu halten, dass die Steinbildung in der Niere oftmals beiderseitig sei und dass die einseitige erfolgreiche Operation noch nicht über das Schicksal der Kranken entschieden hat. 
5. Die Diagnose der einseitigen, primären Nierentuberkulose ist noch sehr schwierig, da die klinischen Erscheinungen noch ebenso unverlässlich sind, wie die Resultate der bakteriologischen Untersuchungen.

6. Die Berechtigung der operativen Behandlung einer diagnosticirten, einseitigen, primären Nierentuberkulose ist heutzu tage nicht mehr in Zweifel zu ziehen.

7. In dem Falle einer einseitigen Nierentuberkulose ist blos die Nephrectomie indicirt. -

8. Immer kann es vorkommen, dass wir wegen einer von dem Nierengewebe ausgehenden, unstillbaren Blutung anstatt der intendirten Nephrotomie eine Nephrectomie vornehmen müssen.

9. Die nach der operativen Behandlang von malignen Nierengeschwülsten beobachtete grosse Mortalität (ca. 75 pCt.) ist besonders auf zwei Ursachen zurückzufübren, nämlich auf die grossen technischen Schwierigkeiten im Bereiche der Operation und auf die Infection des Organismus auf metastatischem Wege. Das Resultat der Zukunft werden wir in der frühzeitigen Diagnose und in der Potenzirung der operativen Dexterität finden.

10. Bezüglich der Häufigkeit der Wanderniere sind die Ansichten überaus abweichend und in der Beurtheilung der verursachten Leiden spielt die individuelle Ansicht eine grosse Rolle. Daher rührt es, dass Manche gar so oft das operative Verfahren (die Nephrorraphie) für angezeigt finden.

11. Das bei Wanderniere auf dem Wege der Nephrorraphie orreichbare Resultat ist einfach in der Fixation der Niere gelegen, und es erscheint ganz gleichgültig, ob die Annähung etwas tiefer oder höher erfolgt sei.

12. Zur Bloslegung der Niere ist die geeigneteste Methode der Czerny'sche Lumbalschnitt und ist es im Interesse der Fixation gelegen, dass die von ihrer Kapsel theilweise entblösste Nierenoberfläche unmittelbar an die von ihrem Fette befreite Jumbalfascio angenäht werde. 